\title{
II. Parlamentarische Strukturen
}

Welche institutionellen, sozialen und mentalen Strukturen waren charakteristisch für die parlamentarischen Systeme der Weimarer und der späten Dritten Republik? Die folgenden Kapitel sollen dieser Frage ohne Anspruch auf Vollständigkeit ${ }^{1}$ nachgehen, indem sie markante Ähnlichkeiten und Unterschiede im direkten Vergleich gegenüberstellen und so die wesentlichen strukturellen Kontexte der parlamentarischen Entwicklungen während der Inflationskrisen umreißen. Betont sei, daß Strukturen dabei nicht als starre Dominanten betrachtet werden, sondern als durchaus flexible und daher stets auch veränderbare Grundlagen und Rahmenbedingungen parlamentarischer Funktionsprozesse.

\section{Reichstag und Abgeordnetenkammer innerhalb des Verfassungssystems}

Die Probleme des Vergleichs beginnen nicht selten bereits bei der elementaren Begrifflichkeit. Reichstag und Abgeordnetenkammer standen als demokratisch gewählte Repräsentativorgane im Mittelpunkt des parlamentarischen Systems. Streng genommen galt allerdings nur der Reichstag als eigenständiges Parlament, während die Chambre des Députés Bestandteil eines echten Zweikammersystems war und nach zeitgenössischem Verständnis zusammen mit dem Senat das französische Parlament darstellte ${ }^{2}$. Diese semantische Divergenz legt es nahe, unsere vergleichende Betrachtung des Verfassungsgefüges mit dem Verhältnis von Reichstag und Abgeordnetenkammer zu den jeweiligen zweiten Kammern zu beginnen.

Rein formal bildete auch die Kombination von Reichstag und Reichsrat eine Art von Zweikammersystem ${ }^{3}$. In gewisser Kontinuität zum kaiserzeitlichen Bundesrat war der Reichsrat ein Mitwirkungsorgan der Reichsländer und somit ein Erbe der föderalen deutschen Verfassungsgeschichte. Die Delegierten des Reichsrats wurden nach festen Schlüsseln je nach Staatsgröße von den Landesregierungen entsandt. Ihre Aufgabe lag gemäß der Weimarer Verfassung in der „Vertretung der deutschen Länder bei der Gesetzgebung und Verwaltung “" ${ }^{4}$. Im Vergleich zum Bundesrat, der gemeinsam mit dem Reichstag die Gesetzgebung ausgeübt hatte, besaß der Reichsrat nur eine sehr beschränkte legislative Funktion. Diese bestand im wesentlichen in einem Einspruchsrecht gegen vom Reichstag beschlossene Gesetze, das freilich mit Zweidrittelmehrheit des Reichstags überstimmt werden

1 Dies gilt erneut auch für den Anmerkungsapparat.

2 Wenn im folgenden auch für die Abgeordnetenkammer der Begriff „Parlament“ verwendet wird, dann geschieht dies in Übereinstimmung mit der neueren Literatur. Vgl. va. Roussellier, Parlement, der sich in seiner Parlamentarismusgeschichte der Jahre 1919-24 allein mit der Abgeordnetenkammer beschäftigt.

3 Maßgebend WRV, Art. 60-67, 74. Allgemein zum Reichsrat vgl. That, Der Reichsrat im Gesetzgebungsverfahren; Rose, Der Reichsrat in der Weimarer Republik; Huber, Verfassungsgeschichte 6, S. 373-389, Mußgnug, Beziehungen, S. $311 \mathrm{f}$. Eine konkrete Untersuchung der Wechselbeziehungen von Reichstag und Reichsrat steht noch aus. - Generell zu Fragen eines Zweikammersystems vgl. Herzog, Zweikammersystem, in: Evangelisches Staatslexikon, Sp. 2587-2589; Schüttemeyer/ Sturm, Wozu Zweite Kammern?; Haas, Sein oder nicht sein.

4 Art. 60 WRV. 
konnte ${ }^{5}$. Ein derartiges suspensives Veto sollte in seinen legislativen Auswirkungen sicher nicht unterschätzt werden. Dennoch ist letztlich Karl Anschütz zuzustimmen, der vom Reichsrat als einem „fakultativ zuständigen Nebenorgan der Reichsgesetzgebung " gesprochen hat ${ }^{6}$. Weitergehende politische Kompetenzen, welche die übrigen parlamentarischen Grundfunktionen des Reichstags hätten beeinträchtigen können, kamen der Länderkammer nicht zu.

Allerdings schlug sich die föderale Tradition Deutschlands nicht nur in der Institution des Reichsrats nieder, sondern auch in den Wechselbeziehungen zwischen Reichs- und Länderparlamentarismus. Dies reichte von der Signalwirkung einzelner Landeswahlergebnisse bis zur engen Beziehung zwischen Regierungsbildung und Koalitionspolitik in Preußen und im Reich7. Wie später zu sehen sein wird, gewann die letztgenannte Frage erstmals an Brisanz, als die DNVP im Herbst 1923 einen möglichen Regierungseintritt im Reich an ein entsprechendes Vorgehen in Preußen koppelte 8 .

Die Abgeordnetenkammer der Dritten Republik übte ihre Funktionen in Kooperation und manchmal auch in Konkurrenz mit einer starken zweiten Kammer aus. Der Senat war ursprünglich als orleanistisches Erbe in den Verfassungskompromiß von 1875 aufgenommen worden und bildete ein wichtiges Element im angestrebten Gleichgewicht der Staatsorgane 9 . Damit entsprach er genau jenem „institutionalisierten Kompromiß zwischen alten und neuen Legitimitätsüberzeugungen "10, wie er für zweite Parlamentskammern charakteristisch ist. Von seinen dreihundert Mitgliedern wurden zunächst 75 von der Abgeordnetenkammer des Jahres 1875 auf Lebenszeit ernannt, die restlichen 225 durch Wahlmännergremien aus regional- und kommunalpolitischen Funktionsträgern in den Departements und Kolonien gewählt. Spätere Reformen hoben die Möglichkeit der Ernennung auf und räumten den wachsenden Städten ein etwas größeres Gewicht in der Besetzung der Wahlkollegien ein. Gleichwohl blieb die zweite Kammer ein stark von der Provinz geprägtes Verfassungsorgan.

Obwohl der Senat geradezu als antidemokratisches, in der Tradition der Pairskammer der Jahre 1818-1848 stehendes Bollwerk konzipiert worden war, das von radikalen Republikanern zunächst mit großem Mißtrauen betrachtet wurde, wandelte er sich rasch in ein weithin respektiertes Organ der Republik. Schon Gambetta erkannte die integrativen Chancen, die mit einer regional fundierten zweiten Kammer verbunden waren und sprach vom "Grand conseil des communes de France“. Die ursprünglich intendierte Rolle des Senats als präsidentielle Stütze in

5 Art. 74 WRV.

6 Anschütz, Die Verfassung des Deutschen Reichs, S. 227.

7. Letzteres wurde nicht allein durch die Größe und Bevölkerungsstärke Preußens gefördert, sondern auch durch seine staatsrechtliche Verklammerung mit dem Reich in der Kaiserzeit. Zum ", preußisch-deutsche[n]" Problem in der Weimarer Republik“ vgl. Möller, Parlamentarismus in Preußen, S. 534-555.

8 Vgl. unten S. 313.

9 Verfassungsgrundlage war das „Loi du 24 février 1875 relative à l'organisation du Sénat “. Zur Geschichte des Senats vgl. v.a. Marichy, La Deuxième Chambre. Leider bietet diese Darstellung nur wenige klare Informationen zur Zwischenkriegszeit. Vgl. daneben auch Zeldin, History 1 , S. 591-593. Generell zum folgenden auch Albertini, Regierung und Parlament.

10 Schüttemeyer/Sturm, Wozu Zweite Kammern?, S. 517. 
einem Konflikt mit der Abgeordnetenkammer wurde im Zuge der Krise von 1877 weitgehend hinfällig, und die von der Verfassung vorgesehene Beteiligung an der präsidentiellen Kammerauflösung war seither nur noch ein theoretisches Recht ${ }^{11}$.

Entscheidend für die starke Position der zweiten französischen Kammer war zunächst allein ihre formelle Gleichberechtigung im Gesetzgebungsprozeß ${ }^{12}$. Fast ebenso bedeutsam wurde aber, parallel zu seiner weitgehenden Republikanisierung, der Anteil des Senats an der regierungstragenden Funktion. Verfassungsrechtlich war anfangs umstritten gewesen, ob eine Regierung nach Artikel 6 des Verfassungsgesetzes vom 25. Februar $1875^{13}$ auch über das Vertrauen der Senatsmehrheit verfügen mußte. Seit zwei Kabinettsrücktritten in den 1890er Jahren ${ }^{14}$ hatte sich diese Auffassung jedoch allmählich durchgesetzt. Die Demission der Regierung Herriot I im April 1925 nach einem verlorenen Vertrauensvotum im Senat bildete dann einen Markstein für dessen weitere Aufwertung in der späten Dritten Republik ${ }^{15}$.

Die politischen Konturen der Senatsfraktionen wichen teilweise von jenen der Abgeordnetenkammer $a^{16}$, was einer klaren Strukturierung der politischen Kräfte Frankreichs keineswegs förderlich war. Die Zusammensetzung des Senats wurde in der Zwischenkriegszeit von einem Übergewicht des in vielen ländlichen Gebieten dominierenden Parti radical geprägt, während Sozialisten und Kommunisten nur extrem schwach vertreten waren. Da die strukturkonservativen Züge des französischen Radikalismus hier stark zur Geltung kamen, entwickelte sich die zweite Kammer immer mehr zu einem Gralshüter des Bestehenden. Dies wurde auch dadurch gefördert, daß die Senatoren im Schnitt deutlich älter waren als ihre Kollegen in der Abgeordnetenkammer ${ }^{17}$. Nicht selten hatten sie dieser selbst zuvor angehört und fanden dann im Palais $d u$ Luxembourg ihren parlamentarischen „Alterssitz“. Genannt seien nur Raymond Poincaré oder Joseph Caillaux ${ }^{18}$. Wie die politische Karriere von Edouard Herriot zeigt, gab es allerdings auch den umgekehrten Weg vom Senat in die Abgeordnetenkammer ${ }^{19}$.

1 Zum letzten Aufscheinen dieser Möglichkeit 1924 im Konflikt des Staatspräsidenten Millerand mit der linken Kammermehrheit vgl. Zweiter Teil, B, Kap I.3.

12 Vgl. zum Verfahren unten S. $110 \mathrm{f}$.

13 "Les ministres sont solidairement responsables devant les Chambres de la politique générale du gouvernement [...].“

14 Die Regierung Tirard demissionierte 1890, indem sie eine Niederlage mehr oder minder als Vorwand nutzte. Deutlicher und auch expliziter war der Einfluß des Senats, als Léon Bourgeois 1895 nach einer Abstimmungsniederlage zurücktrat. Allerdings ist hierbei zu berücksichtigen, daß die Regierung wahrscheinlich auch in der Kammer keine Mehrheit mehr besessen hätte. Vgl. Mayeur, Vie politique, S. $165 \mathrm{f}$.

15 Vgl. unten S. 455 - Nachdem es vor dem Ersten Weltkrieg nur einen Regierungssturz durch den Senat gegeben hatte (1913 Kabinett Briand), wurden in der Zwischenkriegszeit folgende Regierungen durch Voten des Senats zum Rücktritt gezwungen: Herriot I 1925, Tardieu II 1930, Laval II 1932, Blum I und II 1937 und 1938. Vgl. auch das in dieser harschen Form für die französische Geschichtsschreibung ungewöhnliche Urteil über den Senat als „fossoyeur de l'institution parlementaire" in Dubief, Le déclin de la Troisième République, S. 158.

16 Vgl. unten S. 67.

1) Gefordert war ein Mindestalter von 40 Jahren.

18 Poincaré ließ sich 1920 nach dem Ende seiner präsidentiellen Amtszeit in den Senat wählen, Caillaux 1925 nach seiner politischen Rehabilitierung.

19 Herriot begann mit 40 Jahren seine nationale politische Karriere 1912 im Senat. 1919 wechselte er dann in die Abgeordnetenkammer. 
Bei aller Bedeutung des Senats muß aber doch betont werden, daß die parlamentarischen Grundfunktionen in weitaus höherem Maße von der Abgeordnetenkammer wahrgenommen wurden. Die Chambre, wie sie nicht zufällig in verkürzter Form oft genannt wurde, besaß einen informellen Vorrang in der Diskussion wichtiger legislativer Vorhaben, ihre Debatten waren erheblich ausführlicher und wurden in der politischen Öffentlichkeit intensiver verfolgt. Von den Wahlen zur Abgeordnetenkammer gingen die entscheidenden politischen Weichenstellungen aus, ihre Mehrheitsverhältnisse waren maßgeblich für die Regierungsbildung und auch für die ganz überwiegende Zahl von Abberufungen der Regierung. Neue Kabinette stellten sich hier der "Investitur" des ersten Vertrauensvotums, und das Aufzeigen parlamentarischer Alternativen war im wesentlichen Aufgabe der Kammeropposition. Trotz mancher Probleme ist ein auf die Abgeordnetenkammer konzentrierter Vergleich mit dem deutschen Reichstag daher durchaus sinnvoll.

In Deutschland wie in Frankreich gab es ansatzweise noch so etwas wie eine dritte Kammer. Mit dem vorläufigen Reichswirtschaftsrat existierte in der Weimarer Republik ein korporatistisches, parlamentsähnliches Versammlungsorgan, das in den Anfangsjahren der Republik in verschiedene Gesetzgebungsprojekte einbezogen wurde ${ }^{20}$. Bei seiner Entstehung 1920 waren räterepublikanische und ständestaatliche Vorstellungen eine bemerkenswerte Mischung eingegangen. Die über 300 Mitglieder - nach einem festen Schlüssel berufen von Gremien der Wirtschaft sowie von berufsständischen Organisationen und Gewerkschaften - hatten de facto nur eine Gutachterfunktion ${ }^{21}$. Die Bedeutung des Reichswirtschaftsrats in der Inflationszeit sollte aber nicht verkannt werden ${ }^{22}$. Vor allem seine Ausschüsse wurden in Sachen „Währungsstabilisierung " $z u$ wichtigen und in der Öffentlichkeit beachteten Diskussionsforen ${ }^{23}$, zumal im Reichstagsplenum entsprechende Auseinandersetzungen nur selten stattfanden und der Reichswirtschaftsrat im Ruf stand, eher zu „sachlicher" Arbeit fähig zu sein. Obgleich 1921-23 gewisse Regeln für die Einbindung in den Gesetzgebungsprozeß festgelegt wurden, kam es in der praktischen Zusammenarbeit doch immer wieder zu Unklarheiten ${ }^{24}$. Für die Bündelung der legislativen Arbeit im Reichstag und für das Prestige der Volksvertretung war all dies nicht förderlich. Eingeleitet durch Sparmaßnahmen im Zuge der Währungsstabilisierung erfolgte seit Anfang 1924 ein rascher Niedergang des Reichswirtschaftsrats.

Auch in der späten Dritten Republik existierte ein wirtschaftliches Repräsentativorgan. Auf Initiative des Cartel des Gauches wurde 1925 - unter anderem nach deutschem Vorbild - ein beratender Conseil national économique geschaffen, wie

20 Verfassungsgrundlage war WRV, Art. 165 Abs. 1. Vgl. hierzu v.a. Hauschild, Der vorläufige Reichswirtschaftsrat; Ritter, Die Entstehung des Räteartikels 165; Riedel, Der Rätegedanke in den Anfängen der Weimarer Republik, S. 139-148; Huber, Verfassungsgeschichte 6, S. 390-402.

21 Listen von Ausschüssen und Mitgliedern in BA Berlin, R 2101, Nr. 772, Bl. 19, 21.

22 Ritter, Entstehung, S. 104, spricht von einem faktisch nur selten herangezogenen Gutachtergremium „ohne wirklichen Einfluß auf die Gesetzgebung und die Wirtschafts- und Sozialpolitik der Regierung“. Die Aktivität der ersten Jahre betont hingegen Huber, Verfassungsgeschichte 6, S. 401.

23 Wichtig waren v.a. die Tagungen des finanzpolitischen Ausschusses, teilweise in gemeinsamer Sitzung mit dem wirtschaftspolitischen Ausschuß.

24 Vgl. ausführliches Aktenmaterial in BA Berlin, R 43, Nr. 1194. 
er schon seit längerem von der CGT gefordert worden war. Dieser nationale Wirtschaftsrat entfaltete vor allem in den 1930er Jahren eine intensive gutachterliche Tätigkeit, seine politische Bedeutung blieb aber während des im Zweiten Teil unserer Arbeit berücksichtigten Zeitraums noch gering 25 .

Die demokratische Legitimierung von Reichstag und Abgeordnetenkammer erfolgte in freien und geheimen Wahlen. Verfassungsgemäß fanden diese in beiden Staaten alle vier Jahre statt. In der Weimarer Republik sorgte die wiederholte Reichstagsauflösung (März und Dezember 1924, März 1928, Juli 1930, Juni und September 1932) allerdings für einen unregelmäßigen und insgesamt schnelleren Rhythmus.

Der auf deutscher Seite 1919/20 vollzogene Übergang zur konsequenten Verhältniswahl war in gewisser Weise die logische Konsequenz des weit entwickelten Parteienwesens. Auf die negativen Folgen der daraus resultierenden fraktionellen Zersplitterung für die parlamentarische Mehrheitsbildung ist in der Literatur zu Recht häufig hingewiesen worden. Zu einem gravierenden Problem wurden die Splitterparteien allerdings erst nach - und teilweise auch infolge - der Inflationszeit ${ }^{26}$. Demokratischer als in der Dritten Republik war das Weimarer Wahlrecht insofern, als es erstmals in der deutschen Parlamentarismusgeschichte passiv wie aktiv auch Frauen an der Wahl teilhaben ließ.

Das 1919 in Frankreich eingeführte Mischsystem von Mehrheits- und Verhältniswahl regelte die Kammerwahlen vom Dezember 1919 und Mai 192427. Kernstück war die Aufstellung von Wahllisten im Rahmen von Wahlbezirken, die in der Regel mit den Departements identisch waren. Erreichte eine dieser Listen in dem einzigen vorgesehenen Wahlgang die absolute Mehrheit, fielen ihr als "prime majoritaire" alle verfügbaren Mandate zu. Andernfalls wurden die den Wahlbezirken zustehenden Sitze proportional auf die angetretenen Listen verteilt ${ }^{28}$. Wichtigste politische Folge dieses Systems war die Begünstigung von breiten Wahlbündnissen, die in sogenannten „listes de concentration“ antraten, um jeweils die absolute Mehrheit im Wahlkreis zu erringen. Dies wiederum wirkte der parteipolitischen Profilierung entgegen und behinderte Ansätze zur Entwicklung strafferer Parteien. Durch die blockartige Vergabe von Mandaten an siegreiche Wahllisten konnten die Zusammensetzung der Abgeordnetenkammer und das Verhältnis der abgegebenen Stimmen relativ stark differieren. 1919 profitierte hiervon der Bloc national, 1924 das Cartel des Gauches. Dieses komplexe „scrutin de proportionnelle bâtarde" war schon bald wieder umstritten. Nachdem bereits seit 1923 eine intensive Wahlrechtsdiskussion geführt worden war ${ }^{29}$, kehrte man 1927 wieder zum alten System des „scrutin d'arrondissement“ zurück ${ }^{30}$. Mehrere Anläufe

25 Vgl. zur Geschichte Chatriot, La démocratie sociale à la française; Rossiter, Experiments with Corporatist Politics in Republican France.

26 Vgl. v.a. Jones, German Liberalism, S. 225-305.

27 Vgl. v.a Cole/Campbell, French Electoral Systems, S. 63-70; Huard, Suffrage universel, S. 231-238. Liste der Wahlbezirke mit Zahl der zu vergebenden Mandate in Berstein, Histoire 1, S. 378-381.

28 Die Reihenfolge der Kandidaten auf den Wahlvorschlägen konnte 1924 vom Wähler durch das Streichen von Namen verändert werden.

29 Vgl. unten S. $377 \mathrm{f}$.

30 Vgl. unten S. 520. 1937 wurde dann ein tatsächliches Verhältniswahlrecht eingeführt, das freilich nur noch in einigen Nachwahlen wirksam werden konnte. 
zur Einführung des Frauenstimmrechts scheiterten in der Zwischenkriegszeit an einer Blockade des Senats. Die Widerstände kamen vor allem aus dem Parti radical, wo man die traditionelle Nähe vieler Frauen zur katholischen Kirche fürchtete $^{31}$.

Die engen Beziehungen zwischen Reichstag bzw. Abgeordnetenkammer und Kabinettsregierung werden später im Kontext der regierungstragenden Parlamentsfunktion skizziert ${ }^{32}$. Hervorgehoben sei an dieser Stelle nur - als entscheidende Bedingung eines parlamentarischen Systems - die verfassungsmäßig in beiden Staaten fixierte Verantwortlichkeit der Regierung vor dem Parlament (Artikel 6 des Gesetzes vom 25. Februar 1875 und Artikel 54 der Weimarer Reichsverfassung).

Obgleich Reichstag und Abgeordnetenkammer im Zentrum einer parlamentarischen Demokratie standen, waren jeweils präsidentielle Komponenten in das Verfassungssystem eingebaut, was die politische Autonomie der Parlamente in unterschiedlichem Maße einschränkte ${ }^{33}$. Abweichend waren in der Dritten Französischen und der Weimarer Republik zunächst vor allem der Wahlmodus und damit die politische Legitimation des Staatspräsidenten: In Frankreich wurde seine Wahl angesichts der bonapartistischen Erfahrungen nicht durch das Volk, sondern durch die in Versailles als Assemblée nationale tagenden beiden Kammern des Parlaments vollzogen. Die Weimarer Verfassung hingegen sah für den Reichspräsidenten die unmittelbare Volkswahl vor. Allerdings kam dieses Element einer direkten Demokratie erst 1925 bei der Wahl Hindenburgs zur Geltung: Ebert war bekanntlich vor Inkrafttreten der Verfassung im Februar 1919 durch die Nationalversammlung mit dem Amt betraut worden, und im Herbst 1922 wurde dieses provisorische Mandat durch den Reichstag bis Juni 1925 verlängert ${ }^{34}$.

Relativ ähnlich war in beiden Republiken die ursprüngliche verfassungspolitische Konzeption des Spitzenamtes: der Staatspräsident als neutraler „Schiedsrichter" über den Parteien und über den politischen Alltagskämpfen, ausgestattet mit einer langen, siebenjährigen Amtszeit, der Möglichkeit einer Wiederwahl sowie mit weitreichenden Kompetenzen. Diese betrafen insbesondere den Oberbefehl über die bewaffnete Macht, die Einsetzung der Regierung sowie die Auflösung des Reichstags bzw. der Abgeordnetenkammer. Letzteres war in der Weimarer Verfassung, wo die Auflösung in die alleinige Kompetenz des Reichspräsidenten fiel (Art. 25), großzügiger geregelt als in den Verfassungsgesetzen der Dritten Republik, wo die Zustimmung des Senats erforderlich war (Art. 5 des Gesetzes vom 25. Februar 1875). Entscheidend aber wurde, daß - wie bereits mehrfach erwähnt - die Kammerauflösung in der Verfassungspraxis seit 1877 tabuisiert war.

31 Vgl. Bard, Les luttes contre le suffrage unisexuel; Reynolds, France Between the Wars, S. 204-212.

32 Vgl. Erster Teil, Kap. III.1.

33 Verfassungsgrundlage waren in Deutschland v.a. Art. 25, 41-51 und 53 der WRV, in Frankreich Art. 2-8 des Gesetzes vom 25. 2. 1875; Art. 2-4, 6-9 und 12 des Gesetzes vom 16. 7. 1875. - Zum deutschen Reichspräsidenten vgl. v.a. Huber, Verfassungsgeschichte 6, S. 307-323; Gusy, Weimarer Reichsverfassung, S. 98-115, mit stärkerer Pcrspektive auf die Amtspraxis jetzt Weber, Das Büro des Reichspräsidenten. - Zum französischen Präsidenten der Republik vgl. v.a. Gicquel, Droit constitutionnel, S. 471; Prélot/Boulouis, Institutions politiques, S. 501-503. Überblick zur Geschichte: Derfler, President and Parliament. Allgemein zur Mischung von parlamentarischen und präsidentiellen Elementen vgl. Steffani, Strukturtypen.

34 Vgl. zu diesem verfassungsrechtlich fragwürdigen Vorgang unten S. 141-144. 
Im Gegensatz zum Präsidenten der französischen Republik verfügte der Reichspräsident nicht über das Recht der Gesetzesinitiative. Ein reguläres Mitwirkungsrecht an der Gesetzgebung besaß er jedoch insofern, als er in bestimmten Fällen per Volksentscheid über ein Gesetz entscheiden lassen konnte, was in der politischen Realität der Weimarer Republik freilich bedeutungslos blieb. Ganz anders verhielt sich dies mit der von Artikel 48 der Reichsverfassung abgeleiteten Ausnahmegewalt, die 1922/23 eine über das ursprüngliche Anwendungsgebiet der inneren Sicherheit weit hinausgehende präsidentielle Gesetzgebung auf dem Verordnungsweg begründete. Diese Entwicklung wird später ausführlich zu behandeln sein.

Insgesamt hatte der deutsche Staatspräsident, insbesondere aufgrund seines uneingeschränkten Auflösungsrechts und seiner Ausnahmegewalt, bereits in der Verfassungskonzeption eine stärkere Stellung als der französische. In der Verfassungspraxis waren diese Unterschiede noch erheblich größer. Gegen das in der französischen Literatur zur Dritten Republik verbreitete Bild eines extrem schwachen Präsidenten sei allerdings betont, daß auch der Président de la République kraft seiner Möglichkeiten bei der Regierungsbildung durchaus gewissen Einfluß auf die parlamentarische Entwicklung gewinnen konnte. Hinzu kommt, daß eine Reaktivierung des Auflösungsrechtes keineswegs ausgeschlossen war und 1924 von Millerand auch angestrebt wurde ${ }^{35}$.

Die Verfassung der Dritten Republik hatte in deutlicher Absetzung vom Zweiten Kaiserreich jeden plebiszitären Ansatzpunkt vermieden. Die Aufnahme von Formen direkter Demokratie in die Weimarer Verfassung resultierte hingegen zum einem aus dem Streben nach einer konsequenten formalen Demokratisierung, zum anderen aber auch aus einem verbreiteten Mißtrauen gegen Parteien und gegen einen vermeintlichen "Parlamentsabsolutismus"36. Gleichzeitig herrschte unter den Verfassungsvätern aber auch wenig Vertrauen in die politische Reife des deutschen Volkes. Sieht man von der Volkswahl des Reichspräsidenten $\mathrm{ab}$, blieben die vorgesehenen plebiszitären Elemente daher eher schwach entwikkelt ${ }^{37}$. Die Möglichkeiten eines Volksbegehrens bzw. Volksentscheids waren eng umrissen ${ }^{38}$. Während der Inflationskrise spielten diese Entscheidungsformen, die

$35 \mathrm{Vgl}$. Zweiter Teil, B, Kap. I.3.

36 Vgl. Huber, Verfassungsgeschichte 6, S. 432-434; Schiffers, Elemente direkter Demokratie, zu den Motiven ebd., S. 141 f.; Kühne, Volksgesetzgebung, S. 123, spricht sogar von „rousseauistischen Vorstellungen der Weimarer Republik". Der Vorwurf des Parlamentsabsolutismus stammte ursprünglich aus der innerfranzösischen Diskussion. Vgl. Anm. 41.

37 WRV Art. 18, 73-77. Vgl. v.a. Gusy, Weimarer Reichsverfassung, S. 93-98. Vgl. auch das prägnante Urteil in Schiffers, Elemente direkter Demokratie, S. 153: „Man wollte einerseits das Parlament als die sichtbarste Verkörperung der Volkssouveränität durch die Elemente unmittelbarer Demokratie bändigen, man versuchte aber andererseits, das Volk als politischen Faktor soweit wie möglich zurückzudrängen. So wie einerseits die Idee des parlamentarischen Regierungssystems blaß blieb, blieben andererseits die Vorstellungen von der Mitwirkung des Volkes an Gesetz- und Verfassungsgebung vage."

38 Art. 73 WRV. Ein Volksentscheid war vorgesehen, wenn dies ein Zehntel der Stimmberechtigten in einem Volksbegehren befürwortete, wenn es der Reichspräsident nach Verabschiedung eines Gesetzes im Reichstag verlangte, wenn die Verkündung eines Reichsgesetzes nach einem parlamentarischen Votum von einem Drittel der Abgeordneten ausgesetzt worden war und sich dann 5\% der Wahlberechtigten für einen Volksentscheid aussprachen oder aber wenn der Reichsrat dies nach einer vom Reichstag beschlossenen Verfassungsänderung forderte. Ferner war unter bestimmten Umständen bei einer Neugliederung von Reichsländern eine Volksabstimmung obliga- 
in ihren Auswirkungen auf die Weimarer Republik inzwischen kontrovers beurteilt werden ${ }^{39}$, keine unmittelbare Rolle, und auch die bloße Existenz ihrer Möglichkeit scheint in den politischen Diskussionen jener Jahre kaum von Bedeutung gewesen zu sein.

Alles in allem war das parlamentarische Verfassungssystem in der späten Dritten Republik infolge der fehlenden plebiszitären Elemente und der schwächeren Stellung des Staatspräsidenten gleichsam in konzentrierterer Form realisiert als in der Weimarer Republik. Daß der präsidentielle Faktor, der in Deutschland ab 1930 zur Systemveränderung führte, bereits in der Inflationszeit erhebliches Gewicht erlangte, steht außer Zweifel ${ }^{40}$. Doch sollten die diesbezüglichen Unterschiede auch nicht überbewertet werden: Weder herrschte in Frankreich ein „Parlamentsabsolutismus" ${ }^{41}$, noch in Deutschland ein funktionsuntüchtiges Mischsystem. Die entscheidenden Differenzen im parlamentarischen „Normalbetrieb“ resultierten eher aus den Verfahrensweisen des faktischen deutschen Einkammer- und des konsequenten französischen Zweikammersystems sowie aus der jeweiligen Nähe zu den unterschiedlichen Funktionstypen des deliberativen und des parteiengestützten Parlamentarismus.

\section{Parlamentarische Organisations- und Kommunikationsformen im Überblick}

Reichstag und Abgeordnetenkammer waren sich als soziale Gefüge in ihren Grundzügen durchaus ähnlich, denn trotz aller Unterschiede im Verfassungssystem hatten die nationalen Parlamente im 19. Jahrhundert eine relativ analoge institutionelle Entwicklung genommen.

Festgelegt wurden die internen Organisations- und Kommunikationsformen teils durch informelle Spielregeln ${ }^{42}$, teils auch durch Verfassungsbestimmungen, überwiegend aber durch die jeweils gültigen Geschäftsordnungen, die aus dem traditionellen parlamentarischen Recht der Selbstorganisation resultierten ${ }^{43}$. Im Weimarer Reichstag arbeitete man in den ersten Jahren mit minimalen Änderungen nach Bestimmungen, die noch aus der Zeit vor 1918 stammten. Im Dezember

torisch. In die Realität umgesetzt wurde nur die erste dieser Möglichkeiten. Zwei von insgesamt acht Volksbegehren führten zum Erfolg und veranlaßten einen Volksentscheid über die Themen der Fürstenenteignung (1926) und des Young-Plans (1929). Vgl. auch Gusy, Weimarer Reichsverfassung, S. 96-98.

39 Entschieden gegen die traditionell negative Bewertung v.a. Jung, Direkte Demokratie in der Weimarer Republik. Widerspruch gegen Jung kam v.a. von Meineke, Die antiplebiszitäre Grundsatzentscheidung des Parlamentarischen Rates. Auf die sich anschließende Kontroverse zwischen beiden Autoren im Jahrbuch für Politik braucht hier nicht eingegangen zu werden. Differenziertes Urteil bei Gusy, Weimarer Reichsverfassung, S. 97 f., sowie bei Kühne, Volksgesetzgebung, z. B. S. 120.

40 Vgl. etwa die Berufung Cunos zum Reichskanzler, den Einsatz von Artikel 48 und die Reichstagsauflösung vom 13. 3. 1924 .

41 So die in der Tradition von Raymond Carré de Malberg stehende Deutung, von der etwa auch Redslob beeinflußt war. Zum Fortwirken in der Deutung der Dritten Republik durch die französische Verfassungsgeschichte vgl. z.B. Gicquel, Droit constitutionnel, S. 475; Prélot/Boulouis, Institutions politiques, S. $495 \mathrm{f}$.

42 Grundsätzlich hierzu Hanke, Informale Regeln. Die ebd. getroffene Unterscheidung von - etwas formelleren - informellen und informalen Regeln erscheint freilich etwas gezwungen. In der vorliegenden Arbeit wird beides unter dem Begriff „informell“ gefaßt.

43 Vgl. Huber, Verfassungsgeschichte 6, S. 360 . 
1922 gab sich das Parlament dann eine neue Geschäftsordnung, die allerdings nicht allzusehr von der bisherigen abwich ${ }^{44}$. Die Grundlage des parlamentarischen Betriebs der französischen Abgeordnetenkammer bildete die überarbeitete Geschäftsordnung aus dem Jahre $1915^{45}$.

Die Stellung des Abgeordneten war in beiden Parlamenten durch drei wesentliche Merkmale gekennzeichnet, die seine politische und materielle Unabhängigkeit sowie eine gewisse symbolische Würde der parlamentarischen Arbeit gewährleisten sollten ${ }^{46}$ :

- Im Prinzip verfügten alle Parlamentarier über ein freies Mandat; sie waren, wie es in Artikel 21 der Weimarer Verfassung hieß, „Vertreter des ganzen Volkes“, „nur ihrem Gewissen unterworfen und an Aufträge nicht gebunden“47. In der Praxis stieß sich diese auch vom Staatsrecht noch weitgehend vertretene ${ }^{48}$ Voraussetzung eines deliberativen Parlamentarismus zum einen am Einfluß der großen lobbyistischen Interessengruppen ${ }^{49}$. Zum anderen stand dem Ideal vom freien Abgeordneten die zunehmende Organisations- und Disziplinierungskraft von Parteien und Fraktionen entgegen. Dieser Prozeß war, wie im nächsten Kapitel auszuführen sein wird, in Deutschland weiter fortgeschritten als in Frankreich. In der Praxis waren die deutschen Abgeordneten derart in ihre Fraktionen eingebunden, daß das freie Mandat kaum mehr als eine verfassungsrechtliche Fiktion darstellte ${ }^{50}$.

- In beiden Staaten gab die parlamentarische Immunität einen doppelten Schutz ${ }^{51}$. So konnten die Abgeordneten nicht für Handlungen oder Äußerungen belangt werden, die sie in Ausübung ihres Mandats getan hatten. Gleichzeitig waren sie vor einer allgemeinen strafrechtlichen Verfolgung solange geschützt, bis das Parlament ihre Immunität formell aufhob ${ }^{52}$.

- Die Parlamentarier bezogen für ihre Abgeordnetentätigkeit Diäten sowie gewisse andere materielle Privilegien wie etwa die Freifahrt mit der Bahn. In Frankreich waren parlamentarische Diäten in bescheidenem Umfang bereits seit 1848 Praxis. Die in der Zwischenkriegszeit gültige, relativ großzügige Regelung stammte aus dem Jahr 190653. In Deutschland hingegen war die Vorstellung einer Abgeordnetenvergütung lange Zeit auf erhebliche Widerstände gestoßen. Erst 1906 wurde den Reichstagsabgeordneten offiziell eine „Entschädigung“ zugestan-

44 Bekanntmachung am 17. 2. 1923; RGBl. 1923 II, S. 101-113. Abdruck z. B. in Reichstags-Handbuch, II. Wahlperiode, S. 219-248. Vgl. Haug, Bindungsprobleme und Rechtsnatur parlamentarischer Geschäftsordnungen, S. 32.

45 Abdruck in: Règlement de la Chambre des Députés, Paris $1919 \mathrm{ff}$. (zugänglich in AAN Paris).

46 Allgemein zum folgenden vgl. v.a. Gusy, Weimarer Reichsverfassung, S. 126-128; Duguit, Traité, S. $178-230$.

47 In Frankreich gab es hierzu keine Verfassungsbestimmung, die Freiheit des Abgeordneten stand aber traditionell im Zentrum des parlamentarischen Systems. Zur deutschen Verfassungstradition vgl. Demmler, Der Abgeordnete im Parlament der Fraktionen, S. 41.

48 Vgl. etwa Anschütz, Verfassung, S. 418.

49 Vgl. unten S. 76-78.

$50 \mathrm{Vgl}$. hierzu die anschauliche Darstellung des fiktiven Abgeordneten Müller-Hinterwalden in Lambach, Herrschaft der Fünfhundert, v.a. S. 11-18.

51 Vgl. auch Westphalen, Parlamentslehre, S. $68 \mathrm{f}$.

52 Zur Handhabung in Deutschland vgl. Mergel, Parlamentarische Kultur, S. 148-152.

53 Vgl. Guiral/Thuillier, La vie quotidienne des députés, S. 106 f.; Birnbaum, Les sommets de l'Etat, S. 35 . 
den, das Verbot einer „Besoldung“ galt aber weiterhin. Artikel 40 der Weimarer Reichsverfassung blieb dann bei dem Begriff der „Entschädigung“, ohne allerdings das explizite Besoldungsverbot $\mathrm{zu}$ wiederholen ${ }^{54}$. Angesichts dieser unterschiedlichen Voraussetzungen überrascht es nicht, daß die Abgeordnetenvergütung in der späten Dritten Republik weniger umstritten war als in der Weimarer Republik ${ }^{55}$ - was man durchaus als Zeichen eines gefestigteren parlamentarischen Systems interpretieren kann.

Das Prestige einer Mitgliedschaft in der französischen Chambre spiegelte sich auch in den persönlichen Insignien, über die jeder Abgeordnete neben dem Abgeordnetenausweis verfügte: Ein Emailabzeichen, das am Knopfloch getragen werden konnte, eine Schärpe sowie eine spezielle Medaille, die jede Legislaturperiode neu geprägt und in die jeweils der Name des Abgeordneten eingraviert wurde ${ }^{56}$, bildeten Symbole der parlamentarischen Würde (s. auch Phototeil), die im nüchternen Weimarer Parlamentarismus fehlten.

Die organisatorische Binnenstruktur beider Parlamente war in den Grundprinzipien analog: Die politischen Kräfte organisierten sich in Fraktionen, die unmittelbaren Leitungsaufgaben einschließlich der disziplinarischen Gewalt kamen dem Parlamentspräsidium zu, ein von den Fraktionen beschicktes Lenkungsgremium (Ältestenrat, Conférence des Présidents) besaß eine gewisse Koordinierungsfunktion, die wesentliche Beratungstätigkeit erfolgte in den Ausschüssen, die großen öffentlichen Debatten und die maßgeblichen Beschlüsse waren dem Plenum vorbehalten. Die stark voneinander abweichenden Strukturen des Fraktionswesens werden im nächsten Kapitel miteinander verglichen; die übrigen Instanzen seien nachstehend kurz skizziert:

a) Die Präsidenten der Abgeordnetenkammer und des Reichstags wurden von ihren Parlamenten gewählt, sie verfügten jeweils über mehrere Stellvertreter und standen dem parlamentarischen Verwaltungsapparat vor. Die Geschäftsordnung verlieh ihnen eine Reihe von disziplinarischen Möglichkeiten, die vor allem im Umgang mit den extremen Fraktionen politisch bedeutsam wurden ${ }^{57}$.

Der Président de la Chambre verkörperte traditionell die Autorität des parlamentarischen Systems im allgemeinen und jene der „Kammer“ im besonderen ${ }^{58}$. Sehr anschaulich wird dies in dem bekannten Gemälde "Jaurès à la tribune" von René Rousseau-Decelle aus dem Jahr 1907, das gleichsam ein Lehrbild des delibe-

54 Vgl. für Deutschland Butzer, Diäten und Freifahrt, v.a. S. 247-315, 373-411. „Tagegelder“, in: Politisches Handwörterbuch, S. 779 f., hier S. 780; Westphalen, Parlamentslehre, S. 69 f.; Mergel, Parlamentarische Kultur, S. 108-123.

55 Zur anhaltend kritischen Diskussion in Deutschland vgl. ebd., S. 109. Eine analoge Debatte scheint es in Frankreich nicht gegeben zu haben.

$56 \mathrm{Vgl}$. den ausführlichen Bericht in L'Illustration, 4. 6. 1932, S. 184-188; 11.6. 1932, S. 227-231; 16. 6. 1932, S. 261-264: „Le quatrième questeur: Voyage autour de la Chambre“. Ebd. auch zu den Räumlichkeiten und zur Organisation des parlamentarischen Alltags.

57 So kam es in der kurzen zweiten Legislaturperiode des Reichstags zu Problemen, nachdem die Maiwahlen 1924 erstmals für eine massive Präsenz kommunistischer und völkisch-nationalsozialistischer Abgeordneter gesorgt hatten. Die nun auftretenden Vorfälle erscheinen rückblickend als Vorzeichen für den breiten Verfall der parlamentarischen Kultur in Deutschland ab 1930. Vgl. mit Beispielen Mergel, Parlamentarische Kultur, S. 167-172.

58 Zur Tradition vgl. Guiral/Thuillier, La vie quotidienne des députés, S. 257-259. Biographische Skizzen zu den Kammerpräsidenten der Dritten Republik in Séguin, 240 dans un fauteuil, S. 857-944; ebd., S. 859-862, kurze Einführung zum Amt. 
rativen Parlamentarismus darstellt ${ }^{59}$ : Über der wogenden Redeschlacht bildet der an seinem erhöhten Pult stehende Kammerpräsident nicht nur den ruhenden Pol, sondern auch die souverän leitende Instanz. Immer aufs neue symbolisiert wurde seine Würde durch den protokollarischen Pomp, der beim feierlichen, von der republikanischen Garde begleiteten Einzug vor jeder Kammersitzung zur Entfaltung $\mathrm{kam}^{60}$. Niemand füllte die ideelle Tradition des Président de la Chambre wohl besser aus als "la République en personne" 61 Edouard Herriot, der das Amt 1925-26 und dann wieder von 1936-40 innehatte. Aber auch die konkrete politische Bedeutung war durchaus beachtlich, obgleich sich der Kammerpräsident üblicherweise aus den tagespolitischen Streitigkeiten heraushielt ${ }^{62}$. In der Regel wurde er - ähnlich wie sein Pendant aus dem Senat - in die Beratungen zur Regierungsbildung eingebunden.

Das Amt des Reichstagspräsidenten beschränkte sich demgegenüber weitgehend auf eine funktionale Ebene, was sich unter anderem auch daran zeigte, daß der Präsident nicht selten kurzfristig in die Rolle des einfachen und durchaus auch parteilichen Abgeordneten wechselte63. Mit der Entfaltung staatlicher Symbolik tat sich die Republik von Weimar ohnehin schwer, in diesem besonderen Falle wirkte sich vor allem das Fehlen einer Tradition des parlamentarischen Systems aus. Wenn der Präsident des Reichstags dennoch wachsende politische Bedeutung erlangte, dann lag dies in erster Linie an den allseits gerühmten Fähigkeiten zur energischen und doch humorvollen Konfliktmoderierung, über die der langjährige Amtsinhaber Paul Löbe (SPD) verfügte ${ }^{64}$.

b) Die von den Fraktionsführern und Ausschußvorsitzenden gebildete Conférence des Présidents und der - ungeachtet des Alters - von den Fraktionen benannte sogenannte Ältestenrat ${ }^{65}$ stellten Leitungs- und Vermittlungsgremien dar. Insbesondere kam ihnen die in bestimmten Situationen bedeutsame Aufgabe zu, den parlamentarischen Terminkalender zu gestalten. Leider ist die Quellenlage zu beiden Gremien extrem schlecht, da im Falle der Conférence des Présidents offenbar nie Akten angelegt wurden und jene zum Ältestenrat nicht überliefert sind.

c) Wie in allen modernen Parlamenten waren die Ausschüsse wichtige Orte der

59 Rousseau-Decelle war einer der bekanntesten französischen Maler seiner Zeit. Das Bild wird heute vom "Kiosque“ der Assemblée nationale als Poster vertrieben; als Titelbild bei Guiral/Thuillier, La vie quotidienne des députés.

60 Nach dem „Einmarsch" über einen langen Teppich erfolgte die Eröffnung der Sitzung durch Abnehmen des Zylinders.

61 Vgl. den treffenden Titel des Buches von Berstein: Edouard Herriot ou la république en personne.

62 Zur spektakulären Ausnahme durch den Auftritt Herriots am 17.7. 1926 vgl. unten S. 490.

${ }_{63}$ Mergel, Parlamentarische Kultur, S. 210. Zum Reichstagspräsidenten vgl. auch Gusy, Weimarer Reichsverfassung, S. $129 \mathrm{f}$.

64 So rühmte z.B. Stresemann am 18.7. 1922, Löbe habe es „durch Takt und Energie wie Humor verstanden, immer wieder das Haus zusammenzuführen und dadurch dazu beizutragen, daß die Verhandlungen dieses Hauses in parlamentarischer Weise erledigt werden konnten “. Verh. RT 356, S. 8749. Ähnlich Fehrenbach am 13.3. 1924 in der letzten Sitzung der ersten Legislaturperiode; Verh. RT 361, S. 12829. - Löbe war, abgesehen von einer Unterbrechung in der zweiten Wahlperiode 1924, als der häufig ungeschickt agierende Deutschnationale Max Walraff das Amt innehatte, von 1920 bis 1932 Reichstagspräsident. Zur Amtsführung und wachsenden Bedeutung vgl. auch Mergel, Parlamentarische Kultur, S. 210f. Vgl. auch Löbe, Der Weg war lang.

65 Der Begriff „Ältestenrat“" erscheint erstmals in der Geschäftsordnung von 1922 ( $\$ 10-12)$, vorher

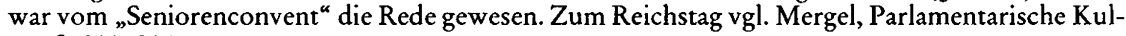
tur, S. 211-214. 
parlamentarischen Detailarbeit ${ }^{66}$. Seit dem späten 19. Jahrhundert hatte sich eine zunehmende Institutionalisierung des Ausschußwesens vollzogen, wobei es eine Wechselbeziehung zur wachsenden Bedeutung der Fraktionen gab. Im kaiserlichen Reichstag waren von den Fraktionen besetzte ständige Ausschüsse seit 1871 in der Geschäftsordnung verankert. In der Dritten Republik gab es zwar schon seit 1876 permanente Kommissionen; doch erst die Geschäftsordnung von 1902 durchbrach die in einer strikten Gewaltenteilungsdoktrin verankerten Vorbehalte gegen eine mögliche Dominanz starker Ausschüsse über die Ministerien und begründete ein System fraktionell besetzter Kommissionen.

Während des Ersten Weltkriegs hatte die Ausschußtätigkeit beiderseits an $\mathrm{Be}$ deutung gewonnen. In Deutschland betraf dies vor allem den Haushalts- bzw. Hauptausschuß, der sich unter den Bedingungen einer eingeschränkten parlamentarischen Öffentlichkeit in gewisser Weise zu einem verkleinerten Kriegsparlament entwickelte und eine Keimzelle der Kooperation zwischen SPD und bürgerlicher Mitte darstellte ${ }^{67}$. Noch bedeutsamer war die kriegsbedingte Stärkung des Ausschußwesens im parlamentarischen System der Dritten Republik: So wurden die Grandes Commissions permanentes angesichts der auch in Frankreich erfolgenden Machtsteigerung der militärischen Führung zu Garanten wirkungsvoller parlamentarischer Kontrolle. Dem Ideal des deliberativen Modells widersprach dieser Funktionsgewinn der Ausschüsse insofern, als dadurch die öffentliche Plenardebatte etwas in den Schatten der konkreten Sacharbeit geriet.

Nach der Geschäftsordnung des Reichstags vom 12. Dezember 1922 gab es 15 ständige Ausschüsse, deren Mitgliederzahlen zwischen 14 und 28 lagen ${ }^{68}$. Zwei davon - der Ausschuß zur Wahrung der Rechte der Volksvertretung, auch Überwachungsausschuß genannt, und der Auswärtige Ausschuß - hatten sogar Verfassungsrang. Artikel 35 sicherte ihre Präsenz auch in Zeiten, in denen der Reichstag nicht versammelt war69. Der politisch bedeutendste und mit Abstand am häufigsten tagende Ausschuß war jener für den Reichshaushalt ${ }^{70}$. Von 1920 bis 1932 stand er, mit einer kurzen Unterbrechung 1924, unter der Leitung des Sozialde-

66 Grober Überblick zur Entwicklung in Deutschland und Frankreich in Dechamps, Macht und Arbeit der Ausschüsse, S. 39-61. Zu Deutschland vgl. v.a. Mergel, Parlamentarische Kultur, S. 191-201; daneben immer noch interessant: Heuss, Der Parlaments-Ausschuß. Zu Frankreich: Barthélemy, Essai sur le travail parlementaire; Guiral/Thuillier, La vie quotidienne des députés, S. 225-238; Gooch, The French Parliamentary Committee System.

67 Schiffers, Hauptausschuß.

$68 \$ 28$ der Geschäftsordnung überließ die Zahl der Mitglieder der einzelnen Ausschüsse dem Reichstag. Mitgliederzahlen nach BA Berlin, R 1501, Nr. 14792.

69 Im Falle des „Überwachungsausschusses“ sollte hieraus im Mai 1923 ein grundsätzlicher Konflikt darüber entstehen, inwiefern dem Ausschuß nach einer Reichstagsauflösung die Wahrnehmung allgemeiner parlamentarischer Rechte, wie etwa der Forderung nach Rücknahme einer Notverordnung, zukomme. Die im Mai 1923 unter der Regierung Cuno getroffene ministerielle Übereinkunft, die Rechte des Überwachungsausschusses restriktiv auszulegen, legte die Verfassungsinterpretation bis zum Ende der Weimarer Republik fest. BA Berlin, R 3101, Nr. 5738/1, Bl. 11 f. Damit war ein möglicher Ansatzpunkt blockiert, um den massiven Funktionsverlust im Bereich der parlamentarischen Kontrolle, der ab 1930 aus den langen Phasen nach einer Reichstagsauflösung resultierte, zumindest partiell abzufangen.

70 Handschriftliche und gedruckte Protokolle in BA Berlin, R 101. Insgesamt gab es von 1919-1933 693 Sitzungen des Haushaltsausschusses, an zweiter Stelle folgt mit weitem Abstand der Ausschuß für Volkswirtschaft mit 264 Sitzungen. Der Ausschuß für Auswärtige Angelegenheiten brachte es demgegenüber lediglich auf 173 Sitzungen. Zahlen nach den Aufstellungen der Berichte im Deutschen Reichsanzeiger, in: Weimar-Index. 
mokraten Hugo Heimann, dessen Kompetenz und Autorität über die Parteigrenzen hinweg breite Anerkennung fanden ${ }^{71}$. Im Haushaltsausschuß, der auch über mehrere Unterausschüsse verfügte ${ }^{72}$, zeigte sich vielleicht am deutlichsten jenes Potential konstruktiver und durchaus auch integrativer Zusammenarbeit, über das der Weimarer Parlamentarismus trotz seiner fast permanenten funktionalen Probleme zweifellos verfügte ${ }^{73}$. Einen besonders hohen Stellenwert besaß auch der Ausschuß für Auswärtige Angelegenheiten. Stresemanns Aufstieg zur Führungsfigur der bürgerlichen Mitte vollzog sich auch dank seiner Funktion als Vorsitzender in den Jahren 1920-2374.

Tab. 1: Ständige Ausschüsse des Reichstags nach der Geschäftsordnung vom 12. 12. $1922^{75}$

1. Wahrung der Rechte der Volksvertretung

2. Auswärtige Angelegenheiten

3. Geschäftsordnung

4. Petitionen

5. Reichshaushalt

6. Steuerfragen

7. Rechnungen

8. Volkswirtschaft
9. Soziale Angelegenheiten

10. Bevölkerungspolitik

11. Wohnungswesen

12. Bildungswesen

13. Rechtspflege

14. Beamtenangelegenheiten

15. Verkehrsangelegenheiten

Vom fachlichen Zuschnitt her stimmten die ständigen Ausschüsse in der Weimarer Republik - ähnlich wie in der Dritten Republik - nur grob mit der Gliederung der Ministerien überein ${ }^{76}$. Auffallend ist, daß es im Reichstag keinen Ausschuß im Bereich des Militärwesens gab77. Die traditionelle, der parlamentarischen Kontrolle weitgehend entzogene Sonderstellung der militärischen Gewalt in der preußischdeutschen Geschichte bis 1918 fand damit eine gewisse Fortsetzung. Das Fehlen eines militärischen Fachausschusses wurde allerdings teilweise durch die Beratungen des militärischen Etats im Haushaltsausschuß kompensiert. Neben den ständigen Ausschüssen existierten in der Weimarer Republik für begrenzte Zeiträume thematische Sonder- oder Untersuchungsausschüsse. Letztere besaßen, erstmals in der nationalen Parlamentarismusgeschichte, sogar Verfassungsrang (Art. 34). Die politische Wirksamkeit der eingesetzten Untersuchungsausschüsse blieb aber insgesamt gering ${ }^{78}$.

71 Eine Biographie dieses sowohl in der zeitgenössischen Öffentlichkeit als auch in der Geschichtsschreibung wenig bekannten, aber doch bedeutsamen und erfolgreichen Weimarer Politikers steht noch immer aus. Einzelne Hinweise auch zur reichspolitischen Bedeutung in Rudischhauser, Hugo Heimann. Wenig ergiebig ist die Autobiographie: Heimann, Vom tätigen Leben.

72 Vgl. ebd., S. 35, zu dem seit 1926 bestehenden Unterausschuß für das Rechnungswesen, mit dem der Reichstag sein Budgetrecht stärken konnte.

73 Mergel, Parlamentarische Kultur, passim.

74 Vgl. auch Turner, Stresemann, S. 108.

$75 \$ 26$.

76 Zumindest in Frankreich war dies bewußt so gestaltet, um eine geschlossene Dominanz gegenüber den Ministerien zu vermeiden.

77 Edinger, Wahl und Besetzung parlamentarischer Gremien, S. 121, spricht von einem „Indiz für die mangelhafte parlamentarische Kontrolle der Reichswehr". Militärische Fragen wurden in anderen Ausschüssen mitbehandelt, v.a. im Auswärtigen und im Haushaltsausschuß.

78 Vgl. zur Inflationszeit die Auflistung von Untersuchungsausschüssen in Poetzsch, Staatsleben 1, S. 121-123. Vgl. auch Erster Teil, Kap. III.4 zur Kontrollfunktion. 
Die Abgeordnetenkammer der Dritten Republik verfügte seit 1915 über 20 Grandes Commissions permanentes mit jeweils 44 Mitgliedern. Die politische Bedeutung des Ausschußwesens lag infolge der von fraktionellen Vorentscheidungen weniger abhängigen Verfahrensweisen des deliberativen französischen Parlamentarismus noch höher als in Deutschland. Personelle Wechsel von Ausschußämtern auf Ministerposten und umgekehrt waren relativ häufig. Insbesondere die Finanzkommission hatte eine extrem starke Stellung und wurde in der Inflationszeit zu einem zentralen Ort der Politik. Anders als in der Weimarer Republik bildete auch das Militärwesen einen wichtigen Sektor der Ausschußarbeit ${ }^{79}$. Neben den "großen“ Kommissionen bestanden in der Abgeordnetenkammer fünf kleinere ständige Ausschüsse (Commissions permanentes non grandes). Hinzu kamen ebenso wie im Reichstag Unterausschüsse, thematische Sonder- sowie Untersuchungsausschüsse.

Tab. 2: Grandes Commissions permanentes in der Chambre des Députés 1920-193280

\begin{tabular}{ll}
\hline 1. Administration générale, départementale & 11. Enseignement et Beaux-Arts \\
et communale & 12. Finances \\
2. Affaires étrangères & 13. Hygiène \\
3. Agriculture & 14. Législation civile et criminelle \\
4. Algérie, colonies, protectorats & 15. Marine marchande \\
5. Alsace-Lorraine & 16. Marine militaire \\
6. Armée & 17. Mines et force motrice \\
7. Assurance et prévoyance sociale & 18. Régions libérées \\
8. Commerce et Industrie & 19. Travail \\
9. Comptes définitifs et économies & 20. Travaux publics et moyens \\
10. Douanes et conventions commerciales & \multicolumn{1}{c}{ de communication } \\
\hline
\end{tabular}

Die Besetzung der Ausschüsse erfolgte in beiden Parlamenten gemäß den fraktionellen Kräfteverhältnissen im Plenum. Die Wahl der Vorsitzenden ${ }^{81}$ und anderer Funktionsträger wurde jeweils intern vorgenommen. Im Reichstag gab es hierzu Vorabsprachen im Ältestenrat, die einen gewissen Proporz der Fraktionen berücksichtigten. Auch Oppositionsparteien kamen auf diese Weise zum Vorsitz einzelner Kommissionen. In der Abgeordnetenkammer hingegen fanden in den konstituierenden Ausschußsitzungen - nach Wahlen und zu Jahresbeginn durchaus offene Abstimmungen statt, wenngleich sich meist die aktuelle Regierungsmehrheit durchsetzte. So zog 1924 der Machtantritt des Cartel des Gauches eine Neubesetzung fast aller Kommissionspräsidenten nach sich. Eine Besonderheit des französischen Ausschußwesens bildete die hohe Bedeutung des Berichterstatters (Rapporteur), der die Ergebnisse der Ausschußarbeit in der Kammer zu präsentieren hatte. Im Falle der Finanzkommission gab es einen ständigen Rap-

79 Neben dem Armeeausschuß existierten auch eine Commission für die Marine militaire und ab 1932 mit militärischer Relevanz ein Ausschuß für Aéronautique. Vgl. Géroudet, Le parlement et l'armée.

80 Die Zählung der Kommissionen ist fiktiv.

81 Die Vorsitzenden der ständigen Ausschüsse in den Jahren 1920-24 in Deutschland und 1919/ 20-26 in Frankreich sind aus den Tabellen in Anhang 3 ersichtlich. 
porteur général - eine Funktion, die erhebliche Chancen zur politischen Profilierung bot ${ }^{82}$.

In beiden Staaten waren die Kommissionssitzungen mit Ausnahme der Untersuchungsausschüsse in der Regel nicht öffentlich. Auch die in den größeren Ausschüssen angelegten Verlaufsprotokolle gelangten nicht an die Öffentlichkeit. In Deutschland wurden Zusammenfassungen der wichtigsten Ergebnisse im Reichsanzeiger publiziert ${ }^{83}$, in Frankreich gingen Informationen über die Ausschußarbeit direkt an die Presse.

d) Öffentliches Forum der parlamentarischen Debatten, Interpellationen und Entscheidungen ist in allen parlamentarischen Systemen das Plenum ${ }^{84}$. In dem noch immer - zumindest in den 1920er Jahren - stark deliberativ geprägten System der späten Dritten Republik kam der Rede auf der parlamentarischen „tribune" eine sehr hohe Bedeutung $\mathbf{z u}^{85}$. Die Plenardiskussion war für den parlamentarischen Willensbildungsprozeß insgesamt wichtiger als in der Weimarer Republik, wo die Entscheidungen in den Fraktionen oft präjudizierend wirkten. Dennoch sollte der Stellenwert der Plenardebatte auch für Deutschland nicht unterschätzt werden, zumal sie ebenso wie in Frankreich eine erhebliche Öffentlichkeitswirkung besaß86. Diese Bedeutung spiegelte sich auch in der beiderseits außerordentlich hohen Zahl an Plenarsitzungen. Der traditionelle Rhythmus der Sessionen war infolge der legislativen Herausforderungen der Nachkriegsjahre durch eine nahezu permanente parlamentarische Präsenz abgelöst worden. Konsequenterweise verzichtete die Geschäftsordnung des Reichstags von 1922 daher bereits auf den Begriff der Session, während dieser in der späten Dritten Republik noch Verwendung fand ${ }^{87}$. Für die Weimarer Republik ist allerdings eine wichtige Einschränkung zu machen: In jenen Phasen, in denen die legislative Funktion des Reichstags weitgehend suspendiert war, wurde auch der Plenarbetrieb nahezu eingestellt. So gab es zwischen dem 13. Oktober 1923 und dem 12. Februar 1924 nur fünf Plenarsitzungen ${ }^{88}$. Durchaus ähnlich war in beiden Parlamenten die Problematik langer Redezeiten, und beiderseits wurde mehrfach versucht, eine Straffung der Debatten zu erreichen ${ }^{89}$.

82 So nutzte der ehrgeizige Maurice Bokanowski (Gauche républicaine démocratique) 1924 diese Position als Sprungbrett für eine Berufung als Marineminister in das Kabinett Poincaré III.

83 Verzeichnis der Berichte im Weimar-Index.

${ }^{84} \mathrm{Zu}$ Deutschland: Mergel, Parlamentarische Kultur, S. 179-190; Gusy, Weimarer Reichsverfassung, S. 128f. Allgemein zum Funktionswandel der Parlamentsdebatte vgl. Olscheski, Die Verschriftung von Parlamentsdebatten, S. 348-351. Für unsere Zwecke zu pauschal ist der Ansatz in Burkhardt, Das Parlament und seine Sprache.

$85 \mathrm{Vgl}$. z. B. die quasi-sakrale Bewertung in Barthous kleinem Leitfaden der Politik: „La tribune est l'autel de la parole: elle veut, comme les autels de la prière, du recueillement et du respect." Ders., Le politique, S. 48. Vgl. auch das Gemälde "Jaurès à la tribune“ aus dem Jahr 1907. Hierzu oben S. $55 \mathrm{f}$. Grundsätzlich zum Stellenwert der parlamentarische Rede auch Rioux, Le Palais-Bourbon; ebd. wird allerdings auch der in den 1930 er Jahren voranschreitende Verfall betont.

$86 \mathrm{Vgl}$. hierzu auch unten S. $73 \mathrm{f}$.

87 Die Session ordinaire dauerte in der Regel von Januar bis Juli/August, die session extraordinaire in der Regel von Oktober bis Dezember. Eine Ausnahme bildete das Jahr 1923, in dem die Sommerund Herbstpause bis November verlängert wurde.

88 Ab 1930 sank die Zahl der Sitzungen dann dauerhaft drastisch ab.

89 Zum Reichstag vgl. Mergel, Parlamentarische Kultur, S. 186 f.; zur französischen Geschäftsordnungsreform von 1926 vgl. Roussellier, Gouvernement et parlement, S. 257. 
e) Neben den aufgeführten Instanzen vollzog sich die parlamentarische Kommunikation auch an Orten, die in den Verfassungstexten und Geschäftsordnungen nicht genannt werden. Auch hierzu sei im folgenden ein kurzer Überblick gegeben:

- Die in der Weimar-Forschung bislang zu wenig beachteten Partei- bzw. Fraktionsführerbesprechungen knüpften in loser Form an den Interfraktionellen Ausschuß von 1917/18 an ${ }^{90}$. Die relativ stark formalisierten Treffen zwischen führenden Vertretern der Koalitionsparteien fanden mit schwankender Intensität statt ${ }^{91}$, nicht selten wurden hohe Ministerialbeamte und vereinzelt auch Repräsentanten anderer Parteien hinzugezogen. Allein für das Jahr 1922 lassen sich zum Beispiel über 21 derartige Treffen nachweisen ${ }^{92}$. In der Regel erfolgten förmliche Einladungen ${ }^{93}$, und manchmal wurde auch "offiziell“ Protokoll geführt. Die Weichen der Koalitionspolitik sind gerade in der krisenhaften Inflationszeit häufig in diesen Sitzungen gestellt worden.

Eine ansatzweise analoge Erscheinung bildeten auf französischer Seite die Treffen der Délégation des Gauches, die in den Zeiten des Linkskartells und der Volksfront die parlamentarische Zusammenarbeit der Regierungsfraktionen erleichtern sollten ${ }^{94}$. Allerdings ist über die Arbeitsweise dieses Gremiums und über die Inhalte der Besprechungen nur sehr wenig bekannt. Während der Amtszeiten von Mitte-rechts-Regierungen, die weniger parteipolitisch definiert waren, hat es derartige semi-formelle Instanzen des parlamentarischen Regierungslagers offenbar nicht gegeben.

Gelegenheiten zur informellen parlamentarischen Diskussion, aber auch zu Kontakten mit Journalisten und Interessenvertretern boten - neben der jeweiligen Kantine - vor allem die Wandelhalle des Reichstags und die couloirs des Palais Bourbon. Während die lange Wandelhalle wohl eher als Nebenschauplatz zu bewerten ist, standen die verwinkelten und doch geräumigen couloirs geradezu im Zentrum der deliberativen parlamentarischen Praxis"5. „Faire les couloirs" bedeutete für französische Abgeordnete einen wesentlichen Aspekt ihrer Tätigkeit. Hier, im „,bouillon de culture des intrigues épanouies et des ambitions sécrètes"96, nahm so manche überraschende parlamentarische Wendung ihren Anfang, wurde so mancher Regierungssturz sorgsam vorbereitet. Wie bedeutsam die Wandelgänge des Palais Bourbon als Ort der oft quer zu allen Fraktionen verlaufenden

90 Zur hohen Bedeutung vgl. auch Witt, Kontinuität und Diskontinuität, S.135f. Versuche zur weitergehenden Neuauflage eines formellen Interfraktionellen Ausschusses konnten sich in der Mittelphase der Weimarer Republik nicht durchsetzen. Vgl. Haungs, Reichspräsident, S. 161-174. - Nachfolger in der Bundesrepublik wurden die sogenannten Koalitionsrunden bzw. -ausschüsse. Vgl. hierzu Schreckenberger, Informelle Verfahren.

91 Meist nahmen zwei oder mehr Vertreter pro Partei teil, darunter in der Regel die Fraktionsvorsitzenden.

$92 \mathrm{Zu} 15$ Besprechungen gibt es Protokolle oder Hinweise in den AdR; zu sechs weiteren fanden sich Hinweise in der Presse oder in nicht publizierten Akten.

93 Vgl. Muster in BA Berlin, R 1501, Nr. 25053, Bl. 4.

94 Vgl. Soulier, L'instabilité, S. 227-231.

95 Zur Bedeutung der couloirs vor dem Ersten Weltkrieg vgl. Guiral/Thuillier, La vie quotidienne des députés, S. 136-139. Die Darstellung erscheint auch für die Zwischenkriegszeit noch weitgehend gültig.

96 So LT, 12. 1. 1922, S. 1, "La scène et les coulisses“, im Zusammenhang mit der parlamentarischen Situation während der Konferenz von Cannes. 
Meinungsbildung und Meinungsmache waren, zeigt der Blick in die Geheimpolizeiberichte der Notes Jean ${ }^{97}$ : Die Vorgänge auf den couloirs waren dort oftmals bis in die wirrsten Gerüchte präsent, die Instanz der Fraktionssitzungen hingegen fand nur sehr selten Erwähnung.

- Auch die gesellschaftlichen Kontakte außerhalb des unmittelbaren parlamentarischen Raumes sind in ihrer Bedeutung nicht zu unterschätzen. Auf deutscher Seite gab es regelmäßige Treffen in Form von "Fraktionskneipen“, aber auch überparteiliche Einladungen zu „Bierabenden“, zu Abendempfängen oder zum „politischen Frühstück“98. Die Anwesenheit von Parlamentariern in politischen Klubs und Salons bot darüber hinaus auch den verschiedenen Interessengruppen Möglichkeiten zur ungezwungenen Kontaktaufnahme99. Für die späte Dritte Republik ist hier relativ wenig bekannt. Traditionell spielten aber Gespräche in den Pariser Salons, beim regelmäßigen Abendessen kleinerer Abgeordnetengruppen und nicht zuletzt auch beim Zusammentreffen von Parlamentariern in bestimmten Cafés und Brasseries eine wichtige Rolle ${ }^{100}$.

Die enge Zusammenarbeit der Abgeordneten auf den verschiedenen institutionellen und informellen Ebenen des Reichstags und der Abgeordnetenkammer erzeugte trotz aller politischen und teilweise auch persönlichen Spannungen und Anfeindungen über Parteigrenzen hinweg tendenziell ein Klima der Vertrautheit, der gegenseitigen Achtung und teilweise auch des Corpsgeistes. Die integrative Wirkung einer gewachsenen parlamentarischen Kultur ist für die Dritte Republik - „la République des camarades“ ${ }^{101}$ - eine von jeher betonte Tatsache. Sie bildete eine wesentliche Voraussetzung für einen immer noch stark von individuellen Entscheidungen geprägten Parlamentarismus. In der Chambre bleu borizon der Jahre 1920-24 war dieses Klima angesichts der Mitgliedschaft vieler Weltkriegsteilnehmer und der dadurch gegebenen Fortdauer eines unmittelbaren Gefühls der "Union sacrée“ offenbar besonders stark ausgebildet ${ }^{102}$. Für den Weimarer Reichstag hat Mergel auf eine im Prinzip analoge „integrative Dynamik“ des alltäglichen parlamentarischen Umgangs hingewiesen, die sich vor allem hinter den Kulissen der Plenardebatten entfaltete. Abgeordnete unterschiedlicher politischer Ausrichtung wurden durch gemeinsame Kommunikationsformen verbunden, die

97 Zur Quellengruppe vgl. oben S. 25.

98 Hierzu Mergel, Parlamentarische Kultur, S. 134-136; Beispiel für ein Frühstück bei den DVPParlamentarier Raumer unten S. 165; Schilderung eines „parlamentarischen Abends" beim „zuständigen Minister" einschließlich eines politisch höchst relevanten Gesprächs mit einem Fraktionskollegen in Lambach, Herrschaft der Fünfhundert, S. 118-122. Ebd., S. 15f. zu „Fraktionskneipen“.

99 Lambach, ebd., S. 86, nennt in diesem Zusammenhang die Deutsche Gesellschaft, den demokratischen Klub, den Reichsklub, den Nationalen Klub, den Juni-Klub, das Gewissen, den Volksdeutschen Klub, den Salon der Frau von Oheimb und den Salon Cassirer.

100 Vgl. zur Zeit bis 1914 Guiral/Thuillier, La vie quotidienne des députés, S. 90f., 175-179, 191-194. Ebd., S. 194 wird die schlechte Überlieferung mit der bei derartigen Kommunikationsformen geübten Diskretion begründet. Cum grano salis gilt diese Erklärung für die gesamte parlamentarische Quellenlage zu Frankreich. Allgemein zur Bedeutung von - meist konservativ ausgerichteten - Salons für die französische Politik im 19. und 20. Jahrhundert vgl. Ory, Le salon.

$101 \mathrm{Vgl}$. die berühmte Polemik von Jouvenel, La République des camarades.

102 Vgl. hierzu die Schilderungen von Paul-Boncour, Entre deux guerres 2, S. 35-37, v.a. über sein gutes persönliches Verhältnis zu General de Castelnau. Der Begriff Chambre bleu horizon spielt auf das Blau der zahlreichen Uniformen an. Allgemein zum Corpsgeist vgl. ncben Jouvenel, La République des camarades, auch Zeldin, History 1, S. $577 \mathrm{f}$. 
erst in den letzten Jahren der Republik infolge des Erstarkens von Nationalsozialisten und Kommunisten erodierten ${ }^{103}$.

Zweifellos bot der alltägliche parlamentarische Umgang im deutschen Reichstag eine Chance, über die fortschreitende soziokulturelle Integration $\mathrm{zu}$ einem besseren Funktionsbetrieb und zu einer allmählichen „Parlamentarisierung “ ursprünglich systemfeindlicher bzw. ambivalenter Parteien beizutragen ${ }^{104}$. Allerdings wäre dazu auch ein längerer Zeitraum erfolgreicher parlamentarischer Tätigkeit notwendig gewesen. Aus Sicht unserer Analyse muß zudem betont werden, daß eine gewisse Vertrautheit und Loyalität innerhalb der Abgeordnetenschaft nicht vor einem problematischen Verständnis parlamentarischer Funktionsprozesse schützte. Vor dem Hintergrund der deutschen Parlamentarismusgeschichte erscheint dies keineswegs überraschend: Während man elementare Formen parlamentarischer Kommunikation schon lange vor 1918 erlernen konnte, fehlte es an Erfahrungen mit einem parlamentarischen Regierungssystem und dessen funktionalen Anforderungen.

\section{Partei-und Fraktionswesen}

Bevor das Fraktionswesen von Reichstag und Abgeordnetenkammer miteinander verglichen werden kann, ist zunächst ein Blick auf die Grundzüge der Parteienentwicklung notwendig. Dabei soll an das angeknüpft werden, was bereits zu den parteigeschichtlichen Traditionslinien sowie zu den Weichenstellungen der Jahre 1918 bis 1920 ausgeführt worden ist ${ }^{105}$.

Der Zuschnitt des Weimarer Parteienspektrums erfuhr nach 1920 noch einige durchaus bedeutsame Veränderungen ${ }^{106}$. An erster Stelle ist die Wiedervereinigung von SPD und USPD im September 1922 zu nennen, die sich unter dem Eindruck der durch den Rathenau-Mord ausgelösten innenpolitischen Erschütterung relativ rasch und reibungslos vollzog. Eine zweite wichtige Modifizierung des Parteiensystems erfolgte im Oktober 1922 durch eine völkische Abspaltung von der DNVP. Die daraus entstandene Deutsch-Völkische Freiheitspartei wurde zum Bündnispartner der jungen NSDAP. Der während der Inflationskrise stattfindende politische Radikalisierungsprozeß schlug dann in den Reichstagswahlen vom Mai 1924 aufgrund des Verhältniswahlsystems voll auf die Mandatsvertei-

103 Mergel, Parlamentarische Kultur, v.a. S. $428-465$.

104 Daß mit Walther Lambach ausgerechnet ein DNVP-Parlamentarier eine ebenso verständige wie werbende Darstellung des alltäglichen Reichstagslebens verfaßt hat (ders., Herrschaft der Fünfhundert), kann als Indiz hierfür bewertet werden. Bei Mergel, Parlamentarische Kultur, v.a. S. 323-331, herrscht allerdings eine wohl zu optimistische Einschätzung hinsichtlich der bereits erreichten „stillen Republikanisierung“ der DNVP.

$105 \mathrm{Vgl}$. Erster Teil, Kap. I.

106 Angeführt seien hier nur die grundlegenden Monographien zur Parteiengeschichte während der Inflationszeit. Zur DDP und DVP: Albertin, Liberalismus und Demokratie; Stephan, Aufstieg und Verfall des Linksliberalismus; Schustereit, Linksliberalismus und Sozialdemokratie; Schneider, Deutsche Demokratische Partei; Jones, German Liberalism; Richter, Deutsche Volkspartei. Zur DNVP: Hertzman, DNVP; Liebe, Deutschnationale Volkspartei; Trippe, Konservative Verfassungspolitik. Zur KPD: Weber, Die Wandlung des deutschen Kommunismus. Zur SPD: Winkler, Von der Revolution zur Stabilisierung; ders., Schein; Maehl, The German Socialist Party; Breitman, German Socialism. Zum Zentrum: Morsey, Zentrumspartei; Ruppert, Dienst. - Vyl. auch den Überblick in Möller, Weimarer Parteiendemokratie in kritischer Perspektive. 
lung im Reichstag durch ${ }^{107}$. Erfaßt man den Vorgang mit den parteitheoretischen Kategorien von Giovanni Sartori, so muß für die deutsche Inflationszeit der Wandel von einem gemäßigten zu einem polarisierten Vielparteiensystem konstatiert werden ${ }^{108}$. Mit der Geldentwertung im Zuge der Währungsstabilisierung wuchs die Verbitterung in Teilen des Mittelstandes, was zunächst zu einem in der Summe bedeutsamen Wachstum interessengebundener Splitterparteien führte. Beide Entwicklungen waren mit massiven Wählerverlusten in einer weitgefaßten politischen Mitte von SPD bis DVP verbunden, von denen lediglich die konfessionelle Zentrumspartei weitgehend verschont wurde.

Die einzige größere Veränderung des französischen Parteiensystems zwischen den Weltkriegen erfolgte, wie bereits geschildert, 1920 auf der politischen Linken ${ }^{109}$. Die Entwicklung der nach dem sozialistischen Spaltungsparteitag von Tours gegründeten Kommunistischen Partei (SFIC, später dann PCF) blieb trotz deutlicher organisatorischer Fortschritte bis Mitte der dreißiger Jahre sowohl in den Mitgliederzahlen als auch in der parlamentarischen Präsenz hinter der Weimarer KPD zurück ${ }^{110}$. Auf der extremen Rechten konnte sich bis 1937, als der Parti social français bei einer Reihe von Nachwahlen von der Einführung des Verhältniswahlrechts profitierte, keine parlamentarisch vertretene Partei etablieren. Statt dessen waren die radikalen Kräfte weitgehend auf den rechten Flügel der Fédération républicaine, auf die kleine parlamentarische Gruppe der „Unabhängigen“ bzw. „Fraktionslosen“ bzw. auf außerparlamentarische Ligen beschränkt. Von einer Polarisierung des französischen Vielparteiensystems in der Zwischenkriegszeit kann daher kaum gesprochen werden. Am auffälligsten neben der Ausbildung einer kommunistischen Linken ist das kontinuierliche Wachstum der Sozialistischen Partei, die sich nach dem Schisma von Tours relativ rasch erholen konnte ${ }^{111}$.

Dem organisatorischen Erstarken der Sozialistischen und Kommunistischen Partei hatten die bürgerlichen Kräfte wenig entgegenzusetzen. Der linksliberale Parti républicain radical et radical-socialiste (in Kurzform: Parti radical), der von allen bürgerlichen Parteien noch die am weitesten entwickelten Strukturen besaß, erholte sich im Zuge der unter dem neuen Parteivorsitzenden Herriot betriebenen

$107 \mathrm{Vgl}$. Anhang, Tab. 4.3.

108 Sartori, Parties and Party Systems. Zur Bedeutung als Krisenfaktor vgl. mit allgemeiner komparatistischer Perspektive Linz, Breakdown of Democratic Regimes 1, S. 25-27.

109 Wie bereits in der Einleitung angemerkt, ist die Literatur zum französischen Parteienwesen stark unterentwickelt. Am wichtigsten für die Inflationszeit ist die Untersuchungen zum Parti radical von Berstein, Histoire. Zur allgemeinen Orientierung über das Parteien- und Fraktionswesen vgl. immer noch: Siegfried, Tableau des partis, sowie mit konkreteren Informationen Carrère/Bourgin, Manuel des partis politiques, und Corcos, Catéchisme des partis politiques. Allgemein zum Stellenwert von Parteien im System der Dritten Republik vgl. immer noch Albertini, Parteiorganisation und Parteibegriff.

110 Vergleichend zur Entwicklung auf nationaler Ebene und in den Metropolen Berlin und Paris Wirsching, Vom Weltkrieg zum Bürgerkrieg?, S. 161-166. Tabelle zur Mitgliederentwicklung in Ziebura, Blum, S. 510. Unter den Bedingungen des bis 1927 gültigen Mischsystems im Wahlrecht und der danach wieder in vollem Umfang hergestellten Mehrheitswahl kam es erst im Rahmen der Volksfront zu einem deutlichen Wachstum der kommunistischen Fraktion in der Abgeordnetenkammer. Allgemein zu SFIC bzw. PCF vgl. v.a. Fauvet, Histoire du Parti communiste français.

111 Vgl. v.a. Judt, La réconstruction du Parti socialiste; Überblicksdarstellung in Lefranc, Mouvement socialiste 2 . 
„reconstruction“ Anfang der zwanziger Jahre zwar rasch von seiner kriegsbedingten Schwächung. Die Partei blieb aber ein loser Verbund von Komitees und regionalen Föderationen; vom Aufbau eines modernen, disziplinierten Parteiapparats konnte keine Rede sein ${ }^{112}$.

Auch bei den anderen Parteien rechts von der SFIO machte die organisatorische Entwicklung kaum Fortschritte, so daß die Dritte Republik weiterhin klar hinter dem Entwicklungsstand des deutschen Parteiwesens zurückblieb. Der 1913 zerbrochene kleine linksliberale Parti républicain-socialiste wurde erst 1923 wiederbegründet und fusionierte 1926 mit dem 1920 in Konkurrenz zur angeschlagenen SFIO formierten Parti socialiste français zum Parti républicain-socialiste et socialiste-français. Zwei Jahre später kam es jedoch erneut zu einer Spaltung113. Äußerst vage waren die Strukturen im Bereich der „gemäßigten“ Republikaner (Modérés). Die rechtsliberale Alliance (républicaine) démocratique sowie die konservative Fédération républicaine blieben organisatorisch kaum greifbar und glichen eher Dachverbänden, deren Tätigkeit sich weitgehend auf die Vorbereitung von Wahlen beschränkte114. Bezeichnend sind bereits die auf ein loses Bündnis verweisenden Parteinamen, und durchaus konsequent erscheint es auch, daß die 1920 vollzogene Umbenennung der Alliance démocratique in Parti républicain démocratique et social 1926 wieder rückgängig gemacht wurde ${ }^{115}$. Das einzige nennenswerte neue Element, das im Laufe der Zwischenkriegszeit innerhalb des bürgerlichen Spektrums hinzukam, war der Ende 1924 gegründete kleine Parti démocrate populaire (PDP), mit dem es gelang, eine christlich-demokratische Partei im französischen Parteiensystem zu etablieren ${ }^{116}$. Insgesamt blieben die Kräfteverhältnisse innerhalb des bürgerlichen Parteienspektrums Frankreichs relativ stabil. Im Vergleich zu Deutschland fällt hier am meisten auf, daß in den Wahlergebnissen der zwanziger Jahre so gut wie keine Erosion des Liberalismus zugunsten konservativer oder rechtsextremer Parteien stattfand.

112 Vgl. v.a. Berstein, Histoire 1, S. 177-258; Nordmann, Histoire des radicaux, S. 189-285; Larmour, French Radical Party. Detaillierter Überblick über die Parteistrukturen in der historischen Gesamtschau in Bardonnet, Evolution de la structure du parti radical. - Vgl. auch das Urteil in Botschaftsbericht-Paris (Hoesch), A 1626, 19.4. 1924, S. 3: „Die ganze Geschichte der radikalen Partei während der abgelaufenen Legislaturperiode ist ein ununterbrochener, mit mehr oder weniger Geschick geführter Kampf des Führers Herriot, seine Schäflein beieinander zu halten. Soweit ihm das überhaupt gelang, war dafür weniger die Gemeinsamkeit der politischen Ideen und des Programms als die Persönlichkeit des Führers entscheidend.“ PA AA Berlin, R 70697.

113 Vgl. Billard, Parti républicain-socialiste; ders., Un Parti républicain-socialiste a vraiment existé.

114 Die Forschungslage ist hier besonders schlecht. Wileman, L'Alliance Républicaine Démocratique, bleibt sehr allgemein. Sanson, L'Alliance républicaine démocratique, behandelt nur die Zeit bis 1920; einige weiterführende Hinweise in dies., Les relations entre l'Alliance démocratique et le parti radical. Zur Fédération républicaine gibt es für die zwanziger Jahre auf nationaler Ebene überhaupt keine Untersuchung. Partiellen Ersatz hierfür bietet die instruktive Regionalstudie von Bernard, La dérive des modérés; manche Hinweise auch in Jeanneney, De Wendel, v.a. S. 440-454 zur Finanzsituation. Für die dreißiger Jahre vgl. Irvine, French Conservatism in Crisis. Vgl. auch zwei kurze Überblicksdarstellungen: Sanson, ARD ou AD (Alliance démocratique); VavasseurDesperriers, Fédération républicaine. Generell zum Begriff der Modérés vgl. Francfort, Réflexion sur le mot „modéré“.

$115 \mathrm{Vgl}$. zum Kontext oben S. $42 \mathrm{f}$.

116 Parlamentarisch war die neue Partei allerdings die gesamte Zwischenkriegszeit über auf eine Gruppe von maximal 18 Abgeordneten beschränkt. Vgl. Delbreil, Centrisme et démocratie-chrétienne; Prélot, Les démocrates d'inspiration chrétienne entre les deux guerres, S. 546. 
Die organisatorischen Differenzen zwischen den Parteien zeigten sich nicht zuletzt auch in der jeweiligen Form der parlamentarischen Repräsentanz ${ }^{117}$. Die deutschen Parteien waren im Reichstag jeweils mit korrespondierenden Fraktionen bzw. Gruppen vertreten. Diese an sich banale Tatsache ist deshalb hervorzuheben, weil die Spiegelbildlichkeit von Partei- und Fraktionswesen in der französischen Abgeordnetenkammer nur teilweise realisiert war. Während die Kommunisten, Sozialisten und Christdemokraten (Parti démocrate populaire) jeweils mit geschlossenen Fraktionen auftraten, läßt sich für die übrigen Parteien eine derartige Zuordnung nicht vornehmen ${ }^{118}$. Das auf den ersten Blick chaotisch wirkende und dem heutigen Betrachter einiges an Mühe abfordernde, gleichwohl aber von einer gewissen Persistenz gekennzeichnete Tableau der bürgerlichen Fraktionen in der Abgeordnetenkammer muß daher genauer erläutert werden.

Im Falle des Parti radical gab es immerhin noch eine eindeutige fraktionelle Entsprechung, obgleich eine Fraktionszugehörigkeit nicht immer auch die Mitgliedschaft in der korrespondierenden Partei bedeutete ${ }^{19}$. Die Fraktion der Républicains-socialistes blieb bis zur Wiederbegründung des Parti républicain-socialiste 1923 ohne Parteibindung ${ }^{120}$. Eine parteipolitisch nicht zuzuordnende diffuse Sammelgruppe am rechten Rand des Parti radical bildete ab 1924 die Gauche radicale. Noch komplizierter war die Lage im Bereich der rechtsliberalen Alliance démocratique $^{121}$. Deren Anhänger verteilten sich über mehrere Fraktionen. Für die Jahre 1920-26 sind dies die Gruppen der Action républicaine et sociale (bis 1924), der Gauche républicaine démocratique, der Républicains de gauche und ab Ende 1925 auch der Gauche indépendante. Die politischen Differenzen waren bereits zeitgenössisch nur schwer zu erkennen. Bei der Entscheidung über die Fraktionszugehörigkeit spielten auch personale Beziehungsgeflechte, Alter und parlamentarische Erfahrung sowie die Absicht, in der fraktionell gesteuerten Besetzung der Ausschüsse bessere Karten zu haben, eine wesentliche Rolle ${ }^{122}$. Nach den Zahlen Wilemans variierte der Prozentsatz von Alliance-Mitgliedern 1920-24 in den ihr nahestehenden Gruppen nur etwa zwischen 25 und $35 \%{ }^{123}$. Ansonsten scheinen

117 Allgemein zum Fraktionswesen der Zwischenkriegszeit in Frankreich: Waline, Groupes parlementaires; aufschlußreich teilweise immer noch Barthélemy, Essai sur le travail parlementaire. Hinweise zum Abstimmungsverhalten 1920-24 in Roussellier, Parlement, passim. - Vgl. auch Hudemann, Fraktionsbildung, zum Fraktionswesen in der Anfangsphase der Dritten Republik, der im Gegensatz zur älteren Forschung den relativ entwickelten Stand des damaligen französischen Fraktionswesens betont. Leider liegen für die spätere Zeit keine ähnlich detaillierten Studien vor. Im Laufe der Dritten Republik scheint es aber - sieht man einmal von Sozialisten und Kommunisten ab - trotz einer gewissen institutionellen Aufwertung eher zu einer strukturellen Schwächung des Fraktionswesens gekommen zu sein.

118 Vgl. auch Anhang, Nr. 2.2. Vgl. allgemein zur Problematik auch Le Béguec, Le parti, S. 25-28.

119 Eine Klärung dieser scheinbar so simplen Frage erscheint inzwischen unmöglich. Das große Abgeordnetenlexikon Dictionnaire des parlementaires français verzeichnet in der Regel keine Parteiangehörigkeit. Ähnlich verfahren meist auch andere biographische Lexika.

120 Hierzu Billard, Parti républicain-socialiste, S. $228 \mathrm{f}$.

121 Der Einfachheit halber soll dieser Name auch für die Phase von 1920-26 verwendet werden, als die Partei offiziell unter dem Signum Parti républicain démocratique et social firmierte.

122 So gehörten der Action républicaine et sociale eine Reihe aufstrebender jüngerer Abgeordnete wie z. B. Paul Reynaud und André Tardieu an. Erfahrene "ministrable“ Politiker aus dem Bereich der Alliance sammelten sich dagegen eher in der Gauche républicaine démocratique, so z. B. Barthou und Maginot. Allgemein zum Fraktionswesen im Umfeld der Alliance vgl. auch Grüner, Zwischen Einheitssehnsucht und Massendemokratie, S. $238 \mathrm{f}$.

123 Wileman, Alliance, S. 380. Leider bleiben die Quellen für die Parteimitgliedschaft unklar. 
diese Fraktionen durch parteilose Abgeordnete und auch durch einzelne Mitglieder des Parti radical gebildet worden zu sein. Eine gewisse Kohärenz zwischen der großen konservativen Fraktion der Entente bzw. Union républicaine démocratique und der Partei der Fédération républicaine wurde erst 1924 erreicht ${ }^{124}$. Die wenigen verbliebenen royalistischen Abgeordneten fanden sich - neben diversen Einzelgängern - bis 1924 in der Gruppe der Indépendants ${ }^{125}$, später dann in der paradoxen Gruppe der Abgeordneten „sans groupe“.

Daß die fraktionelle Gliederung des Senats teilweise von jener der Kammer abwich, vergrößert noch die Probleme einer eindeutigen Zuordnung von Partei- und Fraktion. Während der Inflationszeit gab es nur vier bzw. zeitweise fünf Senatsfraktionen 126: die dominierende Gauche démocratique radicale et radicale-socialiste ${ }^{127}$ (im folgenden mit der Kurzform Gauche démocratique bezeichnet), die Gauche républicaine (Mitte-rechts), die Union républicaine (Rechte) sowie die kleine Gruppe der Droite. Seit 1924 existierte zeitweise noch eine von der Gauche démocratique nach rechts abgespaltene Union démocratique et radicale. Eine sozialistische Senatsfraktion bestand erst seit 1927128 .

Für den heutigen Betrachter verwirrend wirkt die nominelle Linkslastigkeit im Fraktionswesen beider Kammern. Das Prädikat „gauche“ führten selbst Gruppen im Namen, die politisch klar in der Mitte bzw. sogar in der rechten Mitte standen. Dieses Phänomen verweist zurück in die Frühphase der Dritten Republik, als eine republikanische "Linke“ gegen eine konservativ-monarchische „Rechte“ stand. Die Traditionshaftung des politischen Systems, verbunden mit einer anhaltenden Mythisierung der "République“, verlieh so dem Begriff "gauche“ einen lang anhaltenden Glanz ${ }^{129}$.

Bei aller Unübersichtlichkeit, welche die fluktuierenden Formen des französischen Partei- und Fraktionswesens in der Zwischenkriegszeit aufwiesen, darf nicht verkannt werden, daß sich im Vergleich zur Zeit vor 1914 in der Abgeordnetenkammer insgesamt bereits eine klarere Zuordnung eingestellt hatte ${ }^{130}$. Die jüngeren politischen Kräfte wie die stärker disziplinierten Sozialisten und Kommuni-

124 Allgemein zur - zumindest bis Ende der zwanziger Jahre - bestehenden Offenheit der Fraktionen der Entente bzw. Union républicaine démocratique auch für Abgeordnete, die nicht Mitglied der Fédération républicaine waren, vgl. Le Béguec, Le parti, S. 27. - 1932 übernahm die konservative Fraktion dann den Namen der Partei.

125 Prominentestes Mitglied war der auf einer Liste des Bloc national gewählte Léon Daudet von der Action française.

126 Marichy, Deuxième Chambre, S. 364-369, bleibt in seinem Kapitel über die politischen Kräfte von 1900 bis 1939 sehr allgemein und geht nicht auf die Senatsfraktionen ein.

127 Bei Bonnefous, Histoire 3 und 4, passim, und im Anschluß daran teilweise auch in der Literatur ist - wenn auch nicht durchgängig - fälschlicherweise auch von der Gauche radicale die Rede. So entsteht bei Bonnefous der Eindruck, es hätte eine Fraktion der Gauche démocratique und eine der Gauche radicale gegeben.

128 Vorher hatten einzelne Sozialisten der Gauche démocratique angehört.

129 Gauchet, La droite et la gauche; Kittel, Provinz, S. 118-120, spricht vom Phänomen des „Sinistrismus“.

130 Immerhin gab es jetzt nur noch eine radikale Fraktion und nicht mehr zwei wie bis 1914, als eine „radikale“ und eine „radikal-sozialistische“ Gruppe existiertc. Vgl. hierzu Bardonnet, Evolution, S, 144 f.; Zeldin, History 1, S. 723. - In diesem Zusammenhang sei auch daran erinnert, daß es - obgleich auch im französischen Parlamentarismus stets ein aktives Fraktionswesen existiert hatte $-\mathrm{zu}$ einer auch in der Geschäftsordnung fixierten Anerkennung der Fraktionen als parlamentarische Instanzen erst im Jahr 1910 gekommen war, als sie im Zuge der Neuordnung der Ausschußbesetzung indirekt anerkannt wurden. Vgl. Waline, Groupes parlementaires, S. 1188. 
sten, aber auch der christdemokratische Parti démocrate populaire nahmen bei der Etablierung parteianaloger Fraktionsstrukturen eine Schrittmacherrolle ein. Vor allem die rechtsliberale Mitte war jedoch einer Gleichrichtung von Partei- und Fraktionsstrukturen kaum zugänglich. Der Parti radical bemühte sich zwar um eine institutionelle Verklammerung von Partei und Fraktion im sogenannten Comité Cadillac, einer Versammlung aller Abgeordneten, Senatoren und Mitglieder des Parteibüros ${ }^{131}$, hatte damit aber letztlich wenig Erfolg.

Vergleicht man die partei- und fraktionspolitische Ausgangssituation in Deutschland und Frankreich unter dem Gesichtspunkt der Loyalität zum parlamentarischen System, so sind erhebliche Unterschiede festzustellen. Weite Teile des nationalliberalen und konservativen Bürgertums standen in Deutschland der parlamentarischen Republik ablehnend oder gar feindlich gegenüber, was die $\mathrm{Hal}$ tung von DNVP und auch DVP maßgeblich prägte. Zwar sind im Hinblick auf die USPD, die DVP und ansatzweise auch die DNVP gewisse integrative Erfolge festzustellen, diese wurden jedoch bereits in der Endphase der Inflationszeit durch das Erstarken der KPD und der völkisch-nationalsozialistischen Bewegung wieder aufgezehrt. Ganz anders war die Lage in Frankreich: Abgesehen von zunächst noch isolierten Positionen innerhalb der Fédération républicaine kann das gesamte bürgerliche Parteienspektrum in den zwanziger Jahren als systemloyal bezeichnet werden, und auch die SFIC steuerte längst keinen so eindeutig systemfeindlichen Kurs wie die deutsche KPD ${ }^{132}$.

Die eben skizzierten Konstellationen wurden in der Inflationszeit zu maßgeblichen Faktoren für die Ausbildung parlamentarischer Regierungsbündnisse: Während in Frankreich jederzeit ein systemloyales bzw. systembejahendes bürgerliches Regierungsbündnis eine Mehrheit in der Abgeordnetenkammer finden konnte, war in Deutschland seit 1920 eine bürgerliche Mehrheitsbildung auf die verfassungspolitisch zumindest ambivalente DNVP angewiesen. Eine klar systembejahende Reichstagsmehrheit konnte nur durch die Kooperation der bürgerlichen Mitte mit der SPD zustande kommen. Derartige Bündnisse waren freilich mit einem erheblichen und - wie zu zeigen sein wird - in der Inflationskrise stark wachsenden sozioökonomischen Konfliktpotential belastet. Dies gilt insbesondere für das Koalitionsmodell der Großen Koalition unter Einschluß der DVP.

Wie eben schon anklang, waren die Voraussetzungen für ein Regierungsbündnis mit den Sozialisten in beiden Parlamenten sehr unterschiedlich. In der französischen Abgeordnetenkammer gab es innerhalb des bürgerlichen Fraktionsspektrums eine klare Links-rechts-Dichotomie. Mit dem wählerstarken Parti radical und den kleineren Républicains-socialistes standen so potentielle Bündnispartner für die Sozialisten bereit. Im Reichstag war der linksbürgerliche Flügel in Form der DDP von Anfang an weitaus schwächer als im Nachbarland, bereits 1920 setzte zudem ein dramatischer Schrumpfungsprozeß ein. Ein linksbürgerlichsozialdemokratisches Bündnis kam daher im Reichstag nicht ernsthaft in Frage. Die stabilste und meist auch die stärkste Kraft unter den bürgerlichen Fraktionen

131 Vgl. hierzu Larmour, French Radical Party, S. 42; Bardonnet, Evolution, S. 125 f.

132 Zur stärkeren Integration der Kommunisten in die politische Kultur Frankreichs mit vergleichender Perspektive Wirsching, Vom Weltkrieg zum Bürgerkrieg?, S. 333-348. 
war das durch eine große Links-rechts-Spannweite gekennzeichnete Zentrum. Die Partei des politischen Katholizismus wurde damit zum wichtigsten Koalitionspartner in den Weimarer Regierungen ${ }^{133}$, sie tat sich aber auf Reichsebene schon bald sehr schwer mit einem einseitig nach links gerichteten Bündnis der „Weimarer Koalition“ zwischen SPD, DDP und Zentrum. Die bloße Existenz der Zentrumspartei förderte ein enges Zusammenrücken der „Mittelparteien“ DDP, Zentrum und DVP und wurde zum Argument für eine auch die DVP einschließende Große Koalition. Diese Blockbildung der bürgerlichen Mitte schränkte die koalitionspolitische Flexibilität des Reichstags empfindlich ein.

Über die inneren Verhältnisse der Fraktionen und über die Gestaltung der Fraktionsarbeit ist für die Weimarer Republik relativ viel ${ }^{134}$, für die späte Dritte Republik hingegen nur sehr wenig bekannt. Die Fraktionen des Reichstags besaBen in der Regel einen Vorstand, dem die Vorsitzenden bzw. ihre Stellvertreter und teilweise noch eine bestimmte Zahl von Beisitzern angehörten, sowie ein Sekretariat, das von einem Geschäftsführer geleitet wurde. Sitzungen des Vorstands und der Gesamtfraktion fanden regelmäßig statt und wurden meist auch protokolliert ${ }^{135}$. In den größeren Fraktionen gab es neben einzelnen Fachleuten themenspezifische interne Kommissionen ${ }^{136}$. Die politische Bedeutung des Fraktionsvorstands und speziell des -vorsitzenden war erheblich ${ }^{137}$. So bildeten die Fraktionsvorsitzenden die entscheidenden Ansprechpartner des Reichspräsidenten im Vorfeld von Regierungsbildungen und die wichtigsten Vertreter bei den "Parteiführerbesprechungen“" $\mathrm{zwischen}$ Koalitionspartnern.

Auf französischer Seite lassen sich nur für die SFIO genauere Angaben über Fraktionsstrukturen machen. Wesentliche Funktionen nahmen hier der Secrétaire, der Secrétaire adjoint und der Secrétaire administratif sowie der Schatzmeister und das mehrköpfige Exekutivkomitee wahr, zahlreiche Sous-Commissions waren für die inhaltliche Arbeit zuständig138. Was die übrigen Kammerfraktionen anbelangt, so ist angesichts einer desolaten Quellen- und Forschungslage wenig be-

${ }^{133}$ Diese Qualität wird in der Literatur meist nachdrücklich betont. Vgl. v.a. Morsey, Zentrumspartei, passim, sowie mit vergleichender Perspektive Newman, Zerstörung, S. 289-292. Die koalitionspolitische Schwerfälligkeit bleibt freilich weitgehend ausgeblendet. Erinnert sei in diesem Zusammenhang nochmals an Zwehl, Zum Verhältnis von Regierung und Reichstag, S. 104-107, der für das Kaiserreich im Zentrum ein Hindernis der Links-rechts-Polarisierung sah.

134 Vgl. zusammenfassend Mergel, Parlamentarische Kultur, S. 201-210, auch zur Ausnahme der autoritären KPD. Das ebd., S. 203, geäußerte Urteil, daß „die parlamentarische Arbeit der Fraktionen erstaunlich wenig professionalisiert" gewesen sei, ist zweifellos zutreffend im Vergleich mit der bundesdeutschen Gegenwart; im Vergleich mit der Dritten Französischen Republik ergibt sich allerdings eher das Bild einer bereits weit entwickelten Organisationsstruktur. Vgl. weiterhin Huber, Verfassungsgeschichte 6, S. $358 \mathrm{f}$. sowie die angegebene parteiengeschichtliche Literatur. Darüber hinausgehende Informationen zur SPD-Fraktion finden sich in Adolph, Otto Wels, S. 105-118; Schulze, Stabilität und Instabilität in der politischen Ordnung von Weimar; Die SPDFraktion in der Nationalversammlung, S. XXII-XXXI. Zum Zentrum vgl. Protokolle Zentrumspartei, S. XXVI-XXX.

135 Die Überlieferung ist allerdings überwiegend verlorengegangen; vgl. hierzu oben S. 26. Zur Praxis der offiziellen Protokollierung in der Zentrumsfraktion vgl. Protokolle Zentrumspartei, S. XXIIf.

136 Detailliert hierzu für das Zentrum ebd., S. XXIX.

137 In diesem Sinn mit instruktiver Differenzierung ebd., S. XXVIII.

138 Vgl. z. B. den Bericht „Vie intérieure“ für den SFIO-Parteitag 1925, in: 22 ème Congrès national du Parti socialiste, S. 111-114. Ebd., S. 112 f., auch Abdruck der am 13.11. 1924 beschlossenen internen Geschäftsordnung der Fraktion. Allgemein zur Organisationsstruktur auch Judt, Reconstruction, S. 55-70. 
kannt ${ }^{139}$. Bei Beobachtung der parlamentarischen Prozesse werden eigentlich nur die présidents bzw. secrétaires erkennbar. Deren Stellenwert lag aber schon infolge der geringeren politischen Kohärenz der meisten Fraktionen deutlich unter dem ihrer deutschen Kollegen. In den Plenardebatten traten sie bei weitem nicht so in Erscheinung, und in den Verhandlungen bei Regierungsbildungen oder im Vorfeld eines Regierungssturzes spielte unabhängig von einer Fraktionsfunktion auch das individuelle politische Gewicht einzelner Parlamentarier eine bedeutende Rolle.

Zweifellos herrschte in den französischen Fraktionen generell ein weniger formalisierter Politikstil als in Deutschland. Fraktionssitzungen werden in der Presse gelegentlich erwähnt; inwieweit diese aber regelmäßig stattgefunden haben, bleibt unklar. Vom Parti radical ist bekannt, daß oft nur eine bescheidene Minderheit der Fraktionsangehörigen an den Sitzungen teilgenommen hat ${ }^{140}$. Wie bereits erwähnt, gibt es von einzelnen Ausnahmen bei den Sozialisten abgesehen keine Überlieferungen von Sitzungsprotokollen. Ob überhaupt regelmäßig Protokoll geführt worden ist, erscheint für die meisten Fraktionen eher zweifelhaft ${ }^{141}$.

Zusammenhalt und innere Disziplin der deutschen Fraktionen lagen insgesamt erheblich höher als auf französischer Seite. Diese allgemeine Aussage, die auch den Befunden zu den Fraktionsstrukturen entspricht, faßt eine im einzelnen vielgestaltige Realität zusammen. Das relativ disziplinierte Stimmverhalten im Reichstag darf nicht darüber hinwegtäuschen, daß immer wieder erhebliche fraktionsinterne Meinungsunterschiede aufkamen, die nur nach mühsamen Sitzungen in ein gemeinsames Abstimmungsverhalten gepreßt werden konnten. Gerade bei SPD und DVP, den „Flügelparteien" der 1923 gebildeten Großen Koalition, wird dies im Zweiten Teil dieser Arbeit zu sehen sein. Bei wichtigen namentlichen Abstimmungen zeigte sich aber meist eine weitgehende Geschlossenheit ${ }^{142}$. Keine einzige Weimarer Regierung - dieser Vergleich bietet sich im Hinblick auf die Verhältnisse in der Dritten Republik an - ist im Reichstag gestürzt worden, weil es in einer Fraktion zu einem unvorhergesehenen Abstimmungsverhalten gekommen wäre. Dennoch entzogen sich auch im Reichstag nicht selten einzelne Abgeordnete der Fraktionslinie. In der Regel wurde dies auch sanktionslos geduldet, zumal die Dissidenten ihre Abweichung häufig nur durch ein unspektakuläres Fernbleiben von der Abstimmung zum Ausdruck brachten. Wenn hin und wieder bei bedeutsamen Voten doch größere Dissidentengruppen innerhalb einer Fraktion

139 Zum Parti radical vgl. Larmour, French Radical Party, S. 41-45.

$140 \mathrm{Vgl}$. die - offenbar auf Presseberichte gestützten - Berechnungen ebd., S. 44. Demnach nahmen in den dreißiger Jahren im Durchschnitt nur 30-40 Abgeordnete - bei einer Gesamtzahl zwischen 110 und 160 - an den Fraktionssitzungen teil.

141 Hudemann, Fraktionsbildung, S. 28, und Larmour, French Radical Party, S. 41, schließen von kurzen protokollähnlichen Presseberichten auf die Anfertigung von Fraktionsprotokollen, die dann verlorengegangen seien. Angesichts der meist nur sehr kurzen und nur sporadisch erscheinenden Pressetexte erscheint diese These jedoch fragwürdig. In der Geschäftsordnung der SFIO-Fraktion aus dem Jahr 1924 (s. Anm. 138) ist zwar die fraktionsinterne „déliberation“ genau geregelt, von einer Protokollierung aber keine Rede.

$142 \mathrm{Vgl}$. auch Mergel, Parlamentarische Kultur, S. 205f. Mergel geht von zunehmender „Abstimmungshomogenität" aus. Allgemein zur Frage der Fraktionskohärenz und Fraktionsdisziplin im Reichstag vgl. auch Markmann, Das Abstimmungsverhalten der Parteifraktionen, S. 17-90. 
auftraten, dann waren es „Signale tiefer Zerwürfnisse“ ${ }^{143}$, die gerade in der Inflationszeit wiederholt zu beobachten waren. Insgesamt führten derartige Divergenzen aber eher zu politischen Lähmungserscheinungen als zum offenen Bruch mit der Fraktion. Hin und wieder kam es zwar auch im Reichstag zur Neubildung parlamentarischer Gruppen. Im Vergleich zum fluktuierenden Zustand der meisten französischen Fraktionen blieben diese Erscheinungen allerdings unerheblich.

Eine Bewertung der Fraktionsdisziplin in der späten Dritten Republik hängt vom zugrunde gelegten Maßstab ab. Geht man von einer nur extrem schwach entwickelten Bindungskraft der Fraktionen im französischen Parlamentarismus des 19. Jahrhunderts aus, dann erscheint die Abstimmungsdisziplin schon als relativ hoch ${ }^{144}$. Orientiert man sich freilich am Maßstab des modernen parteienstaatlichen Parlamentarismus, oder legt man auch nur die Verhältnisse im Weimarer Reichstag zum Vergleich an, dann muß für die späte Dritte Republik von einer immer noch schwach entwickelten Fraktionsdisziplin gesprochen werden. Damit korrespondierte eine parlamentarische Willensbildung und Entscheidungsfindung, die oft stärker von individuellen Beziehungen und von kleinen informellen Grüppchen um markante Persönlichkeiten bestimmt war. Vielfach konnte in wichtigen Abstimmungen nur dank der allgegenwärtigen Vertrauensfrage, dem einzig wirksamen Disziplinierungsmittel der Regierungen, eine gewisse Kohärenz des Regierungslagers geschaffen werden.

Allerdings gab es hier zwischen den verschiedenen Kammerfraktionen deutliche Unterschiede: Diszipliniert agierten die Sozialisten, wo die „unité du vote“ als Leitbild galt und auf den Parteitagen entsprechend Rechenschaft abgelegt werden mußte ${ }^{145}$. Im bürgerlichen Spektrum besaßen die weitgehend geschlossen auftretende Fraktion der konservativen Entente bzw. Union républicaine démocratique ${ }^{146}$ sowie - ab 1924 - die christdemokratische Gruppe der Démocrates (populaires) ${ }^{147}$ das höchste Maß an Abstimmungsdisziplin. Deutlich schwächer war diese innerhalb des französischen Liberalismus. Selbst in wichtigen, über die Zukunft eines Kabinetts entscheidenden Voten war das Stimmverhalten hier manchmal ein schwer kalkulierbarer Faktor, der jede feste Koalitionsbindung unmöglich machte. Die große Fraktion des Parti radical fiel immer wieder durch eine ausgeprägte interne Lagerbildung auf, in der sich erhebliche Differenzen über den Kurs der Partei manifestierten ${ }^{148}$. Noch unübersichtlicher waren die Verhält-

${ }^{143}$ Mergel, Parlamentarische Kultur, S. 206. Allgemein zu Divergenzen in den Fraktionen mit weiterführenden Literaturangaben ebd., S. 205-207.

${ }^{144}$ So v.a. die Bewertungen in Roussellier, Parlement, passim. Vgl. auch die Tabellen zur Abstimmungsdisziplin im Zweiten Teil, B.

145 Vgl. z. B. Materialien zum sozialistischen Parteitag Anfang Februar 1925, in: 20ème Congrès national du Parti socialiste S.F.I.O, S. 70 f., mit genauer Auflistung. Alle „divergences de vote“ werden hier namentlich genannt. Zum disziplinarischen Druck des SFIO auf die sozialistische Fraktion vgl. auch Judt, Reconstruction, S. 61 f. - Etwas anders war die Situation bei der SFIC. Die teilweise mangelnde Präsenz bei Abstimmungen resultierte aus dem Primat der Propagandaarbeit.

${ }^{146}$ Für die Phase 1920-24 wird dies durch die detaillierten Untersuchungen in Roussellier, Parlement, S. 127-130, S. 170-177 und S. 268-272, untermauert. Zu erheblichen internen Divergenzen in der Partei vgl. aber Bernard, La dérive des modérés, S. 257-259.

147 Vgl. zu beiden Fraktionen auch die Tabellen im Zweiten Teil, B.

148 Hierzu für die Jahre 1920-24 detailliert Roussellier, Parlement, S. 119-121, 166-169, 259-262; zur späteren Zeit: Berstein, Histoire 2, S. 86-89. Vgl. auch die pointierte - freilich etwas übertriebene - 
nisse in den wechselnden Gruppierungen der rechten Mitte. Wie Roussellier für die erste Legislaturperiode 1920-24 nachgewiesen hat, läßt sich hier im Stimmverhalten eher eine diffuse Zersplitterung als eine konkrete Lagerbildung erkennen ${ }^{149}$. Für politische Überraschungen war dieser „éternel marais“ der Mitte immer gut ${ }^{150}$. Die kammerinternen Unterschiede im Grad der Disziplinierung wurden 1923 von Ministerpräsident Poincaré in einer parlamentarischen Antwort auf den Sozialisten Léon Blum mit einem treffenden Wortspiel gekennzeichnet: „Je suis plus sûr de votre hostilité que de la fidélité de mes amis eux-mêmes." 151

Von den interfraktionellen Kooperationsformen der deutschen Parteiführerbesprechungen und der französischen Délégation des Gauches war bereits im vorhergehenden Kapitel die Rede. Beschränkten sich diese Instanzen weitgehend auf eine Ad-hoc-Kooperation von Regierungsfraktionen, so ist die Mitte 1922 ins Leben gerufene „Bürgerliche Arbeitsgemeinschaft“ zwischen DDP, Zentrum und DVP als weitergehender Versuch eines informellen Fraktionsverbundes zu werten, der zeitweise eine erhebliche innenpolitische Relevanz erlangte. Einzelne Politiker sahen die Arbeitsgemeinschaft auch als Ausgangsbasis für die Bildung einer großen bürgerlichen Partei der Mitte. In der Realität blieb dieser Gedanke jedoch chancenlos. So beschränkte sich die Funktion der Bürgerlichen Arbeitsgemeinschaft, die 1924 rasch an Bedeutung verlor, letztlich auf ein zeitweiliges Austarieren der durch die Fusion von 1922 erstarkten Sozialdemokratie ${ }^{152}$.

Insgesamt besaß die Weimarer Republik von der organisatorischen Entwicklung des Partei- und Fraktionswesens her bereits die Strukturen eines parteiengestützten parlamentarischen Systems. Die junge deutsche Demokratie war daher gleichsam zur Modernität verdammt und konnte nicht einfach die individualisierenden Verfahrensweisen des französischen Parlamentarismus übernehmen. Der in Frankreich bestehende relative Rückstand in der Ausbildung eines modernen Parteiwesens zeigte sich besonders innerhalb der liberalen und konservativen Kräfte, die weiterhin nur lose organisiert waren und von einer strukturellen Analogie zwischen Parteien und Fraktionen weit entfernt blieben. Allerdings darf hier kein pauschales Bild gezeichnet werden. Parteien relativ modernen und solche traditionellen Charakters bestanden in der späten Dritten Republik nebeneinander, was für die Funktionsfähigkeit des parlamentarischen Systems eine besondere Herausforderung bedeutete. Das später zu analysierende Schwanken zwischen modernen und traditionellen parlamentarischen Funktionsweisen läßt sich auch als Folge dieser strukturellen Divergenzen innerhalb des französischen Parteiensystems deuten.

Neben den Unterschieden in der organisatorischen Entwicklung des Parteiwesens sei resümierend auch die deutsch-französische Differenz in der Haltung zum politischen System hervorgehoben: Mehrere wichtige Reichstagsparteien

Aussage in Bardonnet, Evolution, S. 160: „La liberté du vote est demeurée en effet la première règle disciplinaire du Parti à l'intérieur du groupe parlementaire. “

149 Roussellier, Parlement, S. 121-127, 169f., 262-268.

150 Vgl. allgemein zum Phänomen: Duverger, L'éternel marais, S. 33-51. Zu den andauernden Disziplinproblemen im Umfeld der Alliance démocratique vgl. auch Grüner, Zwischen Einheitssehnsucht und Massendemokratie, S. 240.

151 JO, Débats, Chambre 1923, S. 3955.

152 Ausführlich zur Entstehung der Arbeitsgemeinschaft vgl. unten S. 129-135. 
lehnten die parlamentarische Republik im Grunde ab oder bekämpften sie sogar offen, während in der Abgeordnetenkammer lediglich die kommunistische Fraktion eine generelle Systemopposition vertrat, und auch dies weniger scharf als die deutsche KPD. Daß die Werte der parlamentarischen Republik in Frankreich über die Jahrzehnte hinweg fast das gesamte politische Spektrum erobert hatten, bildete nicht nur die Voraussetzung für eine stets mögliche systemadäquate Regierungsbildung, sondern auch für die ständige Präsenz einer loyalen Opposition ${ }^{153}$.

\section{Beziehungen zu politischer Öffentlichkeit und Interessengruppen}

Reichstag und Abgeordnetenkammer standen in vielfachen Wechselbeziehungen zur politischen Öffentlichkeit sowie zu gesellschaftlichen und ökonomischen Interessengruppen, die öffentliches Aufsehen teilweise eher mieden oder im Verborgenen agierten. Eine detaillierte Analyse dieser strukturellen Kontexte würde den Rahmen unserer Arbeit sprengen und bald auch - insbesondere im Hinblick auf Frankreich - an die Grenzen des Forschungsstandes stoßen ${ }^{154}$. Der folgende Überblick beschränkt sich daher auf einige grundsätzliche Überlegungen.

$\mathrm{Daß}$ die Tätigkeit der Parlamente in einem parlamentarischen System im Blickfeld der Öffentlichkeit und sozioökonomischer Interessengruppen steht, liegt auf der Hand und soll hier nur kurz thematisiert werden. Diese Wirkung geht über die von Bagehot im 19. Jahrhundert idealtypisch formulierten Aufgaben der „teaching function“ (Belehrung des Volkes) und „informing function“ (Information der Öffentlichkeit) ${ }^{155}$ weit hinaus, sie reicht von einem bloßen Unterhaltungseffekt über zustimmende und ablehnende Reaktionen auf die parlamentarische Tätigkeit im allgemeinen und bestimmte parlamentarische Prozesse im besonderen bis zur Aktivierung von Versuchen, Einfluß auf die Parlamente zu gewinnen.

Grundsätzlich ist der hohe Stellenwert zu betonen, den Reichstag und Abgeordnetenkammer während der 1920er Jahre in dem immer noch zentralen politischen Medium der Presse einnahmen ${ }^{156}$. Vor allem die Tageszeitungen berichteten ausführlich über wichtige Parlamentssitzungen sowie über Bildung, Krisen und Rücktritte von Regierungen. Wie bereits einleitend erwähnt, waren führende Blätter wie etwa die Frankfurter Zeitung oder Le Temps meist hervorragend über die Vorgänge und Wirrungen des parlamentarischen Betriebes informiert. Parla-

$153 \mathrm{Vgl}$. auch die Überblickstabelle 5.2 im Anhang.

${ }^{154} \mathrm{Zu}$ Deutschland vgl. grundsätzlich auch den Überblick in Mergel, Parlamentarische Kultur, S. 340-398, der allerdings teilweise andere Fragestellungen behandelt.

155 Vgl. oben S. 20, Anm. 92.

156 Zur Presselandschaft: Koszyk, Geschichte der deutschen Presse 3; Bellanger (Hrsg.), Histoire générale de la presse française 3; Manéry, Histoire de la presse de 1914 à 1939. Allgemeine Hinweise auch in Asmuss, Republik ohne Chance?; Becker, Demokratie des sozialen Rechts. Eine umfangreiche Datensammlung (u.a. zu Auflagen und politischen Tendenzen) bietet die von der Kommission für historische Pressedokumentation an der Österreichischen Akademie der Wissenschaften erstellte Zeitungsdatenbank "Strukturdaten der Berliner Tagespresse der Weimarer Republik“. Online: http://www.oeaw.ac.at/pdok/hypress.html (März 2004). Zum Stellenwert von Journalisten im parlamentarischen Betrieb der Weimarer Republik vgl. Mergel, Parlamentarische Kultur, S. 343-346. Der Rundfunk kann als politisches Medium für die Zeit der Inflationskrisen noch vernachlässigt werden. 
mentsreden wurden auf den vorderen Seiten der Tageszeitungen nicht selten ausführlich zitiert, vereinzelt sogar noch - wie im 19. Jahrhundert - in weiten Passagen abgedruckt. Die Instabilität der parlamentarischen Systeme fand so einen geradezu fiebrigen Ausdruck in der Presse, was phasenweise das öffentliche Krisenbewußtsein erheblich gesteigert haben dürfte.

Die Wirksamkeit der Parlamente auf die Öffentlichkeit spiegelt sich auf komplexe Weise auch in den Wahlergebnissen. Zufriedenheit oder Unzufriedenheit über die Tätigkeit der Regierungen gehen hier ebenso ein wie Einschätzungen von und Hoffnungen auf parlamentarische oder auch außerparlamentarische Alternativen. Es wurde bereits darauf hingewiesen, daß gerade in einer Zeit, die von der Existenz bedeutsamer systemfeindlicher Kräfte geprägt war, die Bedeutung der parlamentarischen Alternativfunktion als sehr hoch zu veranschlagen ist.

Die Haltung der Öffentlichkeit gegenüber den Parlamenten wurde einerseits von den parlamentarischen Vorgängen beeinflußt und andererseits von den vorab in Öffentlichkeit und Gesellschaft bestehenden Vorstellungen und Interessen. Sicher ist es generell plausibel, für die Weimarer Republik von einer „Erwartungsüberlastung " der Öffentlichkeit auszugehen ${ }^{157}$, wenngleich dieser Druck nicht zu statisch gesehen werden sollte. Überzogene Erwartungen an das parlamentarische System im allgemeinen und an bestimmte politische Kräfte im besonderen haben innerhalb der Öffentlichkeit vielfache Enttäuschungen hervorgebracht und im parlamentarischen Raum ein Problem für politische Kompromisse dargestellt. Die mangelnde Erfahrung der deutschen Gesellschaft mit einem parlamentarischen Regierungssystem spielte hierbei eine Rolle, aber auch die scharf ausgeprägten Interessengegensätze, die sich in der fortgeschrittenen sozioökonomischen Modernität Deutschlands entwickelt hatten. Auch das in Öffentlichkeit und Staatsrecht immer noch vorherrschende Parlamentarismusverständnis war von Bedeutung: Man sah im Reichstag vor allem eine möglichst genaue Repräsentation der deutschen Gesellschaft ${ }^{158}$ und weniger ein Organ langwieriger Meinungs- und Entscheidungsbildung. Das selbst- und machtbewußte Agieren relativ moderner Parteien wurde vor dem Hintergrund der kaiserzeitlichen Verhältnisse, aber auch angesichts des problematischen Vorbildes, das der traditionell geprägte französische Parlamentarismus für Deutschland bildete, eher als parteiegoistische Verirrung, denn als logische Konsequenz eines parlamentarischen Systems bewertet. Vorstellungen und Erwartungen wichen unter diesen Umständen selbst dann von den parlamentarischen Realitäten ab, wenn diese leidlich „normal“ funktionierten. Die offenkundigen Funktionsstörungen des Reichstags gaben dann der öffentlichen Parlamentarismuskritik erst recht Nährstoff. Ebenso wichtig aber war, daß sich die Diskrepanzen zwischen Idee und Realität vielfach auch in den Köpfen der Reichstagsabgeordneten wiederfanden und somit das parlamentarische Handeln unmittelbar beeinflußten. Auf diesen Aspekt wird weiter unten (Erster Teil, Kap. II. 6) gesondert einzugehen sein.

In der politischen Öffentlichkeit Frankreichs herrschte insgesamt ein erheblich pragmatischeres Verständnis des parlamentarischen Systems, zumal sich dieses

157 Ebd., S. 410.

158 Vgl. ebd., S. 362-367. 
seit Jahrzehnten und zuletzt auch während des Ersten Weltkriegs bewährt hatte. An Mißstände, Skandale und endlose Regierungskrisen war man seit langem gewöhnt - und doch hatte sich die parlamentarische Republik festigen können. Zwar stieß das allmählich auch in Frankreich entstehende Parteiwesen auf heftige Kritik, eine grundsätzliche Infragestellung des - traditionell ohne Parteien auskommenden - französischen Parlamentarismus konnte sich daraus freilich nicht entwickeln. Allerdings darf das Bild nicht zu harmonisch gezeichnet werden. Angesichts der großen ökonomischen, sozialen und außenpolitischen Herausforderungen wuchsen auch in Frankreich die politischen Erwartungen, während sich vielfach entweder Unbehagen an den traditionellen parlamentarischen Mechanismen oder aber Kritik an den parteipolitischen Neuerungen breitmachte. Auch in Frankreich legte sich dadurch ein diffuser öffentlicher Druck auf das parlamentarische System.

Auf die Frage nach der konkreten Wirksamkeit von Öffentlichkeit und Interessengruppen auf die Parlamente kann weder für die Weimarer Republik noch für die späte Dritte Republik eine einfache Antwort gegeben werden. $\mathrm{Zu}$ vielfältig und oft auch undurchsichtig waren die Kontakte, zu schwer fallen generalisierende Aussagen über die Kraft der bis in die parlamentarische Sphäre vordringenden Einflüsse. Im folgenden sollen einige Felder im Beziehungsgeflecht von Parlament, Öffentlichkeit und Interessengruppen skizziert werden, wobei insbesondere auch die deutsch-französischen Unterschiede zu markieren sind.

Die Differenzen in der Parteienentwicklung hatten auch weitreichende Konsequenzen für die jeweiligen Beziehungen von Parlament und Öffentlichkeit. So gab es in der gesellschaftlichen Bindung des Parteiensystems markante Abweichungen zwischen Deutschland und Frankreich. Bekanntlich waren die Weimarer Parteien noch stark in spezifischen soziokulturellen Milieus verankert (vor allem sozialdemokratische bzw. kommunistische Arbeiterschaft, politischer Katholizismus und ländlich-protestantisches Milieu ${ }^{159}$ ); die Parteien waren daher nicht selten mit einem spezifizierten Erwartungsdruck fragmentierter Teilöffentlichkeiten konfrontiert. Tendenziell trifft dies zweifellos auch für die französischen Sozialisten und Kommunisten zu, wenngleich die soziale Zusammensetzung hier weniger homogen war als bei SPD und KPD und starke agrarische und kleinbürgerliche Anteile aufwies ${ }^{160}$. Auch der Parti radical wurzelte in vielen Regionen in einem charakteristischen, überwiegend klein- und bildungsbürgerlichen Milieu. Allerdings konnte ein ähnliches Milieu in anderen Regionen eine ganz andere politische Orientierung aufweisen. Ausschlaggebend für die Wahlentscheidung waren nicht selten lang zurückreichende kulturelle Traditionen, die viel mit dem regionalen Stellenwert der katholischen Kirche zu tun hatten. So lassen sich die Unterschiede in der Provinz zwischen einer traditionell konservativen "France blanche“ und einer radikalen, in den zwanziger und dreißiger Jahren zunehmend auch soziali-

159 Den Forschungsstand zusammenfassend: Wirsching, Weimarer Republik, S. 89-95. Zur DVP und DNVP vgl. Pyta, Dorfgemeinschaft und Parteipolitik, v.a. S. 285-311; Kittel, Provinz, v.a. S. 525-539.

160 Hierzu und allgemein zur inkohärenten Sozialstruktur der Parteien ebd., S. 117; Micaud, French Political Parties, S. $112 \mathrm{f}$. Vergleichend zur Sozialstruktur von SPD und SFIO Winkler, Klassenkampf versus Koalition, S. $186 \mathrm{f}$. 
stischen und kommunistischen "France rouge" nur unzureichend mit soziologischen Faktoren erklären ${ }^{161}$.

Die französischen Abgeordneten waren stärker in der lokalen und regionalen Öffentlichkeit ihrer Wahlkreise verankert als die deutschen Parlamentarier. Dies hing, wie bereits erwähnt, mit dem Wahlrecht zusammen, aber auch mit einem traditionellen Parlamentarismusverständnis, wonach der Abgeordnete vor allem Repräsentant, Ansprechpartner und Interessenvertreter seiner heimischen Wähler war. Zweifellos trug dies zu einer gewissen „Provinzialisierung“ der nationalen Politik bei.

Nicht nur das Parteien-, sondern auch das sozioökonomische und politische Verbandswesen war in Deutschland stärker entwickelt als in Frankreich. Der Reichstag bildete das Ziel einer extrem vielfältigen Lobbyarbeit seitens der „unsichtbaren Mächte" moderner Interessengruppen ${ }^{162}$. Unter den großen deutschen Verbänden spielte in der Inflationszeit der Reichsverband der Deutschen Industrie (RDI) eine wichtige Rolle, wobei innerhalb des Verbandes vor allem schwerindustrielle Interessen zur Geltung kamen ${ }^{163}$. Freilich richtete sich die Einflußnahme dabei mindestens ebenso auf die Ebene der Regierung und der Ministerialapparate wie auf jene des Reichstags bzw. der nahestehenden Reichstagsparteien. Die Entparlamentarisierung der Gesetzgebung in der Inflationskrise leistete dieser an das Kaiserreich anknüpfenden Praxis noch Vorschub ${ }^{164}$.

In Frankreich übten sich zahlreiche mittelständische Verbände in der „défense“ konkreter wirtschaftlicher Interessen ${ }^{165}$. So weit sich dies nach dem bisherigen Forschungsstand überhaupt sagen läßt, hatten die großen Verbände, wie die Union des intérêts économiques oder das schwerindustrielle Comité des forges ein vergleichsweise geringes parlamentarisches Gewicht ${ }^{166}$. Wichtiger war wohl die personelle Präsenz führender Persönlichkeiten aus der Wirtschaft innerhalb der Alliance démocratique und der Fédération républicaine ${ }^{167}$. Eine herausgehobene

161 Zeldin, History 1, S. 373-379; Kittel, Provinz, S. 118-120; ders., Die „deux France“ und der deutsche Bikonfessionalismus.

162 Zur Vielfalt anschaulich Lambach, Herrschaft der Fünfhundert, S. 75-87; Zitat ebd., S. 77; vgl. auch ebd., S. 78: „Die Syndici aller industriellen Gruppen gehören zu den ständigen Benutzern des roten Teppichs in der Wandelhalle des Reichstags."

163 Überblick zur Rolle des RDI in der Zeit des Ruhrkampfes und der Währungsstabilisierung in Wolff-Rohé, Reichsverband, S. 321-355. Weisbrod, Schwerindustrie, behandelt Verbandsstrukturen und Einflußmöglichkeiten nach der Währungsstabilisierung.

164 In diesem Sinne besonders Maier, Recasting Bourgeois Europe, S. 355-420.

165 Vgl. hierzu am Beispiel der Parlamentarier im Departement Seine: Le Béguec, Le poids de la boutique et du négoce.

166 Allgemein zum Forschungsstand, zur relativ zögernden Entwicklung von Interessengruppen in der Dritten Republik, aber auch zum geringen Interesse der Forschung vgl. Le Béguec, Groupes de pression et politique. Speziell zu der vom Senator Ernest Billiet geleiteten Union des intérêts économiques, die in den Jahren 1919-24 eine recht lebhafte politische Rolle spielte und insbesondere auch gegen ein Bündnis von Radicaux und Sozialisten agitierte, ebd., S. 458-460. Zum Comité des forges v.a. Jeanneney, De Wendel. S. hierzu auch Anm. 175. Gegen den bereits zeitgenössischen Mythos eines allmächtigen Comité des forges wendet sich Moine, Le comité des forges pendant l'entre-deux-guerres; vgl. auch Fraboulet, Le Patronat de la métallurgie et l'Etat, zur Union des Industries et Métiers de la Métallurgie (UIMM). Beide Autoren betonen, daß der vor allem auf die Kommissionen gerichtete parlamentarische Einfluß - neben der Einwirkung auf die Ministerien nicht überschätzt werden darf.

167 Vgl. Garrigues, Les patrons et la politique, S. 146-149. Aber auch Garrigues stellt ebd., S. 149, fest: „Ce n'est pas dans les chambres que se joue l'essentiel de l'influence.“ 
Bedeutung im politischen Leben nahmen die Kriegerverbände der „anciens combattants" ein, die für ihre spezifische Interessenvertretung auch intensiv parlamentarische Kontakte pflegten und darüber hinaus einen nicht unwesentlichen Anteil an der allgemeinen politischen Meinungsbildung besaßen ${ }^{168}$. In eher traditioneller Manier gab es in der Abgeordnetenkammer auch interessengeleitete $\mathrm{Zu}$ sammenschlüsse von Abgeordneten quer zu den politischen Fraktionen ${ }^{169}$.

Analog zur Milieubindung zeigt sich auch eine besondere Nähe der deutschen Parteien zu bestimmten Wirtschaftszweigen, Verbänden und Gewerkschaften ${ }^{170}$. Erinnert sei hier nur an die engen Beziehungen der DVP zum RDI, der DNVP zum Reichs-Landbund, der SPD zum Allgemeinen Deutschen Gewerkschaftsbund (ADGB) und der Zentrumspartei zu den Christlichen Gewerkschaften ${ }^{171}$. Parlamentarisch relevant wurden diese Beziehungen nicht zuletzt durch die Mitgliedschaft von aktiven Interessenvertretern im Reichstag 172. Die kleine schwerindustrielle Gruppe um Hugo Stinnes innerhalb der DVP-Fraktion bildet hierfür wie im Zweiten Teil immer wieder zu sehen sein wird - während der Inflationskrise zweifellos das wichtigste Beispiel173. Die interessenpolitischen Einflüsse stellten insgesamt einen komplizierenden und die Spielräume meist verengenden Faktor der Koalitionspolitik dar.

In Frankreich spielten Verbindungen zwischen Parteien und Verbänden - in insgesamt deutlich schwächerem Maße als in Deutschland - auf der politischen Linken eine Rolle, wo das Parteiensystem halbwegs feste Strukturen besaß. Sozialisten und Kommunisten standen in enger Beziehung zu den seit 1921 gespaltenen Gewerkschaftsdachverbänden der Confédération Générale du Travail (CGT) und der Confédération Générale du Travail Unitaire (CGTU). Der Parti radical wurzelte in einem gesellschaftlichen Terrain, in dem auch Freimaurerlogen und linksliberale Verbände wie die Ligue des droits de l'homme beheimatet waren ${ }^{174}$. Industrielle Kreise standen vor allem der Fédération républicaine nahe. Mit François de Wendel, dem lothringischen Stahlindustriellen, Vorsitzenden des Comité des Forges und einem der „régents“ der Banque de France, gehörte von 1919 bis 1932 eine führende Persönlichkeit der französischen Wirtschaft als Mitglied der konservativen Fraktion der Entente (Union) républicaine démocratique der Abgeord-

168 Dank Prost, Les anciens combattants, 3 Bde., ist die Forschungslage in diesem Punkt ausgezeichnet. Vgl. v.a. ebd., Bd. 1, S. 98-102, zum öffentlichen Kampf gegen das Cartel des Gauches.

$169 \mathrm{Vgl}$. Guiral/Thuillier, La vie quotidienne des députés, S. 253-255. Beispiel für die Tätigkeit in: Compte Rendu des Travaux du Groupe de Défense Paysanne et du Groupe Viticole.

170 Überblick zum relativ modernen Verbandswesen der Weimarer Zeit in Ullmann, Interessenverbände, S. 124-182. Die ohnehin bedeutsame verbandspolitische Tradition des Kaiserreichs war in Krieg und Nachkriegszeit noch intensiviert worden.

171 Zum RDI vgl. Wolff-Rohé, Reichsverband; speziell zur Verflechtung der DVP mit Interessengruppen vgl. Döhn, Politik und Interesse; zum Reichs-Landbund vgl. Merkenich, Grüne Front gegen Weimar, v.a. S. 134-156 zu den parteipolitischen Verbindungen sowie zur parlamentarischen und bürokratischen Einflußnahme; zum ADGB und zum Allgemeinen freien Angestelltenbund (AfA): Potthoff, Freie Gewerkschaften, v.a. S. 238-305.

172 Mergel, Parlamentarische Kultur, S. 214-217, spricht hier mit einem zeitgenössischen Begriff von "Querverbindungen“.

173 Weitere prominente Reichstagsmitglieder aus den Führungskreisen der Schwerindustrie waren während der Inflationszeit Albert Vögler (DVP) und Clemens Lammers (Zentrum).

174 Vgl. z. B. Kittel, Provinz, S. 408-416; Teyssandier, La vie politique et les parlementaires du Cantal, S. 127-132. Zu den dreißiger Jahren auch Larmour, French Radical Party, S. 17-59. 
netenkammer an ${ }^{175}$. Horace Finaly, der mächtige Direktor der Banque de Paris et des Pays-Bas, verfügte über enge persönliche Beziehungen zur politischen Linken; er unterstützte sowohl die Finanzpolitik Poincarés als auch die des Cartel des Gauches ${ }^{176}$.

Die Presse stellte in den 1920er Jahren sowohl in Deutschland wie in Frankreich einen wesentlichen parlamentarischen Einflußfaktor dar. Grundsätzlich ist zunächst auf die immer noch hohe Zahl politisch relevanter - wenn auch nicht immer auflagenstarker - Tageszeitungen zu verweisen. Beispielhaft genannt seien hier nur die beiden sozialistischen Parteiorgane Vorwärts und Le Populaire, die linksliberalen Blätter Le Quotidien, Frankfurter Zeitung und Vossische Zeitung, die Zentrumsblätter Kölnische Volkszeitung und Germania, der rechtsliberale Meinungsführer Le Temps und die DVP-nahe Kölnische Zeitung, die schwerindustrielle Deutsche Allgemeine Zeitung sowie - mit Nähe zur DNVP - die Neue Preußische Zeitung und die Deutsche Tageszeitung. Die politische Funktion der Zeitungen konnte stark variieren. Nur vereinzelt kam es zu klaren journalistischen Einflußnahmen auf die parlamentarische Entwicklung. So wurde Le Quotidien 1923/24 zur vielbeachteten Antriebskraft des Cartel des Gauches. Teilweise ging es auch weniger um Einflüsse aus der „Öffentlichkeit“ auf das Parlament als vielmehr um den Einsatz parteinaher Blätter im politischen Meinungskampf durch Parlamentarier, Parteien oder Regierungsvertreter. Die Presse wurde somit gleichsam zum erweiterten parlamentarischen Diskussionsraum, ein Phänomen, das in Frankreich bereits vor dem Ersten Weltkrieg verbreitet war. Beide Varianten überlagerten sich, als die zentrumsnahe Germania im Sommer 1923 durch vehemente Attacken eine Pressekampagne gegen die Regierung Cuno entfachte und deren parlamentarische Ablösung entscheidend vorantrieb, nachdem über Monate hinweg in der Zentrumsfraktion eine von der Parteiführung mehr oder minder erzwungene Zurückhaltung geherrscht hatte ${ }^{177}$. Neben der „Meinungspresse“ („presse d'opinion“) hatte sich in Frankreich, vor allem auch dank des großen hauptstädtischen Marktes, bereits eine neuartige Massenpresse nach amerikanischem Vorbild entwickelt (z.B. Le Matin, Le Petit Parisien), deren politische Sympathien eher dem liberal-konservativen Spektrum galten. In gewisser Weise analog hierzu stand in Deutschland die wachsende Pressemacht des Hugenberg-Konzerns (vor allem Berliner Lokal-Anzeiger und Der Tag) ${ }^{178}$.

Die öffentliche Präsenz von - meist radikalen - Parteien und Verbänden oder auch von demonstrierenden Bevölkerungsmassen auf den Straßen der großen Städte gewann ansatzweise bereits in den 1920er Jahren an politischer Bedeutung. Sie wurde vor allem in Deutschland zu einem wichtigen Element des öffentlichen Klimas, das den Handlungsdruck auf die Parlamente erhöhte. Während der deutschen Hyperinflation zeigten sich in der Bevölkerung zudem Anzeichen wirt-

175 Vgl. Jeanneney, De. Wendel. Der Autor reduziert allerdings den bis dahin verbreiteten Mythos vom allmächtigen de Wendel erheblich und kommt so auch zu einer skeptischen Einschätzung des verbandspolitischen Einflusses.

176 Vgl. Bussière, Horace Finaly, S. 227-254. Der Autor hat erstmals die umfangreichen archivalischen Bestände von Paribas zu Finaly ausgewertet. Allerdings geriet Finaly 1925 in einen heftigen Gegensatz zu Finanzminister Caillaux. Vgl. unten S. 484, Anm. 306.

177 Vgl. unten S. 220-223.

178 Holzbach, Das „System Hugenberg“, S. 290-297. 
schaftlicher Massenpanik wie etwa die Plünderung von Geschäften. Ebenso kam es im Sommer 1923 zu großen Streikbewegungen. Der sozialdemokratische Finanzminister Rudolf Hilferding sprach in diesem Zusammenhang Ende August im Haushaltsausschuß des Reichstags von der „ungeheure[n] Erregung und Gärung, die die Massen in der letzten Zeit der Regierung Cuno ergriffen hatte“"179.

Die Parlamente wurden in den 1920er Jahren nur in Ausnahmefällen zum räumlichen Ziel von Straßenkundgebungen. Nach den schweren Unruhen, zu denen es am 13. Januar 1920 bei den Demonstrationen gegen das Betriebsrätegesetz vor dem Reichstag gekommen war, wurde eine „Bannmeile“ um den Reichstag festgelegt, die fortan für politische Demonstrationen weitgehend tabu war ${ }^{180}$. Vor der französischen Abgeordnetenkammer im Palais Bourbon fanden am 21. Juli 1926, dem Tag, als die Idee des Linkskartells mit dem Sturz der Eintagesregierung Herriot II endgültig Schiffbruch erlitt, Umzüge rechtsradikaler Ligen und Bevölkerungskundgebungen statt, die durchaus beängstigend auf die Parlamentarier wirkten $^{181}$.

So bedeutsam und vielfältig die Beziehungen zwischen Parlamenten und Öffentlichkeit in der Weimarer Republik und in der späten Dritten Republik auch waren, ein inzwischen ganz entscheidender Einflußfaktor bestand damals noch nicht. Die demoskopische Meinungsforschung wurde erst in den 1930er Jahren in den Vereinigten Staaten entwickelt ${ }^{182}$. Die führenden Politiker und die parlamentarischen Vorgänge waren daher noch nicht im Banne omnipräsenter Umfragewerte und zumindest in dieser Beziehung freier als heute.

\section{Politische und berufliche Erfabrungen der Abgeordnetenschaft und ibrer Fübrungsgruppen}

Die soziale Zusammensetzung des Reichstags und der Abgeordnetenkammer ist im Rahmen unseres Untersuchungsansatzes vor allem in zweifacher Hinsicht von Interesse ${ }^{183}$. Zum einen stellt sich die Frage, welches $\mathrm{Maß}$ an politisch-parlamentarischer Erfahrung unter den Abgeordneten verbreitet war, wobei Aspekte wie Lebensalter, Dauer der Parlamentszugehörigkeit, Regierungserfahrung und Ausübung sonstiger politischer Funktionen zu berücksichtigen sind. Zum zweiten

179 BA Berlin, R 101, Nr. 1364, Bl. 240.

180 Vgl. Mergel, Parlamentarische Kultur, S. 85-87.

181 Vgl. unten S. $495 \mathrm{f}$.

182 Allerdings gab es in Frankreich bereits seit der Zeit vor 1914 Vorläufer in Form sogenannter „enquêtes", die meist von einzelnen Presseorganen zu bestimmten Themen durchgeführt wurden. Dabei handelte es sich freilich noch nicht um quantifizierende Erhebungen. Beispiele in Raithel, Das „Wunder" der inneren Einheit, S. 32. Soweit ersichtlich, spielten derartige Umfragen in der Inflationszeit der 1920er Jahre keine Rolle.

183 Erneut sei betont, daß keine handbuchartige Vollständigkeit angestrebt wird. Die Darstellung und die Tabellen stützen sich neben der verfügbaren Literatur - für Deutschland v.a. Mergel, Parlamentarische Kultur, S. 98-108 - auch auf eigene Erhebungen aus biographischen Nachschlagewerken. Soweit keine gesonderten Hinweise erfolgen, stammen die Zahlen aus eigener Berechnung. Zu Deutschland: Reichstags-Handbuch, I. und II. Wahlperiode; M.d.R.; Schröder, Sozialdemokratische Parlamentarier; Haunfelder, Reichstagsabgeordnete der Deutschen Zentrumspartei. Zu Frankreich: Notices et portraits 1919, 1924; Normand, Tout le Parlement; Dictionnaire des parlementaires français; Avril u.a., Personnel politique français 1870-1988; Estèbe, Les Ministres de la République 1871-1914; Dictionnaire des ministres. 
soll die berufliche Zusammensetzung betrachtet werden. In welchem Maße spiegelte sich, so ist hier zu fragen, die unterschiedliche Nähe zu den Idealtypen des "klassischen" und des parteiengestützten Parlamentarismus auch in der beruflichen Struktur beider Parlamente?

Den zeitlichen Rahmen der folgenden Ausführungen bilden die erste und zweite Legislaturperiode des Reichstags (1920-1924, 1924) sowie die 12. und die erste Hälfte der 13. Legislaturperiode der Abgeordnetenkammer (1919/20-1924, 1924-26). Die beiden genannten Leitfragen, die eine Brücke schlagen sollen zwischen den prosopographischen, gruppenbiographischen und soziokulturellen Analysen innerhalb der neueren Parlamentarismusforschung ${ }^{184}$ und einem konkreten politischen Untersuchungsinteresse, beziehen sich zunächst auf die Gesamtheit der Parlamentarier. Ausgehend von der Annahme, daß die entscheidenden parlamentarischen Vorgänge in hohem Maße von einem relativ kleinen Kreis führender Abgeordneter geprägt wurden, soll daneben eine Gruppe ausgewählter Parlamentarier näher in den Blick genommen werden. Diese Auswahl bezieht sich - mit gewissen Modifikationen, die aus nationalen Besonderheiten des parlamentarischen Betriebes resultieren - auf die relativ leicht feststellbare Ausübung von Führungsfunktionen: Berücksichtigt werden die Parlamentspräsidenten, alle Vorsitzenden ständiger Ausschüsse, für den Reichstag auch die stellvertretenden Vorsitzenden des Finanz- und des Auswärtigen Ausschusses, für die Abgeordnetenkammer auch der ständige Berichterstatter in der Finanzkommission, weiterhin alle Fraktionsvorsitzenden sowie auf deutscher Seite alle mehrfach belegbaren Teilnehmer an „Parteiführerbesprechungen" 185 . Insgesamt werden damit etwa 7 bis $8 \%$ aller Abgeordneten erfaßt (vgl. Tab. 3.1-3.4 im Anhang) ${ }^{186}$.

1. Die meisten Reichstagsabgeordneten der Jahre 1920-24 konnten nur auf eine kurze Erfahrung im Nationalparlament zurückschauen. Nachdem im Plenum der Weimarer Nationalversammlung etwa $37 \%$ bereits vor 1919 Mitglieder des Reichstags gewesen waren ${ }^{187}$, sank der „kaiserzeitliche“ Anteil nach den ersten Reichstagswahlen auf rund $25 \%$. Innerhalb von zwei Jahren wurde somit im Übergang zur Weimarer Republik das parlamentarische Personal weitgehend ausgetauscht, wobei erstmals eine bescheidene Zahl von Frauen in das Parlament einzog (etwa 8\%) ${ }^{188}$. Mit dem Umbruch war im Vergleich zum Reichstag von 1912 auch eine Verjüngung der Altersstruktur verbunden ${ }^{189}$.

184 Vgl. etwa Best, Mandat ohne Macht; Mergel, Parlamentarische Kultur; Grèzes-Rueff, La culture des députés français; Le Béguec, L'entrée au Palais Bourbon. Gruppenbiographische Analysen finden sich teilweise auch in den Einleitungen der in Anm. 183 genannten biographischen Nachschlagewerke.

185 "Mehrfach" heißt für die Zeit von 1920-24 eine mindestens fünfmalig feststellbare Teilnahme, für die kurze 2. Wahlperiode 1924 eine mindestens zweimalige Teilnahme.

186 Zweifellos übergeht die nach formalen Kriterien vorgenommene Auswahl manchen informell einflußreichen Parlamentarier. Diesem Einwand ist allerdings entgegenzuhalten, daß bei einer weiteren Flexibilisierung die Probleme der Vergleichbarkeit weiter gewachsen wären.

187 Berechnet nach Molt, Der Reichstag vor der improvisierten Revolution, S. 358.

188 Der Nationalversammlung gehörten 41 Frauen an $(9,6 \%)$, dem ersten Weimarer Reichstag 37 $(8,0 \%)$. Vgl. Bremme, Die politische Rolle der Frau in Deutschland, S. $121 \mathrm{f}$. Im weiteren Verlauf der Weimarer Republik sank der Frauenanteil dann noch etwas ab.

189 Vgl. die Aufstellungen nach Alterskohorten in den Reichstagshandbüchern. Allgemein zur Tendenz Mergel, Parlamentarische Kultur, S. 98 f., 104. Auch bei anderen soziokulturellen Faktoren gab es 1918/19 einen deutlichen Modernisierungsschub. Best, Mandat ohne Macht, S. 185-194, 
Ein etwas anderes Bild ergibt sich, wenn man die Gruppe der führenden Parlamentarier der Jahre 1920-24 betrachtet. Hier hatten 17 von 37 Abgeordneten Reichstagserfahrungen, die in die Zeit vor 1919 zurückreichten; dies entspricht einem Anteil von 53\%. Meist lag der erste Einzug ins Parlament im Jahr 1912. Auffallend sind die parteipolitischen Differenzen: Die führenden Funktionsträger der „alten“ Parteien, USPD/SPD und Zentrum, waren weitgehend bereits Mitglieder des letzten kaiserzeitlichen Reichstags gewesen. Für die DDP und die DNVP läßt sich dies nur etwa für die Hälfte sagen, von sieben führenden DVPParlamentariern gar nur für einen, nämlich den langgedienten Abgeordneten Gustav Stresemann. Konzentriert man die Analyse allein auf die Fraktionsvorsitzenden, dann ist insgesamt ein noch etwas höherer Grad an Reichstagserfahrung festzustellen (etwa 67\%) ${ }^{190}$. Bei genauerer Betrachtung der entscheidenden Krisenphase 1922-24 zeigt sich allerdings, daß in drei wichtigen Fraktionen Parlamentarier an der Spitze standen, die dem Reichstag vor 1919 nicht angehört hatten: Oscar Hergt bei den Deutschnationalen, Carl Petersen bei der DDP und - ab August 1923 - Ernst Scholz bei der DVP ${ }^{191}$. Wendet man schließlich den Blick auf die Regierungserfahrung der führenden Parlamentarier, so zeigt sich der wenig überraschende Befund, daß kein einziger von ihnen vor 1919 ein Minister- bzw. nach kaiserzeitlicher Terminologie - ein Staatssekretärsamt bekleidet hatte; fünf von ihnen (etwa 14\%) übten dann allerdings in der Zeit von 1919 bis 1924 eine Funktion als Minister bzw. Reichskanzler aus.

Ein kurzer Ausblick sei auch auf die zweite Wahlperiode des Reichstags im Jahr 1924 geworfen. Das markanteste soziale Charakteristikum ist hier die Verjüngung in der Altersstruktur des Plenums, ausgelöst vor allem durch das Erstarken von Kommunisten und Völkischen bzw. Nationalsozialisten ${ }^{192}$. Die Zahl der bereits im Kaiserreich erprobten Parlamentarier lag jetzt bei etwa $16 \%$. Auch in der Gruppe der führenden Parlamentarier erfolgte ein gewisser Veränderungsschub. Im Vergleich zur Gesamtheit der Reichstagsabgeordneten blieb die parlamentarische Erfahrung der ausgewählten Führungsgruppe weiterhin deutlich erhöht. Bei etwa $41 \%$ reichte diese bis vor 1919 zurück, fast alle anderen führenden Parlamentarier waren spätestens seit 1920 Mitglied des Reichstags gewesen.

In der französischen Abgeordnetenkammer kam es nach dem Ersten Weltkrieg aus zeitgenössischer Perspektive zu einer auffallend starken Fluktuation. Joseph Paul-Boncour spricht in martialischer Rhetorik gar davon, das neue Wahlrecht habe bei den Kammerwahlen vom 16. November 1919 ein „Massensterben“ unter den bisherigen Parlamentariern ("une hécatombe des anciens parlementaires“) angerichtet ${ }^{193}$. Im Vergleich zum Weimarer Reichstag relativiert sich freilich diese

behandelt fünf Felder: „Urbanisierung“ („Anteilswert der bei Mandatsübernahme in Großstädten von über hunderttausend Einwohnern lebenden Abgeordneten“), "Säkularisierung“ (Anteil der „Dissidenten“), „Verbürgerlichung“ (Entwicklung des Adelsanteils), „Sekundarisierung“ („Übergang der Dominanz wirtschaftlicher Interessenrepräsentation vom agrarischen auf den gewerblich-industriell-kommerziellen Bereich“), „Institutionalisierung“ („positionelle Verflechtung zwischen den Funktionsebenen des politischen Systems").

190 Vgl. auch Ritter, Kontinuität und Umformung, S. 256.

191 Scholz wurde erst 1921 Mitglied des Reichstags, nachdem er zuvor Wirtschaftsminister im Kabinett Fehrenbach gewesen war.

192 Vgl. die Einteilung nach Altersgruppen in Reichstags-Handbuch, II. Wahlperiode, S. 561.

193 Paul-Boncour, Entre dcux guerres 2, S. 37. 
Aussage, denn die personelle Kontinuität der Abgeordnetenschaft 1919/20-24 lag erheblich höher als in der ersten Weimarer Reichstagsperiode. Rund $45 \%$ der Deputierten der 12. Legislaturperiode hatten der Kammer bereits vor 1919 angehört. Bei den führenden Parlamentariern (vgl. Anhang, Tab. 3.3) betrug dieser Anteil etwa $67 \%$. Die parlamentarische Erfahrung war auch deshalb größer als in der deutschen Auswahlgruppe, weil die Führungsschicht der Abgeordnetenkammer im Durchschnitt ein vier Jahre höheres Mandatsalter aufwies (10,3 gegenüber $6,3 \mathrm{Jahre})^{194}$. Auch das durchschnittliche Lebensalter lag etwas höher als bei der deutschen Vergleichsgruppe (durchschnittlicher Geburtsjahrgang 1867 gegenüber 1870 auf deutscher Seite). Eine klare Differenz zeigt sich schließlich in der größeren Regierungserfahrung: $\mathrm{Da}$ es unter den Bedingungen eines parlamentarischen Systems mit häufig wechselnden Kabinetten auch eine entsprechende Fluktuation zwischen Abgeordneten- und Ministerbänken gab, hatten 30\% der führenden Kammerabgeordneten schon vor 1919 ein Minister- oder Staatssekretärsamt innegehabt ${ }^{195}$.

In der Kammer der 13. Legislaturperiode ab 1924 konnten noch rund 35\% der Deputierten auf eine Zugehörigkeit vor 1919 zurückblicken. In der Gruppe der führenden Abgeordneten (vgl. Anhang, Tab. 3.4), die infolge der Neubesetzung der Ausschußpräsidenten nach dem Machtwechsel erhebliche Veränderungen aufweist ${ }^{196}$, galt dies im Zeitraum von 1924 bis 1926 sogar für $69 \%$. Erneut liegen durchschnittliches Mandats- (10,2 Jahre) und Lebensalter (durchschnittlicher Geburtsjahrgang 1872) der parlamentarischen Elite höher als in der analogen Gruppe führender Reichstagsabgeordneter 1924. Da der Machtwechsel zum Cartel des Gauches eine Reihe von Sozialisten in funktionale Führungspositionen brachte, sank der Anteil der führenden Abgeordneten mit Regierungserfahrung leicht ab (24\%).

Wendet man sich schließlich der Frage zu, welche politischen Prägungen die Abgeordneten vor oder auch neben ihrer parlamentarischen Funktion erfuhren, so läßt sich erneut ein deutlicher Unterschied erkennen. Daß in Deutschland vor allem die politischen Parteien als „Erfahrungshintergrund“ dominierten ${ }^{197}$, ist eine bekannte Tatsache - ebenso wie der umgekehrte Befund, daß dies in Frankreich mit Ausnahme der sozialistischen und kommunistischen Linken eben nicht der Fall war ${ }^{198}$. Hingegen war in Frankreich die Ausübung lokaler und regionaler Mandate und Ämter weitaus stärker verbreitet als auf deutscher Seite ${ }^{199}$. Funktionen wie Bürgermeister (Maire), Adjoint au maire, Conseiller municipal und Con-

${ }^{194}$ Berechnet nach der Parlamentszugehörigkeit vor 1919 gemäß Anhang, Tab. 3.1 und 3.3. Zur häufigen Wiederwahl etablierter französischer Abgeordneter vgl. auch Birnbaum, Sommets, S. 40.

195 Überblick über Minister- und Staatssekretärsposten in Estèbe, Ministres; Dictionnaire des ministres.

196 Zum Modus der Besetzung vgl. oben S. 59.

197 Mergel, Parlamentarische Kultur, S. 99. Über die Hälfte der Mitglieder des ersten Reichstags hatten demnach „führende Parteipositionen inne oder hinter sich“.

198 Le Béguec, L'entrée au Palais Bourbon, v.a. S. 1602, geht erst für die dreißiger Jahre von einem stärkeren Gewicht für die parlamentarische Rekrutierung aus.

199 Vgl. exemplarisch Teyssandier, La vie politique et les parlementaires du Cantal, S. 151-160; Les parlementaires du Nord-Pas-de-Calais, S. 145-147; grundsätzlich auch Dogan, Les filières de la carrière politique en France, S. 480-482. Nach Birnbaum, Sommets, S. 40, übten von 1900-1940 zwei Drittel der Kammerabgeordneten vor ihrem nationalen ein lokales Mandat aus. 
seiller général auf kantonaler oder Departementsebene wurden nicht selten im Geburtsort bzw. in der Geburtsregion des Abgeordneten wahrgenommen. Die meisten Deputierten behielten derartige Ämter, die oft nur nominell oder überhaupt nicht mit einer Parteizugehörigkeit verbunden waren, auch während einer Kammerzugehörigkeit bei. Herriot war beispielsweise von 1905 bis 1957, mit nur kurzer Unterbrechung während der Vichy-Zeit, Bürgermeister von Lyon. Diese Verklammerung von lokaler und nationaler Abgeordnetenfunktion bildete ein wichtiges Element für die Kontrolle des zentralisierten französischen Verwaltungsapparats ${ }^{200}$, gleichzeitig war sie Ausdruck einer anhaltend intensiven regionalen Verwurzelung des parlamentarischen Systems in Frankreich.

2. Auch bei den Angaben, welche die Abgeordneten in den Parlamentshandbüchern über ihre berufliche Herkunft gemacht haben, zeigen sich markante Unterschiede ${ }^{201}$. So lag der Anteil der Beamten bzw. Staatsbediensteten im Reichstag weit über dem in der Abgeordnetenkammer: knapp 30\% auf deutscher Seite gegenüber gut $10 \%$ auf französischer, wobei es sich hier in erster Iinie um Gymnasial- und Volksschullehrer handelte ${ }^{202}$. Noch auffallender ist im Reichstag die hohe Zahl an Partei- und Verbandsfunktionären, darunter zahlreiche soziale Aufsteiger ohne den bislang unter deutschen Abgeordneten dominierenden Hochschulabschluß ${ }^{203}$ und insbesondere auch relativ viele ehemalige Arbeiter. Nimmt man Erst-, Zweit- und Drittnennung der erlernten und ausgeübten Berufe im Reichstagshandbuch von 1920 zusammen, dann war der Großteil aller Abgeordneten zeitweise von einer Partei, einer Parteizeitung oder einem Verband besoldet worden. Zahlreiche SPD- und Zentrumsabgeordnete stammten beruflich aus den parteinahen Gewerkschaften, während in den beiden liberalen Parteien und in der DNVP vor allem Vertreter von Agrar- und Industrieverbänden $\mathrm{zu}$ finden waren ${ }^{204}$. Bezeichnenderweise ist für die französische Abgeordnetenkammer die vermutlich geringe - Zahl von Partei- und Verbandsfunktionären nicht feststellbar, da entsprechende Kategorien der beruflichen Einordnung zeitgenössisch gar nicht verwendet wurden 205 .

Umgekehrt fällt für die Abgeordnetenkammer der Jahre 1919/20-26 der hohe Anteil an freien Berufen ins Auge. Hierzu zählen vor allem Unternehmer, Ärzte und Apotheker sowie Rechtsanwälte und andere freiberufliche Juristen ${ }^{206}$. Diese neue politische Elite, bei der berufliche und politische Klientel häufig eine enge Verbindung eingingen, hatte bereits in den ersten Jahrzehnten der Dritten Repu-

200 So treffend Dogan, Filières, S. 480.

201 Parlamentshandbücher s. Anm. 183. Analyse zu Deutschland vgl. v.a. Best, Mandat ohne Macht; resümierend auch Mergel, Parlamentarische Kultur, S. 99-104, mit detaillierten Angaben aus der Literatur zu einzelnen Parteien sowie ebd., S. 101, mit Überblickstabellen. Zu Frankreich Dogan, Filières, S. 472 mit Tabelle.

202 Summarische Berechnung für 1920-24 bzw. 1920-26 nach Mergel, Parlamentarische Kultur, S. 101, und Dogan, Filières, S. 472.

${ }^{203}$ Mergel, Parlamentarische Kultur, S. 103.

20+ Vgl. ebd., S. 102 sowie Best, Mandat ohne Macht, S. 190-192 (hier unter dem Stichwort „Sekundarisierung"). Die jeweils genannten Prozentanteile nach Parteien bleiben in ihrer Definition (Mitglieder oder Funktionäre) allerdings unklar. - Zum Sozialprofil der SPD-Abgeordneten vgl. auch Schröder, Politik als Beruf?

205 Vgl. auch Tabelle in Ziebura, Blum, S. $508 \mathrm{f}$.

206 Vgl. auch Teyssandier, La vie politique et les parlementaires du Cantal, S. 62-67; Gaudemet, Les juristes et la vie politique de la III ${ }^{\mathfrak{c}}$ République. 
blik weitgehend die alten Notabeln aus regionalem Adel und Großbürgertum abgelöst ${ }^{207}$. Die Zahl der Juristen war zwar nicht mehr ganz so hoch wie zu Beginn der Dritten Republik, entsprach aber dem seit den achtziger Jahren des 19. Jahrhunderts erreichten Stand (etwa 30\%). Vor allem für die Legislaturperiode von 1919-24 kann man daher noch mit einem gewissen Recht von einer „République des avocats" sprechen; erst im Laufe der Zwischenkriegszeit sollte dieser Prozentsatz allmählich etwas absinken ${ }^{208}$. Insbesondere die hauptstädtische Anwaltsausbildung erwies sich als leistungsfähiger Mechanismus der politischen Rekrutierung. Zwei bekannte Absolventen waren zum Beispiel Raymond Poincaré und Alexandre Millerand, die 1882 die Plätze eins und zwei im Wettbewerb der "conférénce des avocats" belegt hatten ${ }^{209}$ und die sich gut vier Jahrzehnte später einen ähnlich endenden Konkurrenzkampf als Minister- und Staatspräsident lieferten ${ }^{210}$. Generell deutet die anhaltend starke und bis zur sozialistischen Linken reichende ${ }^{211}$ parlamentarische Präsenz freier Berufe darauf hin, daß weiterhin eine von regionalen Honoratioren bestimmte politische Kultur dominant war. Der Reichstag der Jahre 1920-24 weist hingegen nur einen niedrigen Anteil an freien Berufen auf. Geringer war vor allem auch die Zahl der - hier meist aus dem Staatsoder Parteidienst kommenden - Juristen ${ }^{212}$.

Obgleich auch in der Abgeordnetenkammer verschiedene „Teilkulturen“213 vertreten waren, wirkte doch das von etwa 70\% der Parlamentarier bis zum Abitur durchlaufene zentralisierte Bildungssystem mit seiner traditionellen Hochschätzung der Antike und seiner intensiven rhetorischen Schulung als integrativer Faktor ${ }^{214}$. Gleichzeitig hob sich damit die französische Abgeordnetenschaft klar von der Gesamtbevölkerung ab. Für den Weimarer Reichstag, der eher als „bildungsfern" gelten kann, ist im Hinblick auf den schulischen Werdegang der Abgeordneten von einer größeren Heterogenität auszugehen ${ }^{215}$.

Die für die Gesamtheit der Abgeordneten skizzierten Grundzüge der Berufsstruktur gelten überwiegend auch für die ausgewählten Gruppen der parlamentarischen Funktionselite ${ }^{216}$. Auffallend ist allerdings, daß hier der Juristenanteil in etwa gleich hoch lag (um die 50\% im gesamten betrachteten Zeitraum), wobei auf französischer Seite die Rechtsanwälte und auf deutscher die Juristen aus dem Staatsdienst dominierten. Ein deutlicher Unterschied zum Gesamtbefund liegt im

207 Halévy, La fin des notables. Zum sozialgeschichtlichen Kontext: Haupt, Sozialgeschichte Frankreichs seit 1789, S. 211-218. Zu den Rekrutierungswegen in der Zwischenkriegszeit: Le Béguec, L'entrée au Palais Bourbon. Zur Zeit vor dem Ersten Weltkrieg: Guiral/Thuillier, La vie quotidienne des députés, S. 21-29.

208 Vgl. auch Roussellier, Les avocats et la Chambre „bleu horizon“.

209 Bernard, L'affaire Millerand. (Hierbei handelt es sich um eine Internetpublikation ohne Seitenzählung.)

210 Vgl. Zweiter Teil, B, Kap. I.3-5.

21: Speziell zur Berufsstruktur der sozialistischen Abgeordneten vgl. die Tabelle in Ziebura, Blum, S. 508 .

212 Nach Mergel, Parlamentarische Kultur, S. 103, „deutlich unter zwanzig Prozent“.

${ }^{213}$ Grèzes-Rueff, La culture des députés français, passim, unterscheidet „primaires“, „propriétaires“, "littéraires", „juristes" und „spécialistes“.

214 Vgl. ebd., v.a. S. $170-172$.

${ }^{215}$ Zitat aus Mergel, Parlamentarische Kultur, S. 103; ebd. allerdings keine näheren Angaben zum schulischen Werdegang. Die Zahl der Hochschulabsolventen sank von über 50\% vor 1918 auf "deutlich unter vierzig Prozent". Ebd.

216 Die folgenden Zahlen jeweils nach eigener Berechnung. 
hohen Bildungsgrad der führenden deutschen Abgeordneten: Fast 70\% hatten das Abitur abgelegt, knapp 40\% waren sogar promoviert. Erneut zeigt sich hier eine gewisse Kluft zwischen der Gesamtheit der Reichstagsabgeordneten und ihrer Führungsschicht.

Resümiert man die im Laufe dieses Kapitels gesammelten Beobachtungen, dann ergibt sich ein kontrastreiches Gesamtbild. Der Reichstag der frühen 1920er Jahre war ein insgesamt eher unerfahrenes Parlament, obgleich sich meist kaiserzeitlich geprägte Parlamentarier in Führungspositionen befanden. Geradezu überdeutlich wird die deutsche Tendenz zum hochentwickelten Parteiwesen: Viele der Abgeordneten waren ihrer Partei nicht nur politisch, sondern auch beruflich eng verbunden. Dank dieser Parteikarrieren waren auch zahlreiche soziale Aufsteiger zu einem Mandat gekommen, was dem Reichstag eine größere soziale Bandbreite verlieh $^{217}$. Diese Merkmale sowie die bescheidene Präsenz von Frauen machten das deutsche Nationalparlament noch nicht zu einem Spiegel der Gesellschaft. Im Vergleich zur Abgeordnetenkammer aber zeigte sich doch eine größere soziale Ähnlichkeit von Parlament und Gesellschaft - was keineswegs verhinderte, daß die Parlamentarier in der politischen Öffentlichkeit häufig als abgehobene Parteivertreter wahrgenommen wurden.

Die Mitglieder der Abgeordnetenkammer bildeten hingegen eine relativ homogene männliche Elite, die insgesamt über eine sehr große parlamentarische Erfahrung verfügte. Dem bereits angesprochenen Corpsgeist konnte dies nur förderlich sein. Entscheidend für den politischen Aufstieg war in der Regel nicht die Partei, sondern die erfolgreiche politische Tätigkeit auf lokaler und regionaler Ebene. Unter diesen Bedingungen fanden besonders viele Angehörige freier Berufe den Weg in die Kammer, darunter immer noch zahlreiche Juristen. Letztlich trug die Kammer weiterhin den Charakter einer der politischen Basis vor Ort eng verhafteten Honoratiorenversammlung. Allerdings war diese inzwischen durchaus parlamentarisch professionalisiert ${ }^{218}$, und ihre Mitglieder entstammten überwiegend nicht mehr den alten Notabeln des 19. Jahrhunderts, sondern waren in ihrer Gesamtheit stärker mittelständisch geprägt.

Inwieweit lassen sich aus den skizzierten Befunden Folgerungen für die politisch-parlamentarischen Entwicklungen der Inflationszeit ableiten? Naheliegend ist zunächst die einfache Hypothese, daß im deutschen Reichstag der parteinahe berufliche Werdegang vieler Abgeordneter, möglicherweise aber auch die „Erfahrungskluft" zwischen Führungsgruppen und Gesamtheit der Parlamentarier die parteiengebundene Form des parlamentarischen Systems im allgemeinen und die Fraktionsdisziplin im besonderen gefördert haben. Daß die deutschen Abgeordneten insgesamt wenig parlamentserfahren waren und daß das meist auf eine deutlich längere Reichstagszugehörigkeit zurückblickende Führungspersonal seine Erfahrungen innerhalb des Kaiserreichs gesammelt hat, war sicherlich keine gute Voraussetzung für eine selbstbewußte parlamentarische Praxis in einer Krisensituation. In der französischen Abgeordnetenkammer hingegen begünstigten

217 Best, Mandat ohne Macht, S. 195 f., sieht in dieser „partiellen Modernisierung“ einen das parlamentarische System belastenden Faktor der Inkohärenz.

218 Betont wird dies etwa in Birnbaum, Sommets, S. 30-47. 
mehrere Faktoren tendenziell die Kontinuität eines hohen parlamentarischen Selbstbewußtseins sowie die Persistenz eines klassischen Parlamentarismusverständnisses und Politikstils. An erster Stelle ist die große parlamentarische Erfahrung zu nennen. Hinzu kamen die relativ homogene soziale Zusammensetzung sowie der immer noch hohe Anteil von redegewandten Rechtsanwälten. Die eben angedeuteten Differenzen werden im folgenden Kapitel noch genauer zu untersuchen sein.

\section{Parlamentarismusverständnis in den Parlamenten}

$\mathrm{Zu}$ den Strukturen des parlamentarischen Lebens lassen sich auch jene langlebigen, im Vorfeld der Ideologien angesiedelten kollektiven Grundvorstellungen zählen, die - manchmal in Form wenig bewußter "unspoken assumptions" 219 - in die politischen Prozesse einfließen. Dies gilt in besonderer Weise für die nun näher zu betrachtenden Muster des Parlamentarismusverständnisses und der Parlamentarismusbewertung, wie sie innerhalb der Abgeordnetenschaft selbst zu erkennen sind ${ }^{220}$. Dabei wird die radikale Kritik der extremen Linken und Rechten weitgehend ausgeklammert. Vielmehr geht es vor allem um jene Kräfte einer weit verstandenen Mitte, die maßgeblichen Anteil am parlamentarischen Geschehen nahmen und deren politische Mentalitäten ${ }^{221}$ daher von besonderer Relevanz für die Funktionsfähigkeit des Systems waren 222 .

Bürgerliche Politiker in Deutschland sprachen vom parlamentarischen Regierungssystem häufig in einem Ton der Unsicherheit und Sorge oder aber in einem der mehr oder minder deutlichen Kritik. Dies lag zweifellos auch an der intensiveren deutschen Krisensituation und insbesondere an der erheblichen Belastung durch exogene, nicht im Parlament selbst verortete Gefahren: Radikale politische Herausforderungen, separatistische Bewegungen, das Damoklesschwert alliierter Interventionen und seit 1922 auch der Prozeß der Hyperinflation bildeten ein massiv wahrgenommenes Bedrohungspotential für den jungen Weimarer Staat. Daneben machte sich aber auch eine mentale Distanz zum parlamentarischen System bemerkbar, die je nach politischem Standort von einer diffusen Unsicherheit des politischen Selbstverständnisses über Skepsis gegenüber einzelnen Ver-

${ }^{219} \mathrm{Vgl}$. generell zum Phänomen: Joll, 1914.

$220 \mathrm{Vgl}$. allgemein v.a. Grüner, Zwischen Einheitssehnsucht und Massendemokratie, der deutsche und französische Liberale in der Zwischenkriegszeit behandelt. Zu Frankreich auch Hinweise in Estèbe, Le parlementaire. - Mergel, Parlamentarische Kultur, und partiell auch Grèzes-Rucff, La culture des députés français, haben einen anderen Ansatz gewählt, indem sie Schematismen der parlamentarischen Sprache bzw. grundlegende Dispositionen des Verhaltens von Abgeordneten untersuchen und dabei jeweils die integrative Wirkung parlamentarischer Kommunikation nachweisen.

221 Über Charakter und Stellenwert politischer Mentalitäten in der so schnellebig wirkenden Moderne liegen bislang kaum Reflexionen vor. Eine instruktive Skizze bietet Rohe, Politische Kultur und ihre Analyse. Allerdings meidet der Autor weitgehend den Begriff der Mentalität und spricht vom „Inhaltsaspekt“ politischer Kultur.

222 Die Darstellung stützt sich - neben der verfügbaren Literatur - in erster Linie auf die verbreitete politische Begrifflichkeit sowic auf parlamentarische Redebeiträge, Wahlaussagen und publizistische Äußerungen führender Abgeordneter und Regicrungsmitglieder der Inflationszeit. Die politische Sprache wird so als Quelle herangezogen, ohne zu verkennen, daß immer auch ein gewisser Anteil rhetorischer und taktischer Floskelhaftigkeit zu berücksichtigen ist. 
fahrensprozessen bis zur offenen Ablehnung der parlamentarischen Demokratie reichen konnte. Im Hintergrund standen Probleme, die innerhalb des parlamentarischen Systems wahrgenommen wurden: starke Gegensätze in politischen Grundfragen, wiederkehrende Krisen der Regierungsbildung und der koalitionspolitischen Kooperation, aber auch die alltägliche Realität des parteiengestützten Parlamentarismus. Je nach politischem Standort und nach Krisensituation wurden die damit verbundenen Probleme als latente oder akute Bedrohung der Einheit und Handlungsfähigkeit der deutschen Nation begriffen. Die im bürgerlichen Spektrum des Reichstags erkennbare Parlamentarismuskritik erwies sich dabei in erster Linie als eine sehr grundsätzliche Parteienkritik.

Die geistesgeschichtlichen Wurzeln des zur Weimarer Zeit überwiegend noch negativ besetzten Parteienbegriffs - Gustav Radbruch hat bekanntlich eher dezent von einer "Parteienprüderie“ gesprochen ${ }^{223}$ - brauchen hier nicht diskutiert zu werden ${ }^{224}$. Um die Intensität und Breite der deutschen Parteien- und damit auch der Parlamentarismuskritik zu verstehen, erscheint es vielmehr aufschlußreich, zunächst jene Leitkategorien zu betrachten, die im politischen Diskurs gleichsam an der Spitze der nationalen Wertehierarchie standen: „Reich“, „Volk“ und „Staat" 225 .

Der Begriff des „Reichs“ bezog sich eher auf den äußeren Zusammenhalt des spät geschaffenen deutschen Nationalstaats, auf die Gefährdung durch Separatismen oder auch auf die außenpolitische Thematik, und er diente zur Abgrenzung gegenüber der deutschen Länderebene. „Volk“ und „Staat“ hingegen verwiesen als die eigentlichen Gegenpole des Parteienbegriffs auch auf die innere Verfaßtheit.

Der aus der geistesgeschichtlichen Tradition stammende und im Ersten Weltkrieg intensivierte Bezug auf ein ethnisch-organisches „Volk“, auf die „Volksgemeinschaft“ oder auch auf den „Volkskörper“ war gängige Praxis in allen bürgerlichen Parteien und teilweise auch in der SPD ${ }^{226}$. Besonders gepflegt wurde er in Teilen der rechten Mitte - etwa bei dem Zentrumsabgeordneten und christlichen Gewerkschaftsführer Adam Stegerwald ${ }^{227}$ oder auch bei Stresemann ${ }^{228}$. Das

223 Gerhard Radbruch, Die politischen Parteien im System des deutschen Verfassungsrechts, in: Anschütz/Thoma (Hrsg.), Handbuch des Deutschen Staatsrechts 1, S. $285 \mathrm{f}$.

224 Vgl. zusammenfassend Sontheimer, Antidemokratisches Denken, S. 188-211; Beyme, Partei, Fraktion, S. 697-732, zur Begriffsgeschichte. Ebd., S. 732, das treffende Urteil, daß die „Entwicklung des Parteibegriffs" in Deutschland "weitgehend die Geschichte eines diskriminierenden Begriffs" war. Allgemein zur langen deutschen Tradition von Parlamentarismus- und Parteienkritik vgl. auch Wasser, Parlamentarismuskritik vom Kaiserreich bis zur Bundesrepublik; Durner, Antiparlamentarismus in Deutschland. Stellvertretend für die zeitgenössische akademische Parlamentarismuskritik sei hier nur die 1923 erstmals erschienene Abhandlung von Schmitt, Die geistesgeschichtliche Lage des heutigen Parlamentarismus, genannt. Vgl. auch am Beispiel Willy Hellpachs Jansen, Antiliberalismus und Antiparlamentarismus, insbesondere auch zu dem spezifisch parteienkritischen Akzent der Parlamentarismuskritik.

${ }_{225}$ Zur Bedeutung der beiden letztgenannten Begriffe im Weimarer Reichstag vgl. auch Mergel, Parlamentarische Kultur, S. 259-264.

226 Koselleck, Volk, Nation. Zur völkischen Ideologisierung des Einheitserlebnisses von 1914 vgl. Raithel, Das „Wunder" der inneren Einheit, S. 479-481. Zur Intensivierung des Konzepts der "Volksgemeinschaft" auch Verhey, Der „Geist von 1914“.

227 Die Leitidee der „Volksgemeinschaft“, verbunden mit einem politisch-gesellschaftlich vormodernen Harmoniestreben und einem ausgeprägten Antiparteienaffekt, spielten bei dem Mentor von Heinrich Brüning - während der Inflationszeit Stegerwalds Privatsekretär - eine wesentliche 
Volk in einem tendenziell eher linken Sinne als Akteur der revolutionären Umwälzung, als Staatsvolk, das jetzt in der parlamentarischen Demokratie selbst über sein Schicksal bestimmte, prägte vor allem die Sprache der Sozialdemokratie, ohne daß hier der ethnische Volksbegriff ganz fehlte. Wie auch die Verwendung in neuen Parteinamen zeigte (DVP, DNVP, BVP), war der schillernde Begriff des Volks nach dem Ersten Weltkrieg allgegenwärtig geworden, ohne daß die Zuordnung zu einem ethnischen oder staatsrechtlichen Verständnis immer eindeutig gewesen wäre.

Fast ebenso häufig verwendeten Parlamentarier von der bürgerlichen Mitte bis zum rechten Flügel der SPD den Begriff des „Staats“, nicht selten in Form eines Postulats. Eingefordert wurde die „positive Mitarbeit“ am Staat bzw. eine „staatsbildende“, „staatserhaltende“ oder "staatspolitische“ Tätigkeit229. „Staat" war hierbei in der Regel eine neutrale ordnungspolitische Kategorie, die - auffallend etwa bei Stresemann ${ }^{230}$ - auch mit dem Begriff der Vernunft und dem Leitbild einer „sachlichen“, konsensorientierten Politik konnotiert war. Bekanntlich war "Staat" ähnlich wie „Volk“ in der deutschen Verfassungstradition des 19. Jahrhunderts als organische und personale Ganzheit gedacht, die für die pluralistische Konkurrenz unterschiedlicher politischer Kräfte nur wenig Gestaltungsraum ließ. Die Politik hatte demnach einem überparteilich zu definierenden „Staats-“ bzw. „Gemeinwohl“ zu dienen ${ }^{231}$. Deutlich ist hier die Tradition der konstitutionellen Monarchie zu erkennen, deren Dualismus von Regierung bzw. Krone und Parlament in der Gesetzgebung notwendigerweise auf Kooperation und Kompro$\mathrm{miß}$ angelegt war ${ }^{232}$. Unter den Bedingungen des parlamentarischen Systems leitete sich hiervon der Glaube an den „gesunde[n] Gedanke[n] der Konzentration der Kräfte ${ }^{* 233}$ und somit auch an die positive Wirkung einer breiten Koalitionspolitik ab ${ }^{234}$.

Rolle. Der Untertitel der vom christlichen Deutschen Gewerkschaftsbund herausgegebenen und als Sprachrohr Stegerwalds dienenden Tageszeitung Der Deutsche lautete: Tageszeitung für deutsche Volksgemeinschaft und für ein unabhängiges Deutschland. Allgemein zu Stegerwald: Schorr, Adam Stegerwald; Forster, Adam Stegerwald; speziell zur Vorstellung einer "Volksgemeinschaft", die hier politisch ein Spektrum von der SPD bis zur DNVP umfasste, ebd., S. 321-326.

228 Vgl. z. B. Zitat unten S. 134, Anm. 113, zum leitenden „Gedanken der Volksgemeinschaft“. Zur Bedeutung für Stresemann vgl. Fritz, The Search for Volksgemeinschaft. Vgl. auch die Polemik der linksliberalen FZ, 14. 10. 1922 ab, S. 1, „Frankfurt, 14. Oktober“: „[...] das Phrasengetöne von der großen Volksgemeinschaft, das man aus dem Munde des Herrn Stresemann und seiner Freunde so regelmäßig vernimmt“.

229 Zur analogen Tendenz im Staatsrecht, allgemein von „Staat“ und „Verfassung“ zu sprechen, vgl. Gusy, Die Lehre vom Parteienstaat in der Weimarer Republik, S. 73-78f. Allgemein zur Tradition eines emphatischen und personalisierten deutschen Staatsbegriffes vgl. „Staat“, in: Historisches Wörterbuch der Philosophie, v.a. S. 42-48.

230 Vgl. z. B. in DS, 5. 11. 1922, S. 673-678, „Politische Umschau“, hier S. 676.

231 Vgl. „Staat", in: Historisches Wörterbuch der Philosophie, v.a. S. 43 f.; Koselleck, Volk, Nation. Vgl. konkret zu zwei Parlamentariern: Huber, Gertrud Bäumer, S. 333, sowie Mikuteit, Der Parlamentarismus im Urteil von Walther Rathenau, S. 116. Mikuteit spricht von einer „harmonistisch getönte[n] Gemeinschaftskonzeption" als Grundlage von Rathenaus Parlamentarismusverständnis.

${ }_{232}$ Zur deutschen Tradition des Konsensprinzips bei gleichzeitiger Verkennung des demokratischen Mehrheitsprinzips vgl. Gusy, Konsensprinzip oder Demokratie.

${ }_{233}$ Stresemann in DS, 5. 11. 1922, S. 673-678, „Politische Umschau“, hier S. 674.

${ }^{234}$ Zum - v.a. liberalen - Glauben an die stärkende Wirkung breiter Koalitionen vgl. auch Papke, Der liberale Politiker Erich Koch-Weser, S. 106 f., mit einem Zitat aus einer vertraulichen Mitteilung der Reichsgeschäftsstelle vom 4. 10. 1923. 
Beim Gebrauch des Staatsbegriffs fehlte meist jeder Bezug zum aktuellen parlamentarisch-republikanischen System ${ }^{235}$. Dies hatte einen ambivalenten Effekt: Zwar wurde so eine Brücke zur deutschen Verfassungstradition geschlagen und auch einem Monarchisten die pragmatische Mitarbeit im Weimarer Staat ermöglicht ${ }^{236}$. Politiker wie Stresemann führten das Wort "Staat" daher gerade auch dann demonstrativ im Munde, wenn die Regierungsbeteiligung der DVP gegenüber der politischen Rechten verteidigt werden sollte oder aber wenn sie - wie bei der Diskussion um das Republikschutzgesetz von 1922 - ein explizites Bekenntnis zur Republik vermeiden wollten ${ }^{237}$. Auch der Begriff „verfassungstreu“ wurde innerhalb von DVP und Zentrum teilweise in diesem Sinne eingesetz $\mathrm{t}^{238}$.

Vom eben Gesagten ist die bürgerliche und die sozialdemokratische Linke teilweise auszunehmen. Hier fand sich durchaus das Bemühen um eine republikanische Füllung des Staatsbegriffs, wenngleich es erkennbar an Bezugspunkten in der eigenen Nationalgeschichte mangelte ${ }^{239}$. Einen gewissen Höhepunkt erreichte diese republikanische Offensive Mitte 1922 nach der Ermordung Rathenaus in den Diskussionen um das große Gesetz zum „Schutz der Republik“240.

Die politische Dominanz des Parteiwesens und die Existenz parteipolitischer Konflikte konnten in einem politischen Weltbild, das noch stark von den Prämissen des traditionellen Volks- und Staatsverständnisses bestimmt war, keinen angemessenen Platz gewinnen, und sie mußten daher letztlich als Bedrohung empfunden werden. Trotz und vielleicht auch wegen des relativ hohen Entwicklungsniveaus deutscher Parteien war es mit ihrer "staatsrechtlichen Legitimität“ zumindest in der bürgerlichen Mitte schlecht bestellt ${ }^{241}$. Sie galten hier noch immer als Vertreter gesellschaftlicher Sonderinteressen, die dem von der Regierung vertretenen Staatsinteresse gegenüberstanden. Konkret zeigte sich dies in den ständig wiederholten und nicht selten vehement moralisierenden Klagen über „Parteiismus“, „Parteisucht“, „Parteigeist“ oder „Parteiegoismus“. Derartige Vorwürfe wurden angesichts der zahlreichen Regierungskrisen nicht nur in der politischen Öffentlichkeit, sondern auch von bürgerlichen Reichstagsabgeordneten formelartig wiederholt ${ }^{242}$. Den argumentativen Hintergrund bildete eine weitverbreitete, weitgespannte und im Gefolge der Hyperinflation stark intensivierte Kulturkritik am Zustand der deutschen Gesellschaft, deren tiefe Klüfte vor allem moralisch gedeutet wurden: Sonderinteressen, Egoismus, Materialismus, die Neigung zu Luxus und Vergnügen und nicht selten auch die Abkehr vom Christentum schienen ver-

${ }^{235}$ Vgl. z.B. die Definition der Funktionen des Staates durch Adam Stegerwald, Die staatsbildende Kraft der Sozialisten, in: Der Deutsche, 16. 7. 1922, S. 1.

236 Vgl. auch Mergel, Parlamentarische Kultur, S. $263 \mathrm{f}$.

237 Vgl. z. B. Zitat unten S. 130, Anm. 85.

238 Vgl. hierzu z.B. die scharfsinnige Analyse in FZ, 22. 8. $1922 \mathrm{mo} / 1$, S. 1, „Die verfassungstreue Mitte".

239 Vgl. allgemein zur Problematik auch Langewiesche, Republik und Republikaner, S. 21.

$240 \mathrm{Vgl}$. unten S. $124 \mathrm{f}$.

${ }^{2+1} \mathrm{Vgl}$. Grüner, Zwischen Einheitssehnsucht und Massendemokratie, S. $227 \mathrm{f}$.

242 Allgemein zur bürgerlichen und insbesondere liberalen Parteienkritik vgl. Jahr, Liberaler Antiparlamentarismus?; Grüner, Zwischen Einheitssehnsucht und Massendemokratie. Speziell zur DDPParlamentarierin Gertrud Bäumer vgl. Huber, Gertrud Bäumer, S. 329-336. 
antwortlich für das Bild einer in sich zerrissenen und nach außen wenig handlungsfähigen Nation ${ }^{243}$.

Es war die alltägliche Realität des Parteiwesens im parlamentarischen Betrieb, die im bürgerlichen Parteienspektrum auf geradezu schizophrene Weise für Unmut sorgte. Dies betraf zum einen die Struktur des Parteiensystems, ein Problem, das vor allem in den beiden liberalen Parteien und im Zentrum wahrgenommen wurde. „Der tiefere Grund" des „deutschen Elends“, so meinte beispielsweise der Zentrumsvorsitzende Marx in seinem Aufruf zur Bildung einer "großen christlichen Partei der Mitte" im Juni 1922, liege bei den Parteien. Notwendig sei daher eine "Vereinfachung und Vereinheitlichung" des deutschen Parteiensystems ${ }^{244}$. $\mathrm{Daß}$ derartige Bemühungen um eine konfliktdämpfende Neustrukturierung der Parteienlandschaft stets an den politischen Realitäten scheiterten, bildete eine ständige Quelle neuer Parteienkritik.

Zum anderen aber klagte man in weiten Bereichen des bürgerlichen Spektrums über die starke politische Stellung der deutschen Parteien, was wiederum eine Reihe spezieller Vorwürfe zur Folge hatte. So wurde die Dominanz der Parteien dafür verantwortlich gemacht, daß sich die weithin geforderten parlamentarischen „Persönlichkeiten“, „Köpfe“ oder „Führer" nicht in dem Maße bilden und durchsetzen konnten, wie dies gerade angesichts der krisenhaften Lage für notwendig befunden wurde ${ }^{245}$. Kein Thema war hingegen jener Mangel an Erfahrung mit dem parlamentarischen System, den man für derartige Defizite wohl eher verantwortlich machen muß.

Noch bedeutsamer war die Kritik am Einfluß, den die Parteien bzw. Fraktionen bei der Regierungsbildung besaßen. Die in der Weimarer Verfassung nicht vorgesehene, nach der Logik des parteiengestützten parlamentarischen Systems aber durchaus zwingende und auch in der politischen Praxis der Weimarer Republik sofort durchgesetzte Koppelung der Kabinettsbildung an eine intensive Beratung mit den potentiellen Regierungsfraktionen gab Anlaß zu einer in allen bürgerlichen Parteien geübten Klage. In diese stimmten auch jene führenden Abgeordneten mit ein, die ihre Fraktionsinteressen in den entsprechenden „Parteiführergesprächen" vertraten ${ }^{246}$. Der im Einverständnis mit Reichspräsident Ebert stehende

${ }^{243}$ Vgl. z.B. den BVP-Fraktionsvorsitzenden Leicht am 8. 10. 1923, als er nach tieferen Gründen für die Aufgabe des Ruhrkampfes suchte und meinte, „sie auf eine und dieselbe Wurzel zurückführen zu müssen, auf den brutalen rücksichtslosen Egoismus, der nur aus der vollständigen Abkehr vom Geiste des Christentums sich erklären läßt". Verh. RT 361, S. 11996.

${ }_{244}$ Abdruck z.B. in Ge, 23. 7. 1922 mo, S. 1, „Aufruf der deutschen Zentrumspartei“. Hintergrund war die einsetzende Diskussion um eine bürgerliche Arbeitsgemeinschaft. Vgl. Zweiter Teil, A, Kap. I.2.

245 Vgl. zu entsprechenden Erwartungen in der politischen Öffentlichkeit Mergel, Parlamentarische Kultur, S. 367-371. Zur zeitgenössischen Bedeutung des „Führungsgedankens“" vgl. auch Fichtner, Führer und Verführer, insbesondere S. 90-98 zu Gertrud Bäumer. Unabhängig von den konkreten politischen Krisen wirkt die Sehnsucht nach starken Persönlichkeiten wie eine Gegenreaktion auf eine zunehmend unübersichtlich und unberechenbar gewordene Welt der Moderne.

${ }^{246} \mathrm{Vgl}$. z. B. Ludwig Haas (DDP) am 5.12. 1923 im Reichstag zur gescheiterten Bildung einer Regierung Albert: „Man hat wieder einmal geglaubt, im Wege von Verhandlungen über die Fraktionen ein vernünftiges Kabinett zustandebringen zu können. Wir stehen prinzipiell auf dem Standpunkt - und ich möchte sagen, von der ersten Regierungskrisis in der Nationalversammlung an haben wir diesen Standpunkt eingenommen -, daß man im Wege der Verhandlungen unter Fraktionen überhaupt kein brauchbares Kabinett zustandebringen kann." Als Begründung folgt eine charakteristische Fehlwahrnehmung des westlichen und besonders des französischen Parlamentarismus: „In 
Versuch des designierten Reichskanzlers Cuno, im November 1922 die Fraktionen weitgehend von der Beratung über die Regierungsbildung auszuschließen, stieß daher - wie später genauer zu verfolgen sein wird - auf breites Entgegenkommen ${ }^{247}$.

Ähnlich problematisch war die Wahrnehmung des Verhältnisses zwischen der amtierenden Regierung und den Regierungsparteien bzw. -fraktionen. Angesichts eines anachronistischen Ideals strikter Gewaltentrennung herrschte hier eine Vorstellung, die dem traditionellen dualistischen Bild von Regierung und Parlament entsprach. Bezeichnend ist etwa die Annahme, Spitzenpolitiker würden - wie dies der Zentrumsabgeordnete Johannes Giesberts anläßlich der Kabinettsbildung von Wilhelm Marx formuliert hat - aus den Regierungsparteien „für die Leitung der Reichsgeschäfte herausgestellt"248. Die enge Verschränkung von Regierung und parlamentarischem Regierungslager, die sich im modernen parteiengestützten Parlamentarismus nahezu automatisch ergibt, stieß vielfach auf Unverständnis. Dies galt insbesondere für das Bestreben der Regierungsfraktionen, möglichst großen Einfluß auf die Regierungspolitik zu gewinnen. Beispielsweise attackierte der DDP-Abgeordnete Ludwig Haas im Dezember 1921 die SPD-Fraktion, weil diese die Aufhebung einer Ausnahmeverordnung verlangt hatte: „Jetzt regiert die Regierung nicht mehr, sondern Sie regieren [...] und wenn die Parlamente regieren und der Regierung die Möglichkeit des Regierens nehmen, das ist ein böser Parlamentarismus" 249 .

So weit, die in Artikel 54 der Weimarer Verfassung vollzogene Bindung der Regierung an das Vertrauen des Reichstags und damit den eigentlichen Kernpunkt des parlamentarischen Systems in Frage zu stellen, ging während der Inflationszeit selbst die DNVP nur selten. Daß sich die große konservative Partei freilich mit dem parlamentarischen System "abgefunden" habe, wie der Fraktionsvorsitzende Oscar Hergt im Juni 1920 im Reichstag versicherte ${ }^{250}$, wirkte insgesamt wenig glaubwürdig. Allzu emphatisch wurde immer wieder das "Fiasko“ oder der „Bankerott" des Systems festgestellt ${ }^{251}$. Insgesamt bewegte sich die DNVP bis zur innerparteilichen Machtübernahme Hugenbergs im Herbst 1928 zwischen scharfer Parlamentarismuskritik auf der einen, und taktischer, zumindest ansatzweise aber auch pragmatischer Mitarbeit auf der anderen Seite 252.

kcinem Lande mit alter parlamentarischer Erfahrung wird ein Kabinett im Wege über dic Fraktionen gebildet. Der Reichspräsident oder der Monarch beauftragt einen Mann, cin Kabinett zu bilden. Dieser eine Mann sucht sich seine Minister." Verh. RT 361, S. 12309.

247 Vgl. hierzu ausführlich Zweiter Teil, A, Kap. II.1.

${ }^{248}$ So in dem Artikel „Reichskanzler Marx“, in: Ge, 30. 11. 1923, S. 1f., hier S. 1. Der erste Satz lautet: „Mit dem Präsidenten Marx hat das Zentrum seine in der Fraktion und in der gesamten Partei geachtetste und beliebteste Persönlichkeit für die Leitung der Reichsgeschäfte herausgestellt."

${ }^{249}$ Verh. RT 352, S. 5284f. (16. 12. 1921). Vgl. etwa auch Mikuteit, Parlamentarismus, S. 103, zu Rathenaus Kritik an der "Fraktionsherrschaft". - Zu den modernen „Regierungsfunktionen“ des Parlaments vgl. allgemein Mößle, Regierungsfunktionen des Parlaments.

250 Verh. RT 344, S. 31 (28. 6. 1920).

251 Vgl. z. B. ebd., unmittelbar nach der eben zitierten Behauptung: „[...] und wir glauben, daß in der hinter uns liegenden Periode der anderthalb Koalitionsjahre dieses parlamentarische System wegen der offensichtlichen Schäden einer so absolutistischen Omnipotenz der Mehrheit des Parlaments vor der Bevölkerung schon heute Fiasko gemacht hat."

252 Vgl. Trippe, Konservative Verfassungspolitik; von dem Bussche, Konservatismus in der Weimarer Republik, S. 79-90; Kittel, Zwischen völkischem Fundamentalismus und gouvernementaler Taktik. Kurze Skizzicrung der unterschiedlichen Strömungen in der DNVP in der Einleitung zu 
Die nahezu selbstverständliche Akzeptanz, die der legislative Einsatz des Artikels 48 sowie die großen Ermächtigungsgesetze des Jahres 1923 in den bürgerlichen Parteien der Mitte fanden, ist stets vor dem Leitbild einer aktiven und möglichst wenig von parlamentarischen Einsprüchen gestörten Regierung zu sehen. Dieses Bild wurde umso bedeutsamer, je mehr sich die innere Krisensituation zuspitzte. Erich Koch-Weser (DDP) verkündete beispielsweise im September 1923: „Wir sind der Überzeugung, daß die Situation so ernst ist, daß die Regierung Zeit und Hände frei haben muß zum Handeln. Die Situation ist nicht so, daß sie durch Reichstagsreden gebessert werden kann, sondern nur dadurch, daß die Regierung, die das Vertrauen der übergroßen Mehrheit des Reichstags besitzt, Zeit hat, so zu handeln, wie es die Umstände gebieten." ${ }^{253}$ Manchmal schlich sich dabei in die Kritik auch jene Verachtung parlamentarischer Diskussion ein, deren Wurzeln bis in die Bismarckzeit zurückreichen. Ernst Scholz lieferte hierfür ein markantes Beispiel: Es sei „schlechterdings nicht zu ertragen“ - so meinte der DVP-Fraktionsvorsitzende im Februar 1924, kurz vor dem Ende der Legislaturperiode, zur parlamentarischen Forderung nach Aufhebung von Rechtsverordnungen, „wenn eine schon etwas abgelebte Henne - verzeihen Sie den harten Ausdruck - wochenlang über ein Ei gackert, das sie nicht einmal selbst gelegt hat ${ }^{\star 254}$.

„Handeln statt reden“, „Taten statt Worte“, diese alten Topoi deutscher Parlamentarismuskritik ${ }^{255}$, die einem simplen Affekt gegen das deliberative Prinzip parlamentarischer Meinungsbildung entsprangen, kamen in der Krise der Inflationszeit zu neuen Ehren. Besonders bemerkenswert ist, daß dies auch im Reichstag selbst der Fall war und daß Parlamentarier der systemtragenden Mitte dabei durchaus eine führende Rolle spielten. Im Hintergrund ist das Ideal einer tatkräftigen Regierung erkennbar, die zwar parlamentarisch verantwortlich ist, aber ohne unmittelbare Mitwirkung der Parteien gebildet wird und in ihrer Amtsführung weitgehend unabhängig von den sie tragenden Reichstagsfraktionen agieren kann.

Gegen die vorherrschende Vorstellung vom übergroßen politischen Gewicht der Fraktionen gab es nur wenig Widerspruch. Eine bemerkenswerte Ausnahme innerhalb der bürgerlichen Parteien bildete Anton Erkelenz. Der Exponent des linken Parteiflügels in der DDP-Fraktion sprach zum Beispiel im Dezember 1922 von der „blasse[n] Theorie, die da besagt, daß Regierungen gebildet werden sollen ohne jede Befragung der Fraktionen“. Man denke sich „einen starken Reichskanzler, hingestellt durch den Reichspräsidenten“. Aufschlußreich und vielleicht auch charakteristisch für die linksliberale DDP ist, daß Erkelenz dieses Ideal nicht aus der zweifellos folgenreichen Tradition des deutschen Konstitutionalismus ableitete, sondern aus der Wahrnehmung des "westlichen Parlamentarismus“. Gemeint ist hier vor allem die Regierungsbildung in Frankreich, die den deutschen Betrachter auf den ersten Blick keine Mitwirkung der Fraktionen erkennen ließ. Der

Westarp, Konservative Politik, S. 17*-19*. Wenn Mergel, Parlamentarische Kultur, v.a. S. 323-331, von einem "pragmatischen Republikanismus" und einer "stillen Republikanisierung“ der DNVP spricht, geht dies meines Erachtens jedoch zu weit.

25.3 Verh. RT 361, S. 11902 (27. 9. 1923).

${ }^{25+}$ Ebd., S. 12507 (27. 2. 1924).

255 Vgl. mit weiter Perspektive Kilian, Das alte Lied vom Reden und Handeln, S. 503. 
DDP-Parlamentarier wies allerdings völlig zu Recht darauf hin, daß „dort [...] die Befragung der Fraktionen diskreter, unauffälliger als bei uns“ geschehe ${ }^{256}$.

Zur unzureichenden Wahrnehmung der „westlichen“ Regierungsbildung kam noch ein zweites grundlegenderes Mißverständnis hinzu. Benannt wurde dies von dem Sozialdemokraten Rudolf Breitscheid, der am 24. November 1922 im Reichstag die dem Anspruch nach fraktionsunabhängige Regierungsbildung Cunos kritisierte und dabei ebenfalls auf das französische Vorbild einging: „Dort, wo die Grenzen zwischen den Parteien flüssig sind, wo es, abgesehen von der sozialistischen Partei, überhaupt keine eigentlich organisierte Partei gibt, ist es natürlich sehr viel leichter, sich nach eigenem Belieben und ungebunden von den Fraktionen sein Kabinett zusammenzustellen. In Deutschland ist das nach der ganzen Geschichte und nach der Struktur des deutschen Parlaments eine Unmöglichkeit." 257

Erkelenz und Breitscheid hielten ihren Kollegen im Reichstag jeweils einen Teilaspekt der deutschen Fehlperzeption französischer Regierungsbildung vor: Zum einen die Annahme, es gebe im Nachbarland keine fraktionelle Beteiligung, und zum anderen die Verkennung der Differenz zwischen einem immer noch stark „klassisch“-deliberativ geprägten System und den Weimarer Realitäten. Die Dauerklage über den zu großen Einfluß der Fraktionen war somit sicherlich nicht immer gleich Ausdruck eines grundsätzlichen „bürgerlichen Unbehagens am parlamentarischen System “258, sondern häufig eher die Folge eines - aus heutiger Sicht - problematischen Verständnisses dieses Systems unter den Bedingungen eines bereits relativ modernen Parteiwesens.

Die fehlende deutsche Erfahrung mit einem eigenen parlamentarischen Regierungssystem trug somit in doppelter Weise zur eklatanten Fehlbewertung der politischen Bedeutung von Fraktionen bei: Viele Abgeordnete blieben, auch wenn sie im Prinzip das parlamentarische System billigten, dem Vorbild der parteiunabhängigen Regierungsbildung und Regierungsführung innerhalb der konstitutionellen Monarchie verhaftet. Zudem hatten die parlamentarischen Verhältnisse Frankreichs eine gewisse Vorbildrolle gewonnen, die der kaiserzeitlichen Praxis durchaus zu ähneln schien. Mentales Festhalten an der konstitutionellen Tradition und trügerische Anschauung des „Westens“ erzeugten so ein den aktuellen Bedingungen völlig unangemessenes Bewertungsideal und gaben der Parlamentarismuskritik gerade in Krisensituationen immer wieder zusätzlichen Anschub.

256 Anton Erkelenz, Von Wirth zu Cuno, in: Die Hilfe, 1. 12. 1922, S. 459f., hier S. 460.

257 Verh. RT 357, S. 9105-9115, hier S. 9109. Breitscheid hatte im übrigen auch die Fragwürdigkeit des vorherrschenden Ideals einer weitgehend selbständig, ohne parlamentarischen Einfluß agierenden Regierung erkannt. Vgl. z. B. seine Reichstagsrede am 27. 4. 1921 - damals noch als USPD-Abgeordneter - bezugnehmend auf Ausführungen des parteilosen Außenministers Walter Simons. Dieser habe gesagt: „Demokratie ist das, daß ein Parlament oder ein Volk eine Regierung einsetzt. Diese Regierung kann dann handeln, und wenn die Regierung gehandelt hat, dann kann sie zur Rechenschaft gezogen werden. Das scheint für meine Begriffe etwas einseitig zu scin. [...] Meine Herren von der Regierung, daß das Parlament Sie wegschicken kann, genügt nicht, wenn Sie in der Zwischenzeit Dummheiten begangen haben. Wir wollen eben die Möglichkeit besitzen, vorher Kontrolle auszuüben und vorher zu versuchen, auf wichtige Schritte einen gewissen Einfluß auszuüben." Verh. RT 349, S. 3449. Allgemein zur guten Frankreich-Kenntnis von Breitscheid vgl. Cavaillé, Rudolf Breitscheid et la France 1919-1933.

258 Winkler, Weimar, S. 185. 
Ähnliche Verständnisprobleme rief das Phänomen einer parlamentarischen Opposition hervor. Hier spiegelte sich eine Begriffsgeschichte, die - spätestens seit dem Scheitern der konstitutionellen Parlamentarisierungstendenzen im preuBischen Verfassungskonflikt - mit der negativen Konnotation einer radikalen und selbstsüchtigen Fundamentalopposition verbunden wurde und die kaum zu einer positiven Bewertung systemimmanenter Opposition gelangen konnte ${ }^{259}$. Statt dessen dominierte das Ideal eines möglichst breiten politischen Konsenses und einer „positiven“ Mitarbeit aller Kräfte am Staat. Der Zentrumsabgeordnete Stegerwald faßte die vorherrschende Auffassung Anfang 1924 prägnant zusammen: „Die Opposition zur Regierung wird in weiten Kreisen des deutschen Volkes als gleichbedeutend mit der Opposition zum Staate angesehen." 260

Derart schroffe Einschätzungen machte sich im Reichstag zwar kaum jemand offen zu eigen, von einer positiven „staatspolitischen“ Bewertung konnte freilich in der bürgerlichen Mitte kaum die Rede sein $^{261}$. Statt dessen stand Opposition hier in der Regel im Ruf der reinen Interessenpolitik und der politischen Verantwortungslosigkeit ${ }^{262}$. Gegenüber der DNVP bezog sich dies auch auf ihre agitatorischen Verhaltensweisen als Oppositionspartei263. Gegenüber der SPD verband sich die Kritik in mehreren Krisensituationen mit dem Vorwurf, daß sich die Partei aus „egoistischen“ Motiven aus der Regierungsverantwortung zurückziehe und „ihre Parteiinteressen über die Staatsnotwendigkeiten“ stelle264. Wie später zu zeigen sein wird, spielten bei der verbreiteten bürgerlichen Forderung nach einer Großen Koalition von SPD bis DVP aber stets auch Intentionen eine Rolle, die über eine konkrete Mehrheitsbildung hinausgingen und die auf eine überparteiliche Volksgemeinschaft oder aber auf eine strategische Eindämmung und Umarmung der SPD zielten. Daß es auch „staatspolitisch“ gefährlich war, wenn eine in der Großen Koalition politisch neutralisierte SPD das Vertrauen der Arbeiterschaft verlor, wurde nur von den wenigsten erkannt ${ }^{265}$.

Ausnahmen in der „anti-oppositionellen“ Grundstimmung bildeten einzelne Stimmen der DDP266 sowie Rechtfertigungen gegenüber dem Vorwurf der

${ }_{259}$ Vgl. Grosser, Sehnsucht nach Harmonie; Jäger, Opposition. Grundsätzlich zu einer traditionellen "Sehnsucht nach Synthese“ in der politischen Kultur Deutschlands vgl. auch Dahrendorf, Gesellschaft und Demokratie, S. 161-242.

${ }^{260}$ Zitiert in Schorr, Stegerwald, S. 83, nach Der Deutsche, 27. 1. 1924.

$261 \mathrm{Vgl}$. auch Euchner, Einleitung, S. 12.

262 So sprach etwa Stresemann am 30.6. 1920 vom "taktische[n] Interesse“ der SPD, „in die Opposition zurückfallen zu sollen“. Verh. RT 344, S. 53. Der DVP-Fraktionsvorsitzende Scholz meinte am 5. 12. 1923: „Ich glaube, für den deutschen Reichstag können wir als Grundsatz des Parlamentarismus leider die völlige Verantwortungslosigkeit der Opposition feststellen." Verh. RT 361, S. 12305.

${ }^{263}$ Umgekehrt war es freilich nicht ganz unbegründet, wenn führende DNVP-Parlamentarier den Vorwurf der Verantwortungslosigkeit strikt zurückwiesen, denn die immer wieder geäußerte Bereitschaft zur Beteiligung an einer bürgerlichen Regierungskoalition stieß bis 1925 weitgehend auf taube Ohren.

${ }^{26+}$ So etwa Adam Stegerwald rückblickend in: Der Deutsche, 27. 1. 1924, 2. Beilage, S. 1, „Rechts‘ und links" “.

265 Stresemann zeigte immerhin Verständnis dafür, daß die SPD um ihren Einfluß in den „Massen“ fürchtete. Vgl. unten S. 183.

266 So Walter Schücking am 11.7. 1922: „Wir als Demokraten, die so viel unter dem alten System gelitten haben, sind der Meinung: es gibt auch ein angeborenes Menschenrecht auf Opposition in einem parlamentarisch regierten Staat. Uns würde es übel anstehen, wenn wir jetzt irgendeinem in diesem hohen Hause oder außerhalb dieses hohen Hauses cinen sittlichen Vorwurf daraus machen 
"Staatsopposition“ seitens der SPD. Hermann Müller reagierte am 25. November 1922 in der Aussprache zur Regierungserklärung Cunos ausführlich auf derartige Kritik: Es sei "die Konsequenz des parlamentarischen Systems, daß die Parteien, die nicht in der Regierung vertreten sind, als Opposition außerhalb der Regierung stehen. Die Opposition [werde] dort, wo sich das parlamentarische System durchgesetzt hat, in ihrer Opposition niemals die Interessen des Landes verletzen. Denn die Opposition [werde] immer das Bestreben haben, eben die Regierung von morgen oder übermorgen zu sein. “267 Freilich wurden derartige Anschauungen, die sich einer modernen Deutung der parlamentarischen Opposition und der von ihr ausgeübten Alternativfunktion annäherten, auch in der SPD nur selten geäußert. Während manche sozialdemokratischen Anhänger einer breiten Koalitionspolitik mit den üblichen oppositionskritischen Bewertungsmustern agierten, argumentierten die Gegner primär parteipolitisch oder klassenspezifisch auf die Legitimationsinstanz „Arbeiterschaft“ hin bezogen und bestätigten damit genau jene Vorurteile, die ihnen seitens der bürgerlichen Parteien und auch seitens innerparteilicher Kontrahenten entgegenschlugen.

Ein analoger Diskurs über Schwächen und Bedrohungen des parlamentarischen Systems wurde während der Inflationszeit in der französischen Abgeordnetenkammer nicht geführt. Ansatzpunkte für eine Infragestellung der parlamentarischen Regierungsverantwortung sind nicht zu erkennen. Der französische Parlamentarismus hatte sich seit langem bewährt und gehörte zu den Gewinnern des Ersten Weltkriegs, offen systemfeindliche Kräfte waren marginalisiert, und in langer Erfahrung war man an scharfe Konflikte ebenso gewöhnt worden wie an die beständige Existenz einer parlamentarischen Opposition ${ }^{268}$.

Unter französischen Abgeordneten herrschte in den 1920er Jahren oft noch ein Ton des Stolzes auf das eigene parlamentarische System, das ganz selbstverständlich als Teil der hoch geschätzten ,institutions républicaines“ galt. Die seit dem späten 19. Jahrhundert übliche Gleichsetzung von Nation und Republik ${ }^{269}$ bildete eine wichtige Grundlage für ein insgesamt positives Parlamentarismusbild. Dem Leitziel der Republik fehlte zudem die konsensorientierte Enge der deutschen Leitbegriffe „Volk“ und „Staat“. Unter dem weiten Dach der Republik blieb mehr Raum für politische Konflikte.

wollten, daß er zur gegenwärtigen Regierung, zur Republik und zur Demokratie in Opposition stände. / Ein parlamentarischer Staat braucht nun einmal eine Opposition. Das Schlimme war das hat unsere inneren Verhältnisse in Deutschland auch so furchtbar zurückgeworfen -, daß früher dieses Recht auf Opposition nicht anerkannt wurde." Verh. RT 356, S. 8431. Bezeichnend ist auch hier die Vermengung von systemloyaler und systemfeindlicher Opposition.

267 Verh. RT 357, S. 9173. Zur Haltung der SPD vgl. auch Euchner, Sozialdemokratie und Demokratie, S. 148-152. Allgemein zur Tradition der moralischen Rechtfertigung angesichts des herrschenden Oppositionsverständnisses vgl. Jäger, Opposition, S. 508, $512 \mathrm{f}$.

268 Zum Oppositionsbegriff in der Dritten Republik liegen bislang keine Untersuchungen vor. Zu der im Vergleich zu Deutschland deutlich positiveren Besetzung in der ersten Hälfte des 19. Jahrhunderts vgl. Jäger, Opposition, S. $484 \mathrm{f}$. Deutlich wird hier zum einen die Bedeutung der allmählichen Parlamentarisierung der konstitutionellen Monarchie, zum anderen die Anlehnung an das englische Vorbild eines kompetitiven Systems. Freilich kam es unter den fluktuierenden parlamentarischen Verhältnissen schon damals nicht zur Ausbildung einer blockartigen Opposition.

269 Begriffe wic „Etat“ oder „peuple“ (im ethnischen Sinn) spielten dagegen im Diskurs der französischen Kammerabgeordneten so gut wic keine Rolle. 
Der im revolutionären Traditionsschatz verankerte und seit der Frühphase der Dritten Republik mythologisch überhöhte Kult der Republik ${ }^{270}$ prägte auch die politische Sprache der Abgeordnetenschaft. Kaum jemand konnte sich dem entziehen, war doch das Bekenntnis zur Republik seit dem Niedergang der diversen Monarchismen zum quasi-verbindlichen politischen Signum geworden. Dies zeigte sich nahezu permanent in der parlamentarischen Rhetorik, aber auch in der beliebten Verwendung des Adjektivs "républicain" in Partei- und Fraktionsnamen.

Letzteres gilt gerade auch für die konservative Fédération républicaine (bzw. für die ihr nahestehenden Fraktionen der Entente républicaine démocratique und dann ab 1924 der Union républicaine démocratique). Etwaigen Zweifeln an der tatsächlichen republikanischen Loyalität wurde hier bereits im eigenen Namen ein demonstratives Dementi entgegengehalten. Freilich ging es dabei nicht nur um Rhetorik. Daß die Grundwerte der Republik und die Traditionen des französischen Parlamentarismus inzwischen auch auf der parlamentarischen Rechten ihren Platz hatten, verkörperte niemand besser als Louis Marin, der in den zwanziger Jahren die führende politische Persönlichkeit der Fédération darstellte. Marins Republikanismus und sein penibler Respekt vor den parlamentarischen Verfahrensweisen waren ebenso berühmt wie seine virulente Deutschfeindlichkeit ${ }^{271}$. Erst in den dreißiger Jahren sollten sich dann die Gewichte innerhalb der Fédération zugunsten der systemkritischen oder gar systemfeindlichen Kräfte verschieben $^{272}$.

Während auf der parlamentarischen Rechten auch ein gewisses Maß an vordergründig-taktischer Sprachregelung in Rechnung gestellt werden muß, kann für das breite linksrepublikanische Spektrum von Radicaux, Républicains-socialistes und Sozialisten von einer tief verankerten republikanischen Mentalität gesprochen werden. Dabei verband sich die Vorstellung von der Republik, die hier als Erbe der "Linken" begriffen wurde, mit den Strukturen und Verhaltensweisen des deliberativen parlamentarischen Systems, aber auch mit der laizistischen Grundtendenz der französischen Innenpolitik ${ }^{273}$. Jeder ernsthafte Versuch, an den bestehenden Verhältnissen etwas zu verändern, mußte daher als Gefährdung der „institutions républicaines" aufgefaßt werden.

Ansätze zur Systemkritik gab es freilich auch schon während der Inflationszeit. In der Regel galt diese Kritik der seit Jahrzehnten gewachsenen Komplexität des französischen Parlamentarismus. André Tardieu etwa klagte 1926: „A la Chambre, dans notre salle des séances, ou dans nos salles de commissions, nous sommes les prisonniers d'habitudes de cinquante ans. “274 Vor diesem Hintergrund entwik-

270 Vgl. oben S. 30 mit Anm. 9.

271 Nach Irvine, French Conservatism in Crisis, S. 100; ebd., S. 6-14, eine biographische und politische Skizze zu Marin. Zu Marin und insbesondere seinem Verhältnis zu de Wendel vgl. auch Jeanneney, De Wendel, S. 427-431, 438-440.

$272 \mathrm{Vgl}$. Irvine, French Conservatism in Crisis, S. 14-17.

${ }^{273} \mathrm{Vgl}$. etwa Berstein, Culture républicaine, S. 242 f.; Überblick zur Entwicklung aus katholischer Sicht in Rémond, L'anticléricalisme en France.

${ }^{274}$ André Tardicu, Impressions d'un nouveau élu. Discours prononcé le 28 avril 1926 par M. André Tardieu au déjeuner de „L'Union du commerce et de l'industrie pour la défense sociale“; AAE Paris, Papiers Herriot, 12, Bl. 5 8, hier Bl. 8R. 
kelte sich in Teilen des politischen Spektrums die Überzeugung, daß eine Reform der parlamentarischen Verfahrensweisen dringend notwendig sei. Leitgedanke derartiger Vorstellungen, die ab etwa 1923 vor allem im Umfeld von Alliance démocratique und Fédération républicaine vertreten wurden, war es zunächst, mehr Effizienz in die langwierigen deliberativen Verfahren zu bringen ${ }^{275}$. Damit verband sich die ganz von den traditionellen Kategorien einer strikten Gewaltentrennung bestimmte Absicht, die Durchsetzungsfähigkeit der Regierung gegenüber der Kammer zu stärken. Im Kern findet sich hier jenes Deutungsmuster, das auch heute noch Teile der Literatur beherrscht: Die Krisensymptome des französischen Parlamentarismus hätten vor allem mit einer übermäßig gewordenen Macht des Parlaments zu tun.

Hinter diesen Vorschlägen und Einschätzungen standen zum einen die Probleme, die in der Endphase des Bloc national infolge der allmählichen Erosion des Regierungslagers und infolge eines verschärften Oppositionskurses von Kommunisten, Sozialisten und Teilen der Radicaux auftraten ${ }^{276}$. Zum anderen spielten auch die finanzpolitischen Herausforderungen eine Rolle, die angesichts von Währungsschwäche, steigender Inflationsraten, ausbleibender deutscher Reparationszahlungen und eigener Sparzwänge immer eklatanter wurden. Im Wahlkampf von 1924 war das Thema „parlamentarische Effizienzsteigerung" vor allem in den Wahlaufrufen ("Confessions des foi“) der Modérés präsent. Es handelte sich darum, wie eine Erklärung im Departement Aube forderte, „de réviser [...] nos méthodes parlementaires et les règlements qui les ont faussées“. Die klar systemimmanente Zielsetzung brachte auch eine "Confession“ im Departement Seine auf den Punkt: „Nous entendons concilier avec le régime parlementaire la stabilité du pouvoir et l'exercice de l'autorité."277 Als konkrete Maßnahmen waren verschiedene Reformen in der Diskussion, etwa die restriktivere Regelung parlamentarischer Redezeiten oder die Stärkung der Befugnisse des Kammerpräsidenten. Ein weiteres Thema in den Wahlaufrufen war die geforderte Einbeziehung von Experten in die Ausarbeitung von Gesetzesvorlagen ${ }^{278}$. Die verschiedenen Vorschläge zu einer Veränderung des parlamentarischen Betriebes blieben allerdings vor der Schwelle der präsidentiellen Prärogative stehen und versuchten ihr Ziel über eine „Rationalisierung" parlamentarischer Verfahren zu erreichen ${ }^{279}$.

275 Die Kritik bezog sich v.a. auf die Rededauer. Vgl. z. B. den Entente-Abgeordneten Camille Blaisot am 12. 1. 1923 in der Debatte um das „Budget général de l'exercice“ 1923: „Tout au long de la discussion générale et tout au long de la discussion des divers chapitres, nous avons dû subir des discours sans fin, très souvent parfaitement inutiles."JO, Débats, Chambre 1923, S. 54.

$276 \mathrm{Vgl}$. Zweiter Teil, B, Kap. I.

277 Chambre des Députés, 13e Législature, Impressions, S. 89, 784.

${ }^{278}$ So heißt es etwa in der "Confession" der Liste d'Union nationale Démocratique im Departement Orne, der auch Adrien Dariac, ein führender Abgeordneter der Républicains de Gauche, angehörte: „Le Parlement lui-même devra se donner de meilleures méthodes de travail en réformant son règlement et en confiant à des techniciens la préparation des lois." Chambre des Députés, $13^{\mathrm{e}}$ Législature, Impressions, S. 587; ebd. auch ein weitergehender Vorschlag für eine Verfassungsreform „dans le but de réprimer l'abus des dépenses publiques par l'attribution exclusive au Gouvernement du droit de les proposer et par la réglementation du droit d'amendement".

279 Die in diese Richtung zielenden, v.a. von Poincaré verfolgten praktischen Ansätze werden im Zweiten Teil B, behandelt. - Der Begriff der parlamentarischen „Rationalisierung“ (bzw. des „parlementarisme rationalisé “) ist in der französischen Literatur weitverbreitet. Nach Gicquel, Droit constitutionnel, S. 128, verweist er auf „un ensemble de règles techniques, destinées à préserver la 
Auch die zeitweise heftige Diskussion um Ermächtigungsgesetze und die daraus abzuleitenden décrets-lois läßt sich als Teil einer Rationalisierungsdebatte verstehen. Das Instrument einer beschränkten legislativen Delegation wurde im Mitte-rechts-Spektrum überwiegend als qualitative Verbesserung des parlamentarischen Systems bewertet, das dessen Anpassungsfähigkeit an neuartige Erfordernisse sichert ${ }^{280}$.

Die radikale und sozialistische Linke hingegen betrachtete die Versuche, traditionelle parlamentarische Verfahrensweisen $z u$ verändern, mit Indifferenz oder Skepsis ${ }^{281}$. Gegen parlamentarische Ermächtigungen regten sich hier zunächst sogar heftige Widerstände. Bezeichnend ist das Urteil des Sozialisten Paul-Boncour, der in einer leidenschaftlichen Kammerrede am 4. Februar 1924 vor einer „vergifteten Waffe" warnte, die sich gegen das parlamentarische Regime wenden werde ${ }^{282}$. Wie später ausführlicher darzustellen sein wird, wurde das Instrument der legislativen Vollmacht auf der Linken zunächst als Symptom für die Gefährdung der Republik durch eine heraufziehende bonapartistische Diktatur gedeutet. Das Cartel des Gauches von 1924 formte sich daher nicht zuletzt auch unter dem traditionellen linken Sammlungsruf der "défense républicaine“. Erst das Scheitern des Linksbündnisses sollte dann den Weg frei machen für eine breitere Akzeptanz parlamentarischer Ermächtigungen.

Die linke Identifizierung mit den bestehenden parlamentarischen Strukturen und Verfahrensweisen betraf allerdings nur die politischen Kompetenzen der Abgeordnetenkammer. Alte Vorbehalte gegen das starke Gewicht des Senats wurden wiederbelebt, als die Kartellregierung Herriot wachsende Probleme mit der eher zur politischen Mitte hin orientierten zweiten Kammer bekam. Sozialisten und Teile der Radicaux diskutierten in diesem Zusammenhang eine Entmachtung des Senats ${ }^{283}$.

Das zentrale Element der deutschen Parlamentarismuskritik, die Klage über das Parteiwesen, spielte in der französischen Abgeordnetenkammer nur eine sehr untergeordnete Rolle. Angesichts eines im Vergleich zu Deutschland nur partiell ausgebildeten Parteiensystems ist diese Feststellung keineswegs überraschend. Allerdings wird immer wieder deutlich, daß der Parteibegriff in der politischen

stabilité et l'autorité du gouvernement, en l'absence d'une majorité parlementaire“. Ursprünglich stammt der Begriff, der dann v.a. für die Verfassung der Fünften Republik eine große Rolle spielte, nach ebd. vom französischen Staatsrechtler Boris Mirkine-Guetzevitch. Vgl. z.B. ders., Les nouvelles tendances du Droit constitutionnel, v.a. S. 18-24. Auch Roussellier, Gouvernement et parlement, wendet ihn bereits für die französischen Reformbemühungen der zwanziger Jahre an.

280 Vgl. unten S. 403 zu Poincarés Rede im Senat am 14.2.1924.

281 Vgl. auch Paul-Boncour, Entres deux guerres 2, S. 88-90. Ebd., S. 89, wird an die Frühzeit der Radicaux erinnert. Diese hätten ihren ursprünglichen Reformwillen aufgegeben, seit sie zur politisch dominierenden Kraft geworden seien. Die Sozialisten hingegen seien zu sehr an Sozial- und Wirtschaftspolitik interessiert gewesen. Zu den Radicaux in den Anfängen der Dritten Republik vgl. Mollenhauer, Auf der Suche nach der "wahren Republik“.

282 JO, Débats, Chambre 1924, S. 486-492. Ebd., S. 492: „[...] cette disposition [...] très nuisible au régime parlementaire par l'arme empoisonnée dont on se servira contre lui“.

${ }^{283}$ Formeller Höhe-, aber auch Endpunkt dieser Debatte war der chancenlose Versuch der SFIO in der im August 1926 wegen einer finanzpolitischen Verfassungsergänzung einberufenen Assemblée nationale, über eine zur Diskussion gestellte Verfassungsänderung die legislative Gleichberechtigung zwischen Abgeordnetenkammer und Senat aufzuheben. Vgl. unten S. 513. Allgemein zur sozialistischen Gegnerschaft gegen den Senat, dessen Abschaffung bereits 1919 gefordert worden war, vgl. Judt, Reconstruction, S. 98 f. 
Mitte und auf der Rechten auch in Frankreich noch überwiegend negativ besetzt war und daß insbesondere die eigene Einordnung in eine strikte Parteidisziplin abgelehnt wurde 284 .

Anders als in Deutschland konnte sich mit dem negativen Parteienbegriff aber durchaus ein positives Parlamentarismusbild verbinden. Freilich war dies ein archaisches Bild, das sich auf die Traditionen der klassischen Deliberation bezog. Von diesem Standpunkt aus konnten die in der Kartellzeit zu beobachtenden Ansätze eines parteiengestützten Systems nur mit Mißtrauen wahrgenommen werden. Daß auf der politischen Linken Parteigremien Einfluß auf parlamentarische Prozesse gewannen, sorgte daher in der liberal-konservativen Mitte für wachsendes Unbehagen. Vom Standpunkt des klassischen Parlamentarismus mußte die Beeinflussung parlamentarischer Prozesse durch Parteibeschlüsse in der Tat als beunruhigendes Symptom der Veränderung aufgefaßt werden ${ }^{285}$.

Die aus moderner Sicht ins Auge fallenden Defizite der Parteienentwicklung und der Parteienkohärenz in großen Teilen des politischen Spektrums Frankreichs waren kein Thema der allgemeinen Parlamentarismusdebatte. Ein relevantes Feld möglicher Reformen blieb im zeitgenössischen Rationalisierungsdiskurs somit weitgehend ausgeblendet. Die Debatten um eine Effizienzsteigerung von Parlament und Regierung durch technische Verfahrensänderungen muten daher im Rückblick auch ein wenig wie eine Ersatzdiskussion dafür an, daß der zur Weiterentwicklung des parlamentarischen Systems und insbesondere zur Stabilisierung der regierungstragenden Funktion erforderliche Ausbau des Parteiwesens kaum vorankam.

In der Zusammenschau der skizzierten deutschen und französischen Vorstellungsmuster fällt zunächst eine grundlegende Analogie auf. Beiderseits hatte das klassische Ideal der Gewaltentrennung zwischen Exekutive und Legislative noch einen hohen Stellenwert. Analog hierzu mangelte es an Verständnis dafür, daß im modernen Parlamentarismus Parteien und Fraktionen eine wesentliche Aufgabe für die enge Verknüpfung von Regierung und parlamentarischem Regierungslager zufällt. Vor diesem gemeinsamen Hintergrund gab es freilich deutsch-französische Bewertungsunterschiede, die jenen der Verfassungsstrukturen und des Parteiwesens in nichts nachstehen. In bürgerlichen Spektrum des Reichstags herrschte eine deutliche Spannung zwischen der Erwartung breiter nationaler Zusammenarbeit für Volk und Staat und der vielbeklagten Realität des Parteiwesens und seiner parlamentarischen Auswirkungen. Ein äußerst labiles und an traditionellen Mustern orientiertes parlamentarisches Selbstverständnis war - so läßt sich das deutsche Dilemma resümieren - mit der relativen Modernität des deutschen Parteiwesens konfrontiert, das seit 1918 begonnen hatte, das neugeschaffene par-

28+ Allgemein zur Partcienkritik im liberalen Spektrum vgl. Grüner, Zwischen Einheitssehnsucht und Massendemokratie, S. 234-241, mit Beispielen für den Philosophen und Gymnasiallehrer Emile Chartier - unter dem Pseudonym „Alain" einer der wichtigsten Publizisten aus dem Umfeld des Parti radical - und für Paul Reynaud, einen führenden Vertreter der Alliance démocratique. Eine Sammlung von Presseartikeln Alains ist zugänglich in: ders., Eléments d'une doctrine radicale, S. 175-183, zum Thema „Parteien“. Allgemein zur „doctrine radicale“ von Alain vgl. Nordmann, Histoire, S. 137-144.

285 Vgl. zu dieser Kritik z. B. den Rückblick von Le Temps zum 50. Jahrestag der Gültigkeit der Verfassung der Dritten Republik; LT, 15. 1. 1926, S. 1, „Le cinquantenaire du Parlement“. 
lamentarische System für sich zu erobern. In der französischen Abgeordnetenkammer, wo ein parteiengestützter Parlamentarismus bislang nur schwach entwickelt war und wo der Leitbegriff der Republik weitgehend mit den Verfahrensweisen des traditionellen parlamentarischen Systems identifiziert wurde, läßt sich - bei aller Kritik, die es en detail gab - eine derart grundsätzliche Diskrepanz nicht erkennen. Die dominierenden politischen Mentalitäten und die konkreten parlamentarischen Realitäten lagen hier zweifellos näher beieinander. 